\title{
USING AN EVALUATION CAPACITY TOOL TO BUILD EVALUATION CAPACITY IN A NONPROFIT ORGANIZATION
}

by

Megan Brooke Miller

\author{
A thesis \\ submitted in partial fulfillment \\ of the requirements for the degree of \\ Master of Science in Organizational Performance and Workplace Learning \\ Boise State University
}

May 2019 
(C) 2019

Megan Brooke Miller

ALL RIGHTS RESERVED 


\section{BOISE STATE UNIVERSITY GRADUATE COLLEGE}

\section{DEFENSE COMMITTEE AND FINAL READING APPROVALS}

of the thesis submitted by

Megan Brooke Miller

Thesis Title: Using an Evaluation Capacity Tool to Build Evaluation Capacity in a Nonprofit Organization

Date of Final Oral Examination: $\quad 25$ February 2019

The following individuals read and discussed the thesis submitted by student Megan Brooke Miller, and they evaluated her presentation and response to questions during the final oral examination. They found that the student passed the final oral examination.

Seung Youn (Yonnie) Chyung, Ed.D. Chair, Supervisory Committee

Donald J. Winiecki, Ed.D., Ph.D. Member, Supervisory Committee

Soo Jeoung "Crystal” Han, Ph.D. Member, Supervisory Committee

The final reading approval of the thesis was granted by Seung Youn (Yonnie) Chyung, Ed.D., Chair of the Supervisory Committee. The thesis was approved by the Graduate College. 


\section{ACKNOWLEDGMENTS}

The process of both completing this thesis and the OPWL program has not been an easy journey, and I owe much of the success of this accomplishment to the many people who have endlessly supported me.

First and foremost, I want to thank Dr. Yonnie Chyung for her tireless support and encouragement through both my thesis and the master's program as a whole. Dr. Chyung has helped me identify my areas for improvement and remained patient as I worked through them to grow. She was also my biggest cheerleader, encouraging me to showcase my work, and giving me endless opportunities to learn from other experts in the field. Her insight and guidance was crucial to this thesis and establishing my knowledge as it is today.

I would also like to thank my committee members, Dr. Winiecki and Dr. Han for their support, critical thinking, and encouragement helping me frame the scope of this research and guiding its progress.

I extend my thanks to Kelly Weak and Jo Ann Fenner for their consistent guidance through the program and helping me take the large steps to get to where I am at today.

Finally, I want to thank my husband, Scott Miller, and family for their support and sacrifice through this process. Each of you had no doubt in my abilities and consistently drove me to push myself and achieve my dreams. You also understood that 
meant balancing work, school, and personal responsibilities and were willing to help out where it was needed. 


\begin{abstract}
Organizational performance improvement cannot be expected without continuous monitoring and evaluations. Nonprofit organizations (NPOs) funded through government grants and other funder contracts face high expectations for evaluation and reporting of data as they are held accountable to their funders. However, NPOs share common struggles in both measuring and building evaluation capacity, which refers to the ability for an organization to conduct an effective evaluation that meets accepted standards of the discipline (Milstein, Chapel, Wetterhall, \& Cotton, 2002). Thus, the purpose of this research was to answer the following research question: How does an NPO use an ECB framework and its tool as a guide while building evaluation capacity?

In order to gain a deep level of understanding of ECB, the researcher reviewed available literature on ECB frameworks and tools and conducted a case study within an NPO labeled "Foothills" (pseudonym) in the Northwest region of the United States to investigate how the organization used a selected ECB framework and its assessment tool towards engaging in ECB. The case study included a series of three focus groups with five key stakeholders of the organization during September through November of 2018 using the organizational evaluation capacity self-assessment developed by Bourgeois and Cousins (2013). The researcher selected this framework based on her assessment at that time that the organization might lack evaluation knowledge and skills and that the comprehensive nature of their framework and associated self-assessment tool would help the organization improve its evaluation capacity. The stakeholders completed the self-
\end{abstract}


assessment tool individually first, and then engaged in focus groups to discuss their experience with the assessment tool, reflect on their current ECB capacity, and make their future ECB plans for continuous organizational improvement.

The focus groups revealed limited evaluation capacity among the stakeholders. Through all three focus groups, the participating stakeholders expressed concern about not understanding terminology and questions used in the assessment. Key areas that participating stakeholders struggled with were defining the evaluation unit, evaluation lead, and the various evaluation projects and processes that the organization had participated in, as indicated by an increase of 'Don't Know' responses on the assessment and discussion within the focus groups. This supported the stakeholders' determination that their foundational knowledge in evaluation was limited. This lack of knowledge in these terms and functions hindered the stakeholders' ability to both answer some of the questions during the self-assessment and fully understand the role of evaluation within the organization.

From this research, it seems that foundational knowledge of evaluation and performance improvement practices may be a prerequisite for organizations to complete this type of assessments and the ECB process. However, this leaves NPOs that have low levels of evaluation capacity with few resources and options to build their evaluation capacity. To better fit the lack of resources and knowledge for NPOs with low and developing capacities, it may be worth establishing ECB resources to grow their foundational knowledge, prior to engaging in more advanced ECB work with the help of a skilled evaluator. This could also save the overall costs for NPOs with low and developing capacities as they use other available tools to build foundational knowledge 
before hiring a potentially expensive evaluation expert for the rest of the ECB and evaluation processes.

If researchers and practitioners work to build these tools and resources to help improve NPOs' evaluation capacity, organizations should then be able to participate more fully in using human performance improvement (HPI) principles to better monitor their overall impact, identify performance issues, and measure the effectiveness of implemented solutions. This will lead to NPOs that are able to operate more effectively and efficiently, create increased funding, and produce greater impacts within the communities they support. 


\section{TABLE OF CONTENTS}

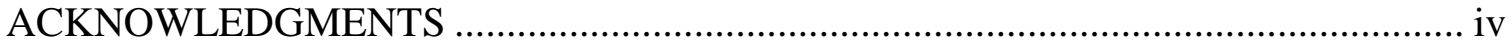

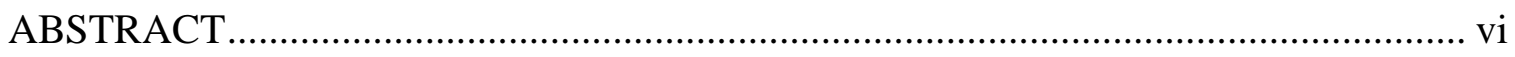

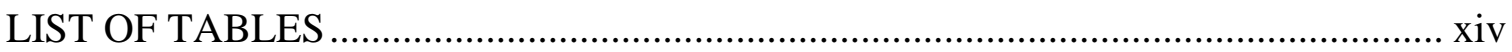

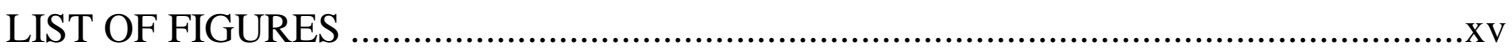

LIST OF ABBREVIATIONS ......................................................................... xvi

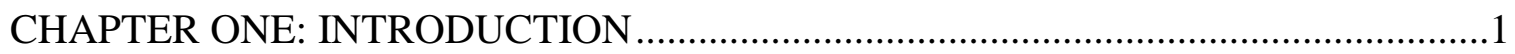

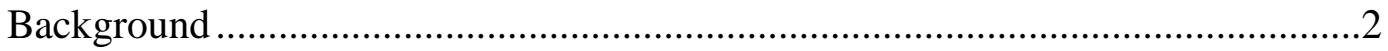

Nonprofit Organizations' Evaluation Capacity .......................................................

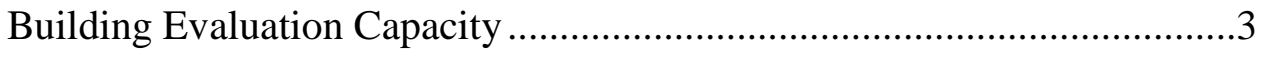

Lacking Expertise on Evaluation Capacity Building ....................................4

Using Frameworks and Tools for Facilitating Evaluation Capacity

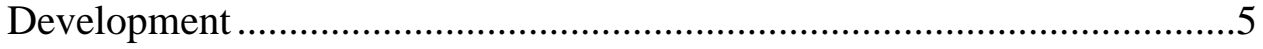

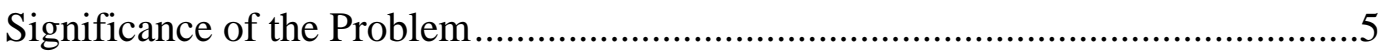

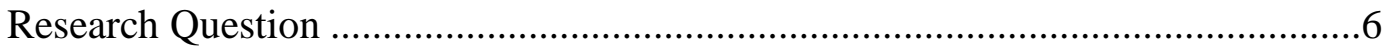

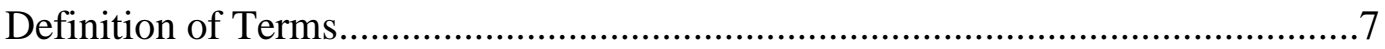

CHAPTER TWO: EVALUATION CAPACITY BUILDING FRAMEWORKS AND

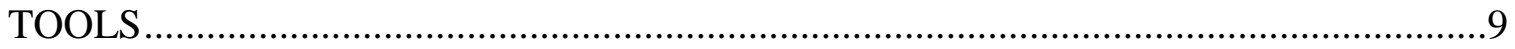

King and Volkov's (2005) Framework .............................................................11

Purpose and Goals of the Framework ........................................................11

Steps Included in the Framework ……......................................................11

Strengths and Weaknesses of the Framework from Case Studies ..............14 
Preskill and Boyle's (2008a) Framework

Purpose and Goals of the Framework ......................................................15

Steps Included in the Framework ...........................................................16

Strengths and Weaknesses of the Framework from Case Studies ..............18

Labin, Duffy, Meyers, Wandersman, and Lesesne's (2012) Integrative ECB

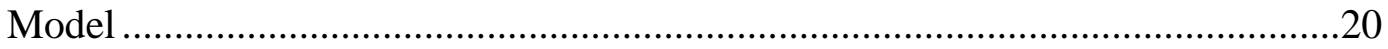

Purpose and Goals of the Framework .........................................................20

Steps Included in the Framework ..............................................................21

Cousins, Goh, Elliott, and Bourgeois' (2014) Framework ....................................21

Purpose and Goals of the Framework ......................................................21

Steps Included in the Framework …………….......................................22

Strengths and Weaknesses of the Framework from Case Studies ..............23

Taylor-Ritzler, Suarez-Balcazar, Garcia-Iriarte, Henry, and Balcazar's (2013)

Evaluation Capacity Assessment Instrument.......................................................24

Purpose and Goal of Instrument ...........................................................24

Components of the Instrument.................................................................24

Strengths and Weaknesses of the Instrument...........................................25

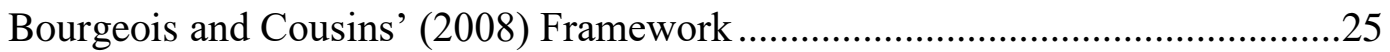

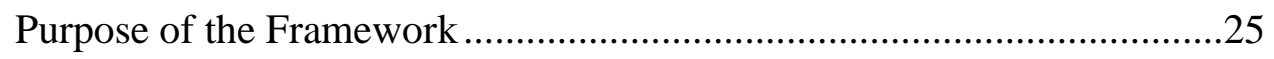

Steps Included in the Framework ……………………….....................26

Organizational Evaluation Capacity Self-Assessment...............................28

Strengths and Weaknesses of the Instrument..............................................29

Summary of ECB Frameworks and Tools ......................................................29

CHAPTER THREE: A CASE STUDY ON AN NPO'S USE OF AN ECB

FRAMEWORK AND ITS TOOL 
Research Question

Research Design: A Case Study .................................................................. 31

Participating Organization and Stakeholders .......................................31

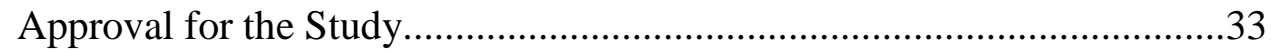

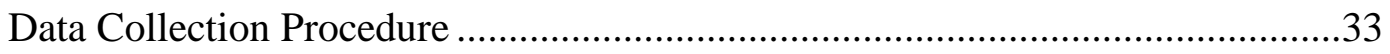

First Focus Group with Organizational Evaluation Capacity Self-

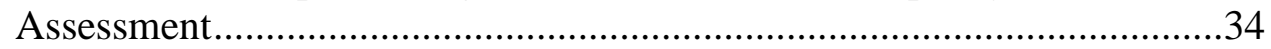

Second Focus Group to Discuss Assessment Results and Plan Strategies 36

Third Focus Group to Discuss an ECB Plan..........................................37

CHAPTER FOUR: DATA ANALYSIS AND FINDINGS ......................................40

Part 1: Assessment Results and Discussion ...................................................40

Dimension 1: Human Resources......................................................4 41

Dimension 2: Organizational Resources..........................................43

Dimension 3: Planning and Conducting Evaluations ...........................46

Dimension 4: Evaluation Literacy .................................................49

Dimension 5: Organizational Decision Making ..................................51

Dimension 6: Learning Benefits ..................................................51

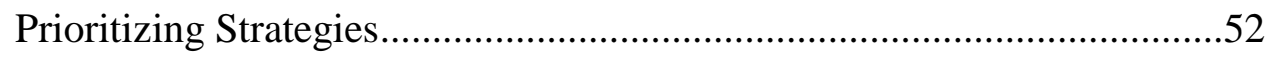

Part 2: Review of ECB Process Within the NPO ............................................53

Facilitators of the ECB Process ........................................................53

Barriers in the ECB Process............................................................55

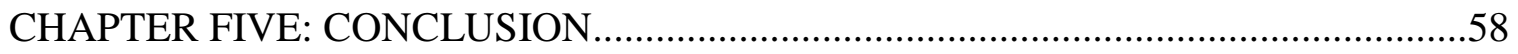

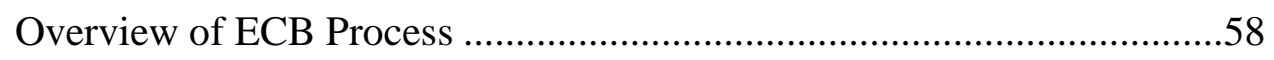

Recommendations for the Use of the ECB Tool ....................................59 
Recommendations for the ECB Process ............................................62

Application to Human Performance Technology ..................................63

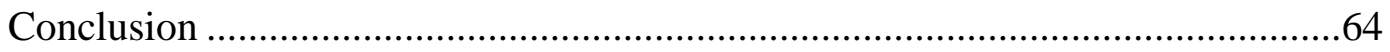

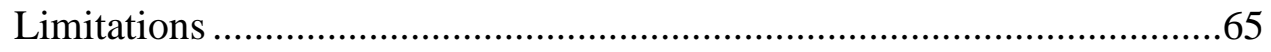

Recommendations for Future Research .............................................65

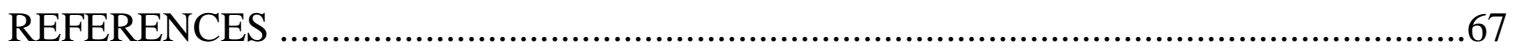

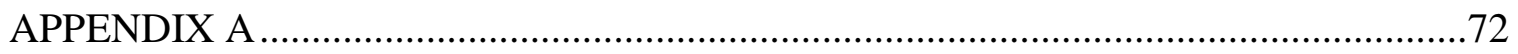

Volkov and Kings (2007) Checklist for Building Organizational Evaluation

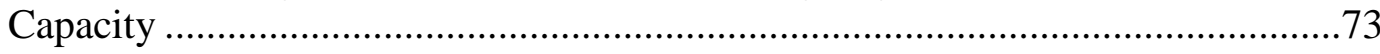

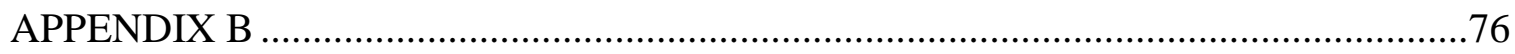

Evaluation Capacity Assessment Instrument (ECAI) ...................................77

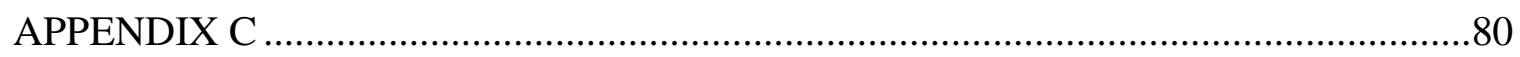

Bourgeois and Cousins' (2008) Organizational Evaluation Capacity Self-

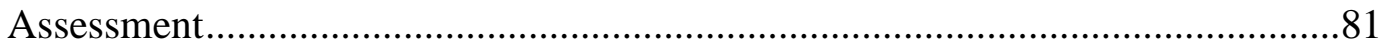

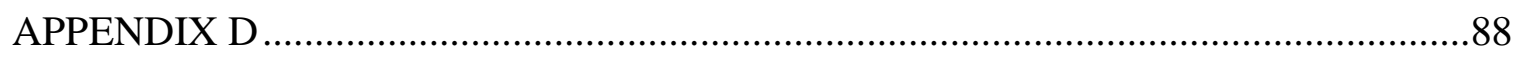

Summary of ECB Frameworks and Tools ..................................................89

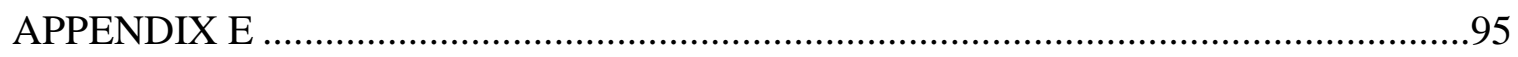

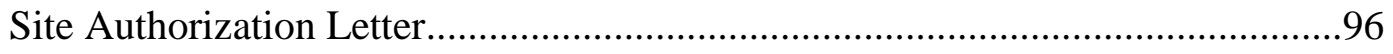

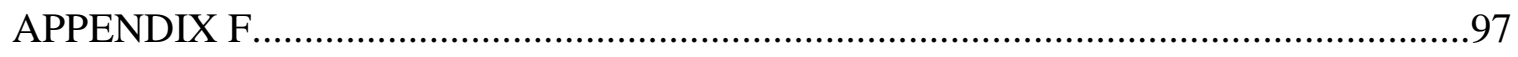

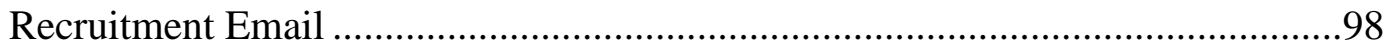

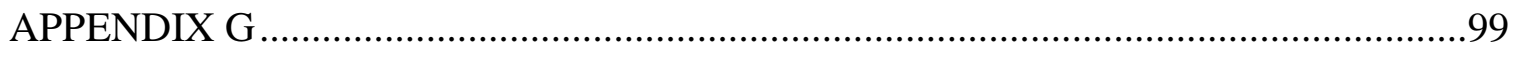

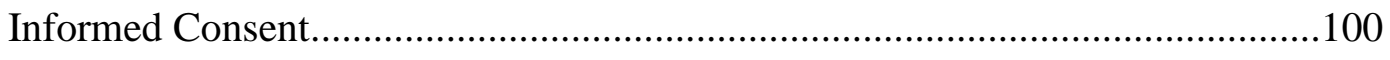

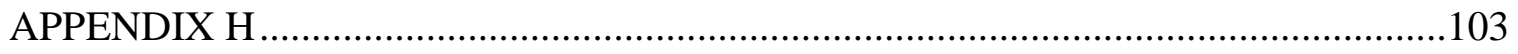

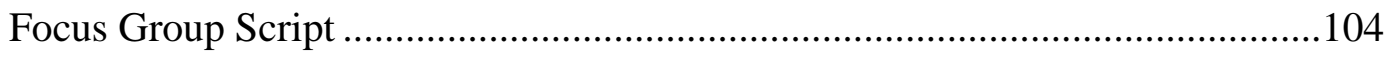




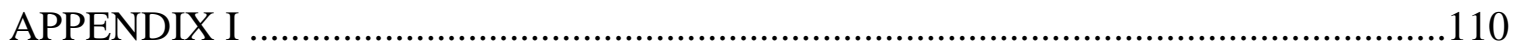

Organizational Evaluation Capacity Self-Assessment Results ..........................111

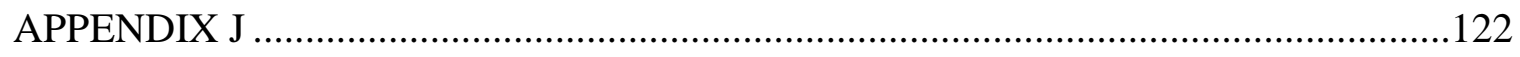

Summary of Organizational Evaluation Capacity Self-Assessment Results .......123 


\section{LIST OF TABLES}

Table 1. Focus Group Topics........................................................................... 34

Table 2. Overall Evaluation Capacity Results ........................................................ 41

Table 3. Human Resources Dimension Results ..................................................... 42

Table 4. Organizational Resources Dimension Results .......................................... 44

Table 5. Planning and Conducting Evaluations Dimension Results....................... 46

Table 6. $\quad$ Evaluation Literacy Dimension Results.................................................... 49

Table 7. Organizational Decision-Making Dimension Results ............................... 51

Table 8. $\quad$ Learning Benefits Dimension Results ..................................................... 51

Table 9. Prioritized Strategies ....................................................................... 52

Table 10. Organizational Evaluation Capacity Self-Assessment ...................................... 81

Table 11. Summary of ECB Frameworks and Tools ..................................................... 89

Table 12. Summary of Organizational Evaluation Capacity Self-Assessment Results.. 123 


\section{LIST OF FIGURES}

Figure $1 \quad$ King and Volkov's (2005) elements of a grounded framework for evaluation capacity building. ( $) 2005$ by the Regents of the University of Minnesota. Reprinted with permission of the University of Minnesota's Center for Urban and Regional Affairs (CURA)..................................... 12

Figure 2. Preskill and Boyle's (2008a) multidisciplinary model of evaluation capacity building. Reprinted with permission @ 2008, SAGE Publications.

Figure 3. Labin et al.'s (2012) integrative evaluation capacity building model. Reprinted with permission (C 2012, SAGE Publications. 20

Figure 4 Cousins et al.'s (2014) conceptual framework depicting organizational capacity to do and use evaluation. Reprinted with Permission, Copyright (c) 2014, John Wiley and Sons. 22

Figure 5. Bourgeois' (2008) conceptual model of evaluation capacity building. (C) Copyright 2008 by Isabella Bourgeois. Used with permission................... 26

Figure 6. Bourgeois and Cousins' (2008) two types of evaluation capacity. (C) Copyright 2008 by Canadian Evaluation Society. Used with permission. 27

Figure 7. Bourgeois and Cousins' (2008) four levels of organizational evaluation capacity. (C) Copyright 2011 by Canadian Evaluation Society. Used with permission. 28

Figure 8. Item level, pattern level, and structure level analysis.............................. 38

Figure 9. Most dimensions being 'intermediate' with one 'developing' capacity... 41 


\section{LIST OF ABBREVIATIONS}

BSU

ECB

NPO

HPI

HPT
Boise State University

Evaluation Capacity Building

Nonprofit Organization

Human Performance Improvement

Human Performance Technology 


\section{CHAPTER ONE: INTRODUCTION}

Over the past three decades, nonprofit organizations (NPOs) have established themselves as a rapidly growing field as their funding continues to increase (McKeever, 2015). This growth in the field has sparked an interest in assessing the impacts of the services provided by these organizations on their communities (Mitchell \& Berlan, 2016). To report on the impacts of services provided, organizations would need to have evaluation capacity, which refers to the ability for an organization to conduct an effective evaluation (Milstein, Chapel, Wetterhall, \& Cotton, 2002). NPOs, however, struggle to both engage in evaluation capacity building (ECB) activities and evaluate their programs due to a lack of organizational resources. These resources include time, money, and most notably the expertise to identify and apply appropriate ECB frameworks. A large selection of these evaluation frameworks and associated tools "require extensive interpretation by trained evaluators" (Cooper \& Shumate, 2016, p. 41) and many NPOs do not have resources to hire such experts. Additionally, there are only a few ECB frameworks and tools to use leaving the NPO sector "lack[ing] validated, generalizable models and instruments" (Taylor-Ritzler, Suarez-Balcazar, Garcia-Iriarte, Henry, \& Balcazar, 2013, p. 194). This brings great concern to the nonprofit field, and researchers have identified a need for reliable, validated resources NPOs can use for self-evaluation (Brown, 2012). 


\section{Background}

NPOs carry an ethical responsibility to their communities to not only deliver promised services or goods but also account for the impact of their programs (Cooper \& Shumate, 2016). NPOs as a whole "must discover and continually seek to improve [their] practices" (Herman \& Renz, 2008, p. 411).

NPOs funded through government grants and other funder contracts face high expectations for evaluation and reporting of data as they are held accountable to their funders (Carman \& Fredericks, 2009; Cooper \& Shumate, 2016). However, NPOs share common struggles in both measuring and building evaluation capacity. Internally, NPOs may not have appropriate resources, time, and money to complete rigorous evaluations (Carman \& Fredericks, 2009). Without having the internal resources, nonprofits may look for evaluation support external to their organization, but many NPOs still do not have the time it takes for key stakeholders to participate in lengthy external evaluations, or the funds to allocate towards such endeavors (Mitchell \& Berlan, 2016). In Carman and Fredericks' (2009) survey of 189 nonprofits regarding their struggles with evaluation, $68 \%$ of them reported a lack of time for evaluation, $46 \%$ of them reported a lack of trained staff, and half of them reported a lack of evaluation expertise. Even for the organizations who do engage in rigorous evaluation, their ability to evaluate effectively and efficiently is problematic as they are often drowned in data without expertise on how to use it (Cooper \& Shumate, 2016) or do not consider using evaluation results as a priority (Taylor-Ritzler et al., 2013).

According to Hoefer (2000), 43\% of NPOs use the lowest level of evaluation only to meet funder requirements. This leaves a gap of NPOs who do not use evaluation to 
monitor and improve their programs left to fall behind in a competitive NPO market contending over scare funds. Additionally, this leaves organizations unaware of the impact of their services or ability to maximize their outcomes in the community. NPOs must improve their evaluation capacity to not only meet growing funder requirements but also to participate in continuous performance improvement practices.

\section{Nonprofit Organizations' Evaluation Capacity}

Evaluation capacity is the ability for an organization to conduct an effective evaluation that meets accepted standards of the discipline (Milstein et al., 2002). Organizations with high evaluation capacity perceive evaluation "as a process that is likely to improve programs and increase funding" (Garcia-Iriarte, Suarez-Balcazar, Taylor-Ritzler, \& Luna, 2011, p. 169). Additionally, NPOs with high evaluation capacity are more likely to use evaluation practices in routine operations and to inform decision making (Carman, 2007). The level of an NPO's evaluation capacity may also affect the service quality and client outcomes, making a high level of evaluation capacity essential to engage in performance improvement activities (Despard, 2017). While researchers agree that measuring and understanding evaluation capacity is important for NPOs, many of these organizations share similar struggles in doing so.

\section{Building Evaluation Capacity}

Evaluation capacity building (ECB) does not have an agreed-upon definition in the literature, but the following is one of the commonly referenced definitions:

Evaluation capacity building is a context-dependent, intentional action system of guided processes and practices for bringing about and sustaining a state of affairs in which quality program evaluation and its appropriate 
uses are ordinary and ongoing practices within and/or between one or more organizations/programs/sites. (Stockdill, Baizerman, \& Compton, 2002. p. 8)

ECB efforts consist of increasing evaluation knowledge and thinking, integrating evaluation practices, and establishing positive motivations towards engaging in evaluation (Garcia-Iriarte et al., 2011). Building this capacity would benefit NPOs in changing the level of their evaluation use from an imposed use to a more mainstreamed, everyday use of evaluation results that promotes performance improvement practices within the organization (Minzner, Klerman, Markovitz, \& Fink, 2014). Lacking Expertise on Evaluation Capacity Building

The lack of both evaluation expertise and resources causes great concern in NPOs that wish to engage in ECB (Mitchell \& Berlan, 2016). When assessing evaluation capacity, NPOs may have to assess multiple criteria of effectiveness which are often independent of one another (Herman \& Renz, 2008) and using a "nuanced, multidimensional approach is more appropriate than a one-size-fits-all approach" (Eckerd \& Moulton, 2011) as different organizations could benefit from different evaluation practices. Additionally, ECB initiatives can be easily lost by turnover in key staff or a loss of leadership support for the use of evaluation results (Bourgeois, Chouinard, \& Cousins, 2008). Most namely, without leadership support, both funding for ECB initiatives and valuing of evaluation findings radically decrease often resulting in a loss of evaluation capacity within the organization. Moreover, NPOs wishing to engage in ECB can often be confused as to where to begin to facilitate ECB. This can result in the 
attempts of implementing components of ECB without success and evaluation fatigue causing evaluation to lose its value within the organization (Bourgeois \& Cousins, 2008). $\underline{\text { Using Frameworks and Tools for Facilitating Evaluation Capacity Development }}$

To compensate for their lack of internal evaluation expertise, NPOs may look for ECB resources to assist them. Michael Quinn Patton (2008) states that the "gold" standard in evaluation requires selecting the appropriate evaluation method(s) to answer particular questions and serve intended use. However, many NPOs lack the knowledge to assess the available ECB resources and match them to the needs of their organization (Herman \& Renz, 2008). In addition, few frameworks and tools have been developed specifically for NPOs to support them in both measuring and understanding their evaluation capacity, and evaluation literature is undecided on which models and instruments are useful for under-resourced NPOs. NPOs can be lost in a clouded array of evaluation research with limited resources and knowledge to a) determine what frameworks and tools are most appropriate for their organization to use and b) implement the right framework and/or tool in their organization. There is a need to provide NPOs with resources that explain the ECB frameworks and tools available to them.

\section{Significance of the Problem}

NPOs need to use evaluation not just to meet funder requirements but also to engage in continuous performance improvement. To do so, they must build their evaluation capacity (Mitchell \& Berlan, 2016). However, ECB literature is still limited and while emerging, the field is left with a gap of not having common measures and frameworks for building evaluation capacity (Wandersman, 2014). Of the ECB literature that does exist, examples of case studies for organizations that have completed successful 
evaluation capacity building programs are available. However, in most cases, the ECB efforts are facilitated by external evaluators and are funded by organizations looking to further ECB research. These case studies, while giving an idea of how evaluation capacity building can be successful, do not provide a realistic model for NPOs as most NPOs do not have the same level of expertise and resources to replicate the outcomes.

ECB in NPOs is not considered to be an easy process, and researchers such as Labin, Duffy, Meyers, Wandersman, and Lesesne (2012) call for a stronger focus on measuring evaluation capacity, knowing how to build it, and addressing the challenges it raises for NPOs. To answer to this call, the purposes of this research was the answer the question: How does an NPO use an ECB framework and its tool as a guide while building evaluation capacity?

\section{Research Question}

This research was conducted to understand the various frameworks and tools that are available for NPOs to use as a guide when building their evaluation capacity and to actually assist an NPO in using an ECB framework and its tool during their early ECB process. There is an assortment of literature that addresses evaluation capacity building; however, the literature remains undecided on which ECB frameworks and tools to recommend for NPOs to use. The researcher conducted a thorough analysis of the current literature on frameworks and tools available to assist NPOs in building their evaluation capacity and presents a summary in Chapter 2 . Then, the researcher conducted a case study to understand how an NPO went through to perceive the value of an ECB framework and its tool, facilitated the use of that framework and its tool, and interpreted the results within its context. During the case study, the researcher aimed to answer the 
following research question: How does an NPO use an ECB framework and its tool as a guide while building evaluation capacity?

The researcher conducted the case study at an NPO in the Northwest region of the United States in the fall of 2018 to investigate their use of an evaluation capacity framework and its tool. A series of focus groups were conducted to identify determinative components that a) facilitate evaluation capacity building or b) are barriers to evaluation capacity building within the organization. The results of this analysis are presented in Chapter 4. The researcher's interpretation of the focus group results, her observations during the case study, and her discussions for NPOs' continuous performance improvement through ECB are presented in Chapter 5.

\section{Definition of Terms}

Nonprofit organizations (NPOs) are organizations established to provide a public benefit (National Council of Nonprofits, n.d.). Several sectors of NPOs exist ranging from environmental, to medical, to assisting with marginalized populations. NPOs have a 501(c)(3) status making them a non-business entity that uses any profit or additional money earned to put back into their services and members.

Performance improvement (PI) is a transdisciplinary field of practice designed with systemic and systematic approaches to assessing processes (behaviors) and producing desirable outcomes (accomplishments) (Chyung, 2019). PI, also known as Human performance improvement (HPI), performance technology (PT), or human performance technology (HPT), examines the current state and desired state of performance (performance analysis), investigates the reasons for the gap between the two (cause analysis), and identifies potential interventions to reduce the gap (intervention 
selection, design, and implementation). PI also involves evaluation of the effectiveness of implementation and outcomes, and change management throughout the process.

Program evaluation is defined as "the systematic assessment of program results and, to the extent feasible, the systematic assessment of the extent to which the program caused those results" (Newcomer, Hatry, \& Wholey, 2004, p. xxxiv). Program evaluation is a part of the larger PI model aimed at identifying the status of a program in relation to its goals.

Evaluation capacity and evaluation capacity building (ECB) are often used interchangeably as evaluation capacity directly identifies areas for objectives to be built to increase capacity. Evaluation capacity is the ability for organizations to participate in evaluation practices. This includes having necessary resources, skill, and technical assistance to facilitate evaluation practices (Despard, 2017). 


\section{CHAPTER TWO: EVALUATION CAPACITY BUILDING FRAMEWORKS AND TOOLS}

During the past three decades, evaluation capacity has become a growing area of interest between evaluators and the nonprofit sector (Minzner et al., 2014). Starting in the 1990s, researchers explored definitions and components of ECB, but it was not until a decade later that the topic of ECB gained more light. In 2000, the American Evaluation Association chose the topic of evaluation capacity building as its conference theme (American Evaluation Association, n.d.). From there, the growth of ECB in the literature has increased steadily with several editions of American Evaluation Association journals highlighting ECB research. As a result of this attention, several researchers have established frameworks displaying how ECB should be executed and what factors lead to its success or failure within an organization. These frameworks vary on their approaches and understanding of ECB; however, they all share the understanding that ECB is a process that is both systematic in its approach and systemic in its reach. Researchers agree that ECB is a complex phenomenon involving issues of individual learning, organizational change, sustained change, and program processes and outcomes (Labin et al., 2012).

To better understand the ECB frameworks and tools, the researcher of this thesis searched several databases to gather published peer-reviewed articles as well as Dissertations and Theses, conference proceedings, and websites. A total of eight databases were searched including, PsycINFO, Academic Search Premier, ProQuest 
Central, Public Administration Abstracts, Primary Search, Sociological Abstracts, Social Work Abstracts, and Web of Science. Search terms included "Evaluation Capacity," “Organizational Evaluation Capacity," "Capacity to do evaluation," "Capacity to use evaluation," "Evaluation in nonprofits," "Evaluation capacity in nonprofits," "Measuring evaluation in nonprofits." The primary journals referenced were the American Journal of Evaluation, Canadian Journal of Program Evaluation, Evaluation and Program Planning, New Directions for Evaluation, Nonprofit Management and Leadership, Nonprofit Policy Forum, and Public Administrative Review. Over 200 related articles were reviewed, and 70 found to be relevant to the topic. Relevant articles were selected based on their application to a nonprofit or social service setting, and usage of evaluation capacity focus. Out of the 200 reviewed articles, 98 were excluded because they focused on organizational capacity building rather than addressing evaluation capacity or evaluation capacity building. An additional seven articles were excluded due to being research proposals, and not including any new information to the field. Another 13 articles were excluded as they showcased ECB within for-profit organizations with additional supports and resources that did not match the research question. Twelve articles were also excluded that utilized evaluation capacity tools or frameworks designed specifically for different types of organizations and were validated as not being appropriate for generalized use.

Given both the newness and the variance in the field of ECB, the researcher did not find that the process of ECB was supported by a single widely-accepted framework or commonly agreed upon tools. This results in a challenge for NPOs when determining 
how to implement ECB practices in their organization. The most commonly referenced frameworks in the literature are discussed in the following sections.

\section{King and Volkov's (2005) Framework}

\section{Purpose and Goals of the Framework}

As one of the first groups of researchers to establish a framework for ECB in NPOs, King and Volkov (2005) looked to create a resource that would assist organizations to strengthen and sustain effective program evaluation practices. Their framework includes four objectives of ECB: 1) to increase an organization's capacity to design, implement, and manage evaluation projects, 2) to access, build, and use evaluative knowledge and skills; 3) to cultivate a spirit of continuous organizational learning, improvement, and accountability; and 4) to create awareness and support for evaluation as a performance improvement strategy (King \& Volkov, 2005). As a result of achieving these objectives, organizations with higher evaluation capacity benefit by having more insight to the success of their programs and utilizing program information to continuously improve the organization.

$\underline{\text { Steps Included in the Framework }}$

To establish an ECB process within an organization, King and Volkov (2005)

developed a framework that includes three major categories: organizational context, ECB structures, and evaluation resources, as seen in Figure 1. 


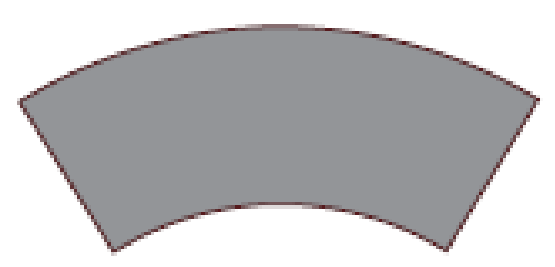

RESOURCES

- Access to evaluation resources

- Sources of support for evaluation in the organization
ORGANIZATIONAL CONTEXT

- External

- Internal

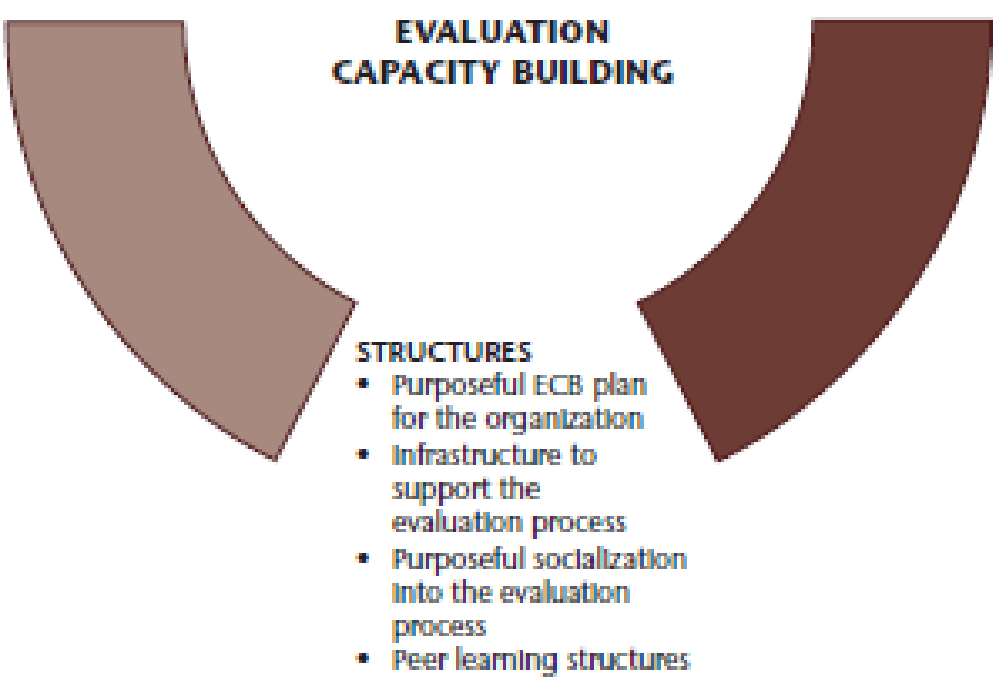

Figure 1 King and Volkov's (2005) elements of a grounded framework for evaluation capacity building. (C) 2005 by the Regents of the University of Minnesota. Reprinted with permission of the University of Minnesota's Center for Urban and Regional Affairs (CURA).

The first category of King and Volkov's (2005) framework is to understand organizational context. Organizational context acts as a catalyst that will either promote the start of ECB or halt it and is comprised of two primary categories, external and internal contexts. External contexts come from funder requirements and accountability NPOs may have. External contexts can also include external support for changes such as shifts in research or funder priorities. Internal contexts relate to the leadership support for ECB including engagement, interest, and demand for evaluation information, and commitment to using evaluation results. As this step of understanding organizational 
context may determine the viability of ECB in an organization, King and Volkov (2005) recommend organizations use a preliminary assessment measuring their readiness for learning and change. If the assessment indicates the organization is open to learning, then establishing ECB through process use may be viable. However, King (2007) notes if any of these contexts are not in support of ECB, then the chance of its success is greatly reduced.

Additionally, this first category includes identifying evaluation champions to promote the use of evaluative thinking within the organization. The role of these champions is to monitor the ECB process and have some understanding of evaluation and the organization. In addition to the evaluation champions, the organization also need a knowledgeable evaluator to facilitate the ECB process and guide capacity building activities. King and Volkov (2005) specify that the role of this evaluator is not as an expert or teacher, but rather as a facilitator to promote evaluative inquiry within the organization. This person works as a liaison between the champions and the organization to establish ECB activities, negotiate with key stakeholders, and manage the overall project.

The second category of the framework is ECB structures. These structures include establishing an ECB plan, having or developing the infrastructure to support evaluation, and promoting purposeful socialization into the organization's evaluation process. This category is tied to both the planning and execution of the ECB process within an organization. At the heart of this category is to establish fruitful ground for process use of evaluation, a concept adapted from Patton (1997). Process use is the purposeful application of an evaluation process to teach evaluative inquiry and is recommended to 
NPOs as this strategy can occur more organically with fewer resources than a formal ECB initiative (King \& Volkov, 2005). To support process use, King and Volkov (2005) recommend establishing peer learning structures in the ECB plan.

The last category of this framework is resources. King and Volkov (2005) note that this category is often where NPOs struggle because without easy access to evaluation resources, ECB will likely suffer. These resources include formal training, just in time evaluation coaching, internal evaluation experts of external consultants, relevant evaluation research including evaluation best practices, and evaluation reference materials such as books, journals, and online resources.

Along with their framework, Volkov and King (2007) introduced an ECB checklist (see APPENDIX A) to assist the organization to identify needs in resources, processes, and planning to create a tailored strategy for evaluation. This tool was designed to be a resource to give organizations a tangible list of 'to-dos' to assess their progress towards high evaluation capacity and the remaining components to address.

During the process of comparing various ECB frameworks and selecting one to be used by an NPO in her case study, the researcher of this thesis also analyzed strengths and weaknesses of individual ECB frameworks when they were applied during other organizations’ ECB efforts.

$\underline{\text { Strengths and Weaknesses of the Framework from Case Studies }}$

Volkov (2008) used this framework in his case study of a nonprofit codenamed as 'The Foundation.' At the start of the case study, The Foundation's organizational goals included increasing their evaluation capacity and becoming a learning organization, to allow them to better use evaluation towards performance improvement practices. 
Through the case study observation, however, The Foundation noted that a lack of support from leadership to make evaluation a priority resulted in a loss of the organization's existing evaluation capacity. In a similar case study by Huffman, Lawrenz, Thomas, and Clarkson (2006), science, technology, engineering, and mathematics (STEM) educators also struggled to successfully apply the framework due to employee turnover, lack of buy-in from key stakeholders, and limited resources. Additionally, individual teachers found it difficult to narrow down capacity building activities as the researchers noted the open-ended nature of the immersion approach to ECB could be daunting for participants.

From this, Volkov (2008) established a series of eight driving forces that contributed to sustainable ECB, including leadership commitment to ECB, clear value and use of evaluation, evaluation integrated in culture, evaluation and ECB strategy, staff training in evaluation, resources for evaluation and ECB, functional monitoring system, and internal evaluation staff. These forces act as a guide for organizations looking to engage in ECB to understand how to better position the initiative for success.

\section{Preskill and Boyle's (2008a) Framework}

\section{Purpose and Goals of the Framework}

During the same boom in evaluation capacity attention, Preskill and Boyle (2008a) worked to establish a more detailed framework of ECB that would include ECB strategies as seen in their multidisciplinary model of evaluation capacity building pictured in Figure 2. 


\section{ORGANIZATIONAL LEARNING CAPACITY}

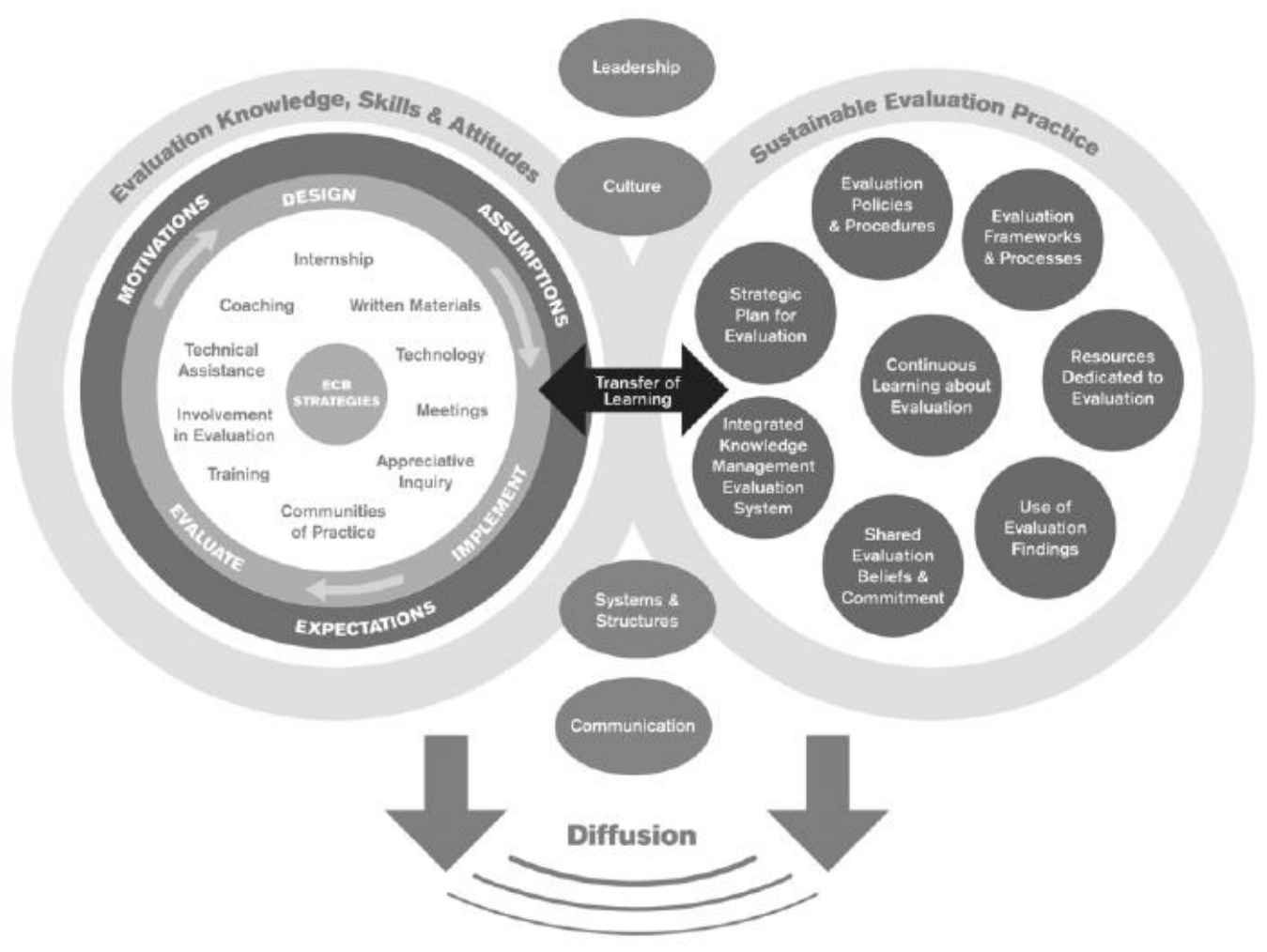

Figure 2. Preskill and Boyle's (2008a) multidisciplinary model of evaluation capacity building. Reprinted with permission (C 2008, SAGE Publications.

While King and Volkov's (2005) framework established a strong foundation for the components to be included in an ECB framework, Preskill and Boyle (2008a) established a more detailed and comprehensive model for organizations to use when forming ECB initiatives. Their goal was that with a more detailed and guiding framework, more organizations would be able to successfully facilitate planned ECB. Steps Included in the Framework

Preskill and Boyle (2008a) considered ECB to be a union of several internal and external organizational factors that, when facilitated correctly, could result in sustained ECB within the organization and a diffusion of evaluation knowledge within the field. 
The left side of their multidisciplinary model of ECB represents the components included in the ECB process within the organization, taking into account all the factors displayed within the circles. This includes identifying the strategies to use during ECB and establishing the design, implementation, and evaluation of the ECB process. To avoid the potential for confusion while selecting an appropriate ECB strategy, Preskill and Boyle (2008a) emphasized the use of organization planning to select appropriate ECB strategies based on the organization's and individual interests, resources, and availability. Preskill and Boyle (2008a) recommend using the Readiness for Organizational Learning (ROLE) assessment (Preskill \& Torres, 2000) to assist in determining the readiness of the organization and which strategies may be most effective.

As the organization determines the ECB strategies, they must also understand the motivations, assumptions, and expectations of the ECB process within the organization and individual employees. Similar to King and Volkov's (2005) framework, Preskill and Boyle (2008a) noted that motivation to participate in ECB is triggered by both internal and external factors. They explained that specific internal and external reasons why organizations may decide to build their evaluation capacity include their desire to participate in government policy-making and planning, their need to adapt to the changes within the organization, and their desire to improve evaluation knowledge and skills and engage in performance improvement.

In addition to motivational factors guiding the organization towards ECB, individual organizations also bring in their own set of assumptions about evaluation and the ECB process. For example, if the organization assumes that evaluation will make programs more effective, then it is more likely that leadership will support ECB. Other 
assumptions include that organization members have the ability to learn how to use evaluation and that the organization will support intentionally promoting learning within the organization. These assumptions often relate to the expectations the organization has for engaging in ECB such as allowing for an increase of funding, engaging in evaluation more frequently, using evaluative findings in decision making, and increasing the adaptability within the organization.

Preskill and Boyle (2008a) emphasize that all components within the left circle "Evaluation Knowledge, Skills, and Attitudes" in Figure 2 as a part of an ongoing assessment of the viability of ECB within the organization. Successfully planning, implementing, and evaluating the ECB process should result in a transfer of learning which leads the organization into the right circle "Sustainable Evaluation Practice" of the model. The right circle includes the several components that contribute to sustaining the gains in evaluation capacity achieved through the ECB process. By assisting organizations to build their evaluation capacity, organizations may see a diffusion of evaluation knowledge both within the organization and the field as collaboration occurs between organizations and establishes a "social epidemic" of evaluation. $\underline{\text { Strengths and Weaknesses of the Framework from Case Studies }}$

García-Iriarte et al. (2011) applied Preskill and Boyle's (2008a) framework to community-based organizations serving adults with intellectual and developmental disabilities in Chicago, Illinois. Through the course of their case study, the researchers focused on building the capacity of a staff member within the organization. Together the researchers and the staff established a collaborative immersion of approaches. Through their work of increasing the capacity of a single individual within the organization, the 
researchers identified the diffusion of evaluative knowledge within the organization to other staff members and the promotion of evaluation as a mainstreamed practice. This indicated that the framework could be successfully applied with an organization to produce ECB results.

Years later, Hilton and Libretto (2017) sought to apply Preskill and Boyle's (2008a) framework to a military setting in Fort Hood, Texas, noting its program's differences from the NPO setting the model was established for. The researchers chose this model as it was the most comprehensive to date; however, they noted it was too conceptual and did not include specific steps for how ECB components should be completed. Additionally, while Preskill and Boyle (2008b) offered a set of ECB objectives, their framework did not include any measurement instruments to assist organizations in understanding ECB progress, making this framework difficult to implement for organizations with limited evaluation and ECB expertise. 


\section{Labin, Duffy, Meyers, Wandersman, and Lesesne's (2012) Integrative ECB Model Purpose and Goals of the Framework}

In their 2012 synthesis of ECB literature, Labin et al. worked to combine the strengths of previous frameworks in their Integrative ECB Model (Figure 3). While previous frameworks mirrored each other, including several of the same components, Labin et al. (2012) looked to answer some of the problems identified with previous models by presenting their model in a linear logic model format, including more clarification on the process for organizations to follow.

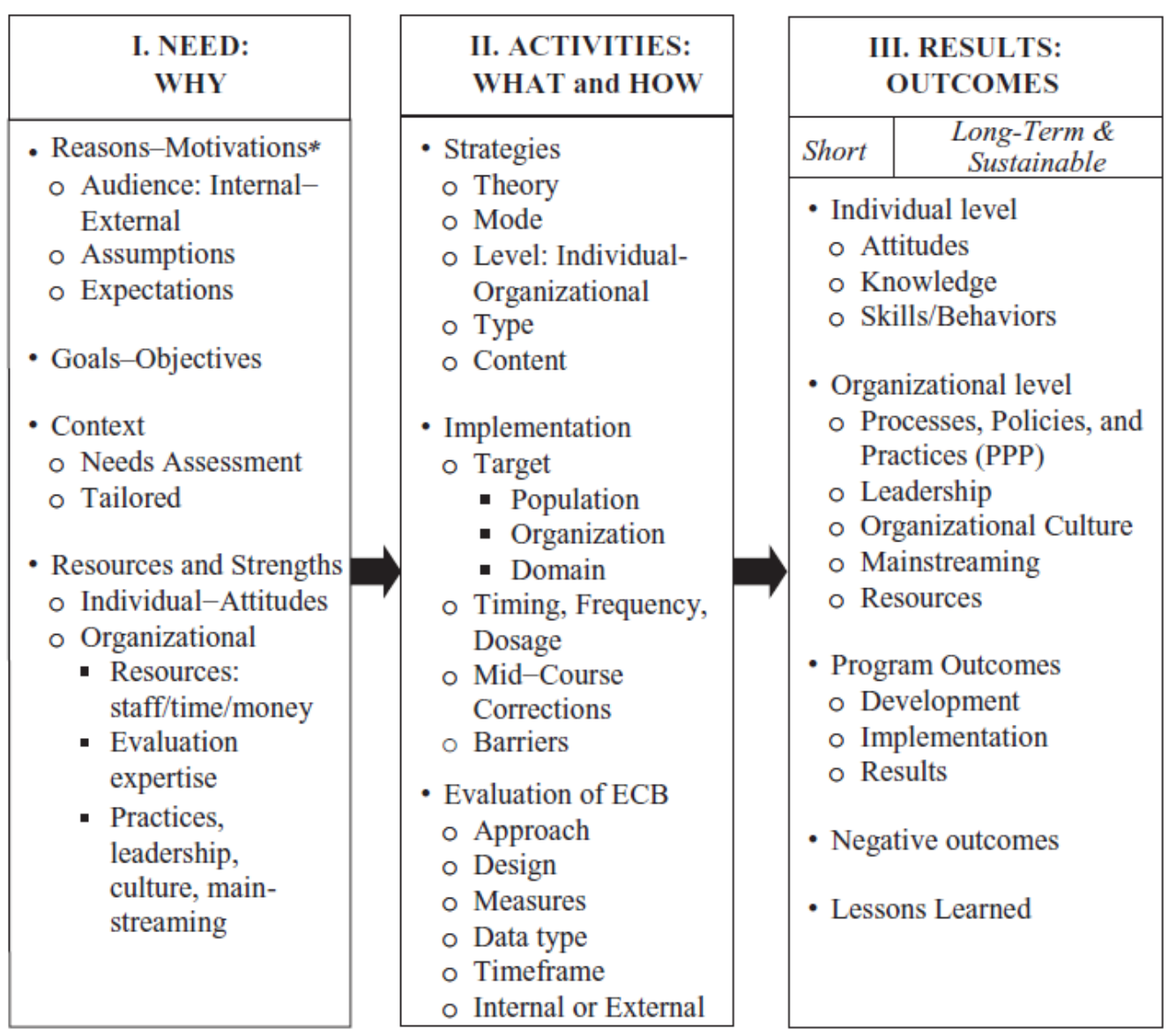

Figure 3. Labin et al.'s (2012) integrative evaluation capacity building model. Reprinted with permission ( 2012, SAGE Publications. 
Steps Included in the Framework

Labin et al.'s (2012) Integrative ECB model is a three-step system for ECB. The first step relates closely to Preskill and Boyle's (2008a) multidisciplinary ECB model including the identification of the ECB needs such as motivation to engage in ECB, assumptions and expectations, and goals and objectives for ECB. The second step of the model includes the activities related to the ECB strategies and implementation. This section differs from Preskill and Boyle's (2008a) framework as Labin et al. include more detail about components to consider when selecting strategies and designing an ECB plan. The last step of this model relates to the outcomes or indicators of evaluation capacity growth. Labin et al. (2012) added to Preskill and Boyle's work with ECB objectives by promoting the need to include three levels of ECB practices: individual, organizational, and program outcomes.

While Labin et al.'s Integrative ECB model was able to synthesize the existing frameworks and provide a more linear ECB process, the ECB field still lacked a comprehensive framework that included applying evaluation use within the organization and any measurement instruments to determine ECB progress.

\section{Cousins, Goh, Elliott, and Bourgeois' (2014) Framework}

\section{$\underline{\text { Purpose and Goals of the Framework }}$}

Frameworks prior to Cousins et al. (2014) focused on an organization's capacity to do evaluation; however, Cousins et al. (2014) noted the need to expand the existing models to include the capacity of the organization to use evaluation.

Cousins et al. (2014) considered the capacity to use evaluation to be an essential element establishing the value of evaluation within an organization. By establishing both 
the capacity to do evaluations and use their results, Cousins et al. (2014) believed that evaluation practices would increase within the organizations as stakeholders support the value gained from these practices.

Steps Included in the Framework

Cousins et al.'s (2014) framework includes three primary components as pictured in Figure 4.

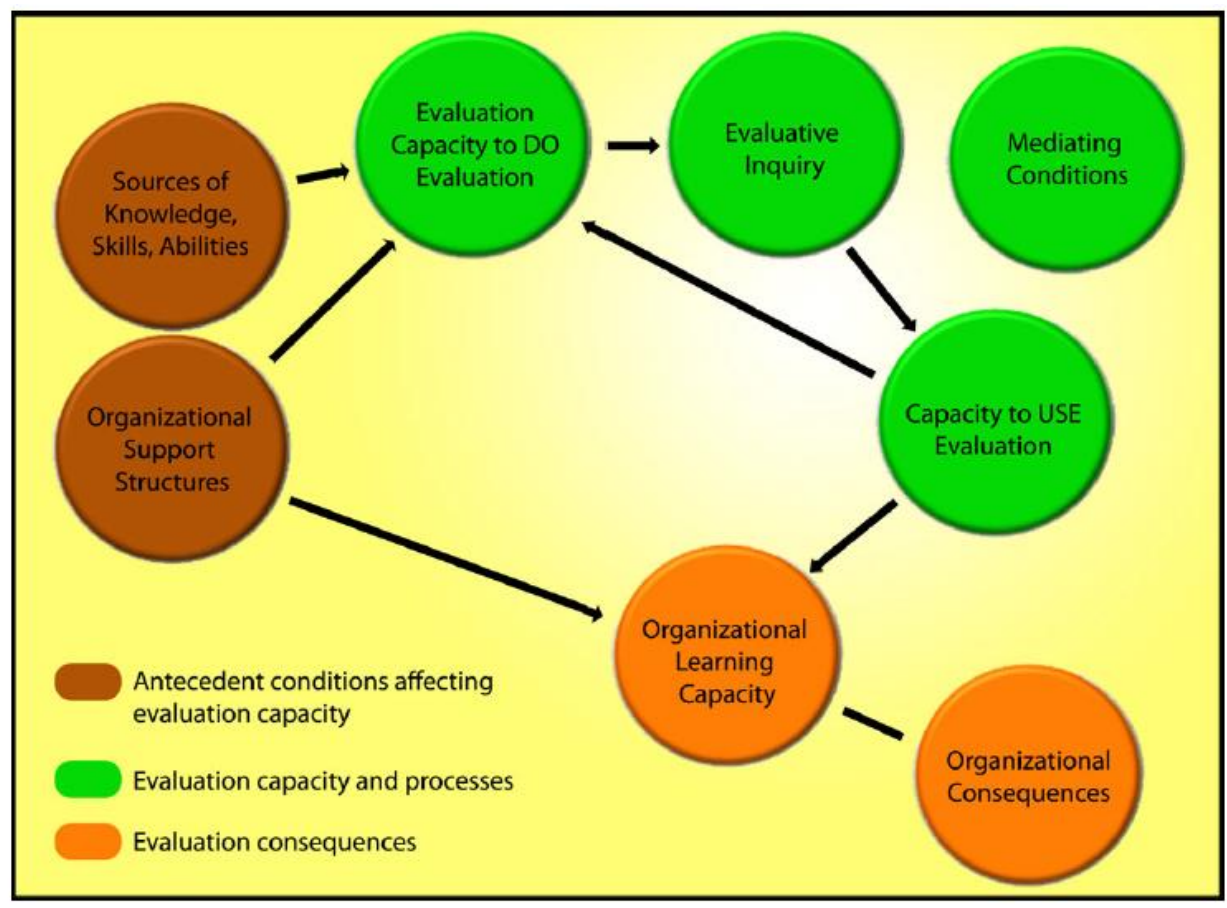

Figure 4 Cousins et al.'s (2014) conceptual framework depicting organizational capacity to do and use evaluation. Reprinted with Permission, Copyright (C) 2014, John Wiley and Sons.

The first component, antecedent conditions affecting evaluation capacity, refers to the factors that contribute to the initiation and sustainability of ECB. These factors mirror the previous findings of King and Volkov (2005) and Preskill and Boyle (2008a).

The second component of this framework is the evaluation capacity and processes within the organization. Cousins et al. (2014) specifically consider the level of evaluation 
capacity to equal the amount of evaluative inquiry occurring within the organization. Evaluative inquiry, defined as "the nature of and extent to which evaluation is actually occurring within the organization" (Cousins et al., 2014, p. 16), and its mediating factors help build the organization's capacity to use evaluation.

The last component of this framework is the evaluation consequences. Similar to Preskill and Boyle's (2008a) model, Cousins et al. (2014) consider organizational learning capacity to be congruent to evaluation capacity. Thus, they conclude that highly developed learning organizations benefit from well-developed capacity to use evaluation (Cousins et al., 2014). If an organization successfully increases their evaluation capacity and views evaluation as beneficial, it is more likely to continue in their evaluation practices, consistent with Cousins, Goh, and Clark's (2005) hypothesis that data use leads to data valuing.

\section{$\underline{\text { Strengths and Weaknesses of the Framework from Case Studies }}$}

Cousins, Goh, Elliott, Aubry, and Gilbert (2013) applied this framework in Canada with NPOs and government agencies, using an online version of the Organizational Learning Survey developed by Goh and Richards (1997). Their results indicated that while NPO and government agencies had differences in contextual circumstances and capacity to use evaluation, there was no significant difference between the two sectors on the capacity to do evaluation; however, when compared to government agencies, NPOs struggled to apply evaluation findings and still needed more ECB resources to successfully overcome their ECB barriers.

While the concept of evaluation use is added to the ECB framework, this model follows a more conceptual approach to ECB, similar to Preskill and Boyle's (2008a), 
which may present difficulties in NPOs with limited expertise being able to successfully implement its components.

\section{Taylor-Ritzler, Suarez-Balcazar, Garcia-Iriarte, Henry, and Balcazar's (2013) Evaluation Capacity Assessment Instrument}

$\underline{\text { Purpose and Goal of Instrument }}$

Taylor-Ritzler et al. (2013) identified the need to have a robust measure that could be used to assess an organization's readiness to engage in ECB and the degree to which ECB is developed and sustained over time, a key element missing from all previous frameworks. The result was the Evaluation Capacity Assessment Instrument (ECAI). While this instrument was not established or endorsed with an ECB framework, it was designed to be a functional tool that complimented key components of ECB research. Components of the Instrument

Taylor-Ritzler et al. (2013) developed the ECAI from a blend of twelve other instruments, taking components from scales of organizational learning, culture, evaluation use, change, and organizational capacity. Their ECAI (see APPENDIX B) includes a mixture of individual factors, organizational factors, and outcomes. Specifically, the individual factors measure the individual's awareness of evaluation, motivation to engage in evaluation, and competence. Organizational factors include leadership, learning climate, and resources for evaluation. Lastly, the outcomes include mainstreaming evaluation use and extent of use of evaluation findings. Questions included were incorporated from elements of the ROLE (Preskill \& Torres, 2000), Volkov and King's (2007) checklist for building evaluation capacity, and Cousins et al.'s 
(2005) evaluation and organizational capacity components. The outcomes support the emphasis on evaluation use supported by Cousins et al. (2014).

$\underline{\text { Strengths and Weaknesses of the Instrument }}$

The ECAI was designed to meet multiple needs in the ECB process as it can be used to assess an organization's readiness to participate in ECB and be re-administered through the ECB process to measure the progress of their ECB initiative. For evaluators with skilled knowledge in the ECB process, this tool could be matched with a framework to guide an organization through ECB. However, NPOs without skilled evaluators would likely struggle to apply these results without having an associated framework or established process.

\section{Bourgeois and Cousins' (2008) Framework}

Purpose of the Framework

For a skilled evaluator, robust frameworks and an instrument now existed to assist in ECB; however, Bourgeois and Cousins (2008) still sought to close the gap of organizations with low evaluation knowledge to apply a framework with an associated tool and achieve similar results. Understanding the limitations of previous ECB research, Bourgeois and Cousins (2008) developed a clear framework that organizations could use as a more simplified guide towards their ECB process, and an associated instrument that allowed them to diagnose evaluation capacity weaknesses and assess the progress of their ECB plan in addressing them.

Similar to previous frameworks, Bourgeois and Cousins (2008) identified two ways that ECB seems to occur in organizations: 1) active participation of ECB using collaboration with trained evaluators or 2) passive participation by fostering 
organizational learning and communities of practice. Either approach to ECB, if done successfully, would yield an increase in both organizational learning and evaluation use. $\underline{\text { Steps Included in the Framework }}$

Following a similar model by Labin et al. (2012), Bourgeois and Cousins (2008) used a linear logic model format to present their understanding of ECB, as seen in Figure 5.

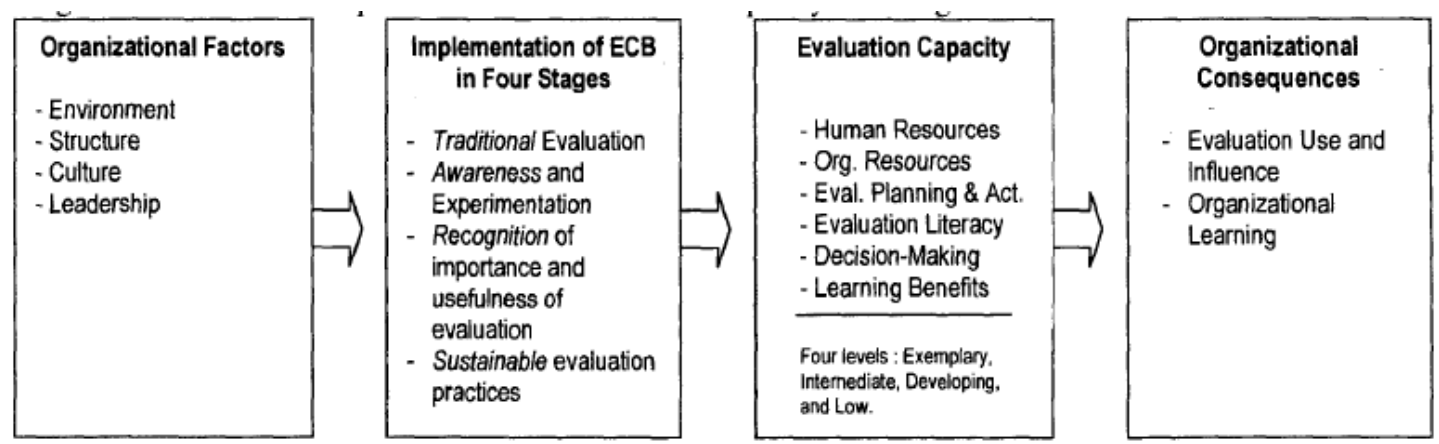

Figure 5. Bourgeois' (2008) conceptual model of evaluation capacity building. () Copyright 2008 by Isabella Bourgeois. Used with permission.

Bourgeois and Cousins (2008) include several of the same organizational factors addressed by King and Volkov (2005) and Preskill and Boyle (2008a) with two additions, incentives and interactions with other organizations. These factors set the stage for the implementation of ECB, which follows a four-stage path ranging from traditional evaluation to sustainability evaluation practices. Through their process of building evaluation capacity, organizations see an impact in six dimensions with varying evaluation competencies and ultimately result in the organizational consequences of evaluation use and influence, and organizational learning.

Steps one, two and four had been previously well addressed in the literature, but the third step was a new contribution resulting from Bourgeois and Cousins' (2008) work. Together, they established dimensions for evaluation capacity and sorted them 
between capacity to do evaluation and capacity to use evaluation, as shown in Figure 6.

These dimensions later translated into a measurable tool organizations should use to both diagnose their ECB needs and assess their ECB progress.

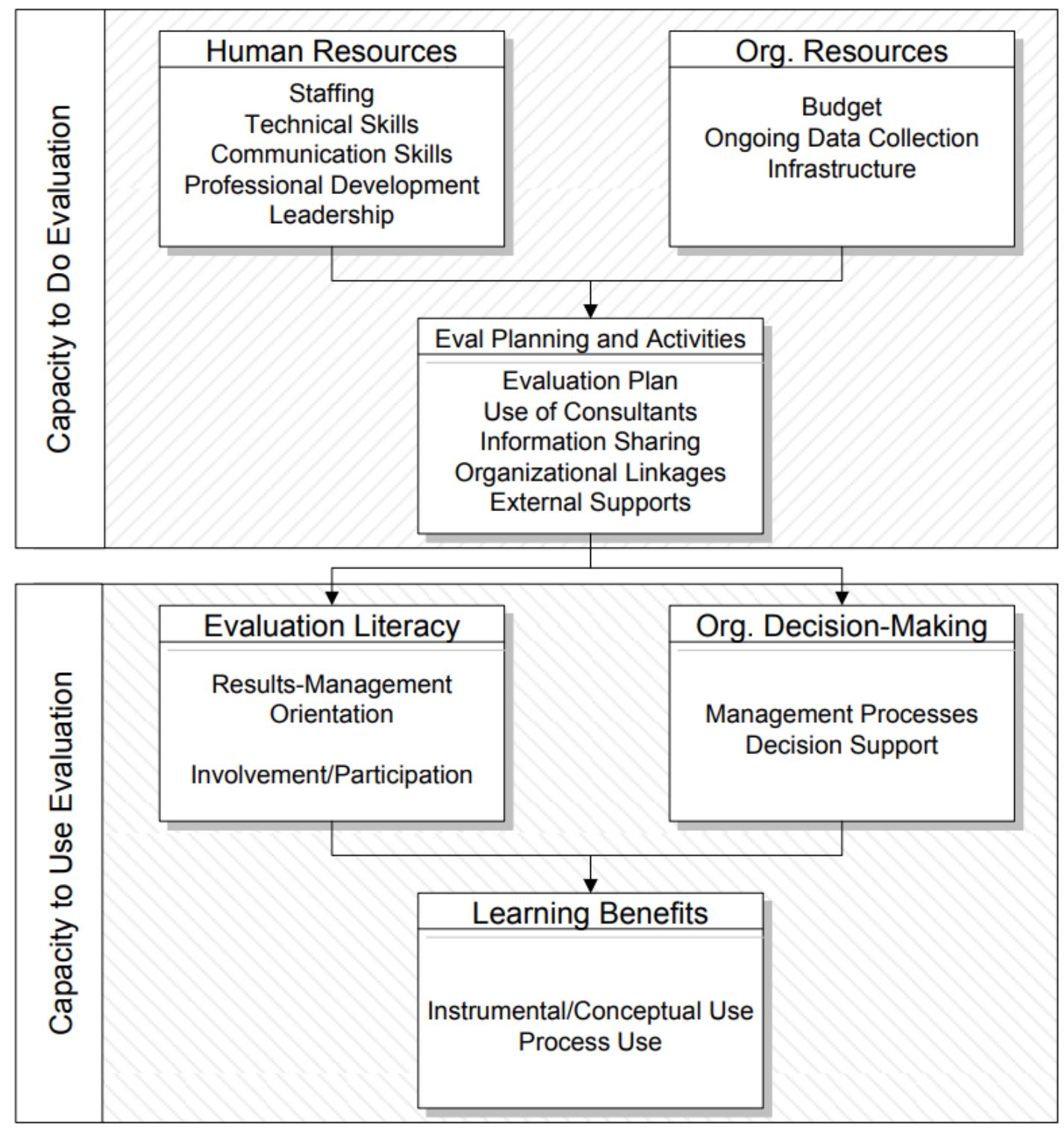

Figure 6. Bourgeois and Cousins' (2008) two types of evaluation capacity. (C) Copyright 2008 by Canadian Evaluation Society. Used with permission. 


\section{Organizational Evaluation Capacity Self-Assessment}

As a key contribution to the ECB literature, Bourgeois and Cousins (2013) also established a tool to measure evaluation capacity allowing organizations to both diagnose areas for improvement and monitor changes over time. In their tool, evaluation capacity is measured through six dimensions and ranked in four levels: exemplary, intermediate, developing, and low, as reflected in Figure 7. Bourgeois and Cousins (2013) recommended organizations use this tool to profile their organization at the beginning of initiating ECB, during the process, and afterward to assess its success. The full selfassessment is available in APPENDIX C.

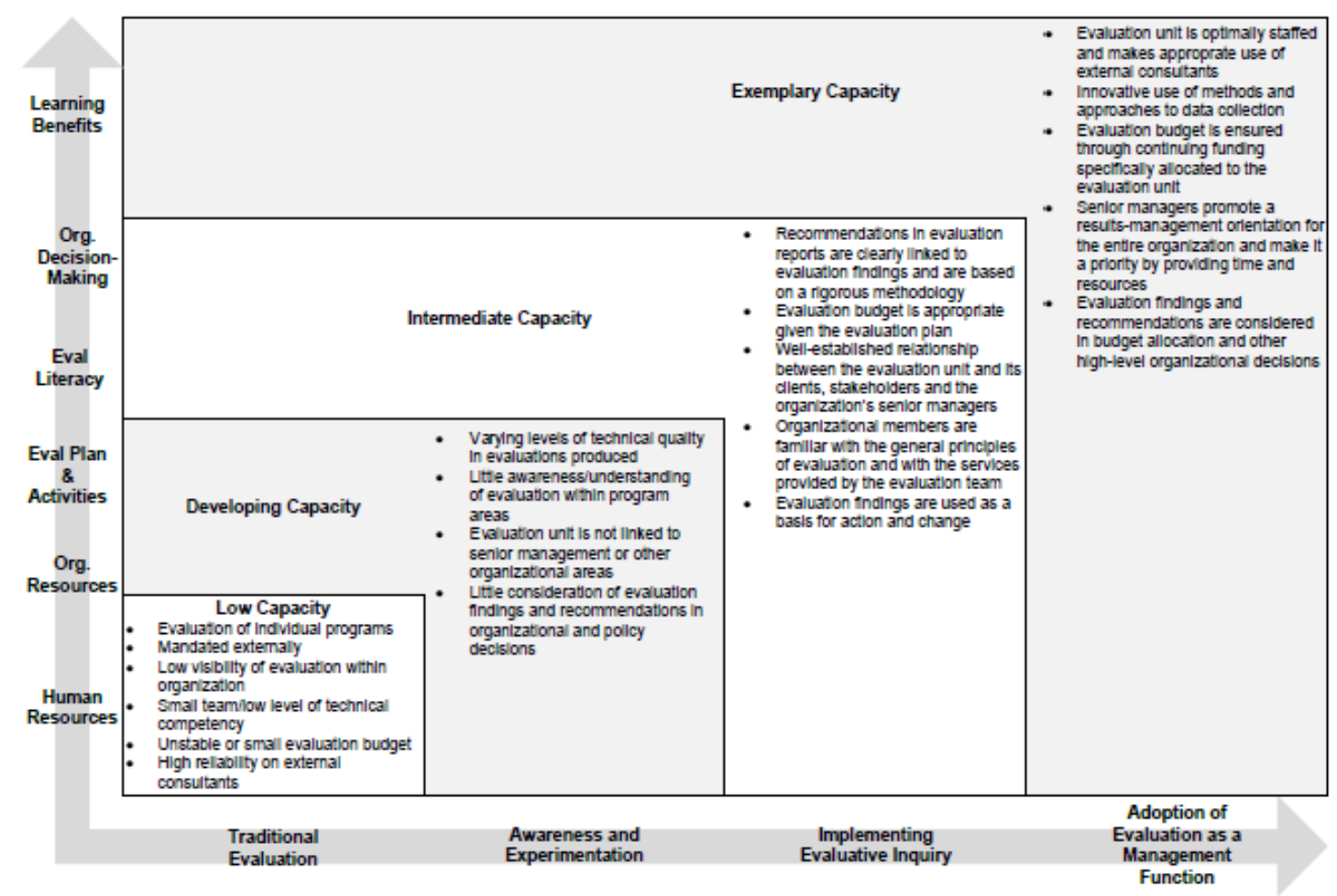

Figure 7. Bourgeois and Cousins' (2008) four levels of organizational evaluation capacity. (C) Copyright 2011 by Canadian Evaluation Society. Used with permission. 


\section{Strengths and Weaknesses of the Instrument}

Bourgeois, Whynot, and Thériault (2015) tested this tool through several case studies within different organizational contexts. Each case study was administered the organizational evaluation capacity self-assessment and participated in interviews with the researchers. In each of the case studies, researchers noted an increase of evaluation capacity and institutionalization. Additionally, the organizations reported that evaluation was used more often, resulting in higher quality evaluation and greater utilization of evaluation results.

Bourgeois, Simmons, and Buetti (2018) conducted another study of their framework and tool years later in 10 Ontario public health units. The goal of this study was to further identify ECB strategies based on the context and needs of the organization. Researchers established a standardized reporting template and completed semi-structured interviews over the phone. Their results indicated that engaged staff members, support of leadership, and organizational tools and structure were some of the main facilitators of ECB. Additionally, their research led to the conclusion that using a multicomponent approach, using several strategies at once, led to better ECB outcomes.

\section{Summary of ECB Frameworks and Tools}

While each framework offers essential insight into the process for ECB within organizations, the ECB field is still new and undecided on which framework to support and which associated instrument to use with ECB efforts. APPENDIX D summarizes the individual components of ECB highlighted in the relative frameworks, any associated tools, and the strengths and weaknesses. 
While no standard measurements exist in the literature currently, several promising case studies indicate ECB success and a few emerging tools that can assist under-resourced NPOs to understand, measure, and build their evaluation capacity. Specifically, Taylor-Ritzler et al.'s (2013) ECAI and Bourgeois and Cousins' (2013) organizational evaluation capacity self-assessment instrument appear to be the most robust measurement tools, combining key components of well-documented ECB models and frameworks.

The ECAI appears to be a good tool to measure both an organization's readiness to engage in ECB and the outcomes of their ECB initiative. However, without an associated framework, it does lack the essential 'how' component to guide NPOs with limited evaluation expertise through the ECB process. Given the relative strengths and weaknesses of these models and tools, it appears that when an organization is using a more knowledgeable and skilled evaluator who can assess appropriate ECB strategies based on organizational analysis, the ECAI may be a good fit to be a simple measurement tool to assess the progress of ECB in the organization.

For most organizations, however, the organizational evaluation capacity selfassessment established by Bourgeois and Cousins (2013) may be a better fit as it provides more insight into the process of diagnosing weak evaluation components within specific areas of the organization and establishing plans to build the capacity accordingly. This tool also acts as a measurement to assess the progress of the ECB process as a whole both encouraging the use of evaluation within the organization and giving organizations an understanding of the success or barriers to the ECB process. 


\section{CHAPTER THREE: A CASE STUDY ON AN NPO'S USE OF AN ECB FRAMEWORK AND ITS TOOL Research Question}

The research question is: How does an NPO use an ECB framework and its tool as a guide while building evaluation capacity? To answer the question, the researcher conducted a case study in a real organization.

\section{Research Design: A Case Study}

The target population for this research is under-resourced NPOs with limited evaluation capacity. Given the level of detail needed to understand the experience an organization goes through when both learning to measure their evaluation capacity and planning to build it, the researcher chose to conduct a case study at one under-resourced NPO, selected as a convenience sample.

Participating Organization and Stakeholders

The organization featured in this case study volunteered to participate in this research with the condition of remaining confidential. To maintain the confidentiality of the organization, the organization in this case study is given the pseudonym of "Foothills." Foothills is a mid-sized NPO in the Northwest region of the United States that provides various programs and support to the community. It has existed for several decades and has sought to build the ability for the managers and leadership to engage in performance improvement practices but has had limited success in doing so on their own. Similar to most nonprofits, Foothills receives funding from government grants, contracts, 
and private donations. They are accountable to these funding parties but have experienced difficulty as funder demands have increased and evaluation practices within the organization have not. Evaluation resources and knowledge in the organization are low; for example, they only recently launched an electronic database that can be used to gather data and hired an employee with evaluation experience within the past year. This has slightly increased their evaluation capacity, but the organization is still seeking to expand evaluation and performance improvement efforts beyond one employee and to spread capacity for evaluation into the organization's culture. Their interest in participating in this research was three-fold; to better evaluate the impact of their programs, to engage in performance improvement practices to enhance the impact of their programs, and to engage in research that could inform other NPOs of lessons learned from their ECB experience.

Within the organization, a total of six employees were invited to participate. They were selected based on their roles' need to use evaluation skills. Also, they would likely benefit from participating in the research because having the ability to better engage in evaluation and performance improvement practices was deemed a critical component of their role. Each invited employee is considered a key stakeholder, directly involved in the design, development, implementation, and maintenance of the programs provided in the NPO. Out of the six employees, five agreed to participate. The participating employees include the overall program's director, two sub-program directors, one program manager, and an operations lead, who was acting as interim program manager at the time of this research. Out of the five participants, four are female and one male. Three participants 
have a master's level education, one has a bachelor's degree and one has a high school diploma.

Approval for the Study

Participation was approved by the overall program director of Foothills to be a part of normal working responsibilities and available for compensation under their existing compensation plan (see in APPENDIX E Site Authorization Letter). The researcher also obtained approval from Boise State University's (BSU) Institutional Review Board for conducting this case study for her thesis.

Participants received an initial recruitment invitation from the researcher via email with an informed consent form attached. All five participants voluntarily signed the informed consent form and agreed to participate in the research. When they met with the researcher for the first focus group, they submitted a hard copy of the informed consent form with their signature to the researcher. Copies of the recruitment email and the informed consent form are available in APPENDIX F and APPENDIX G.

\section{Data Collection Procedure}

The researcher conducted a series of three focus groups in the fall of 2018. Focus groups were selected over interview or survey options as the participants' roles were interconnected and the researcher desired to assess the organizations' collective evaluation capacity, not just individual participants' separate opinions. The researcher believed a focus group environment would allow those with differing levels of evaluation knowledge to share their understanding and interpretation to the group so that the group could better understand the use of an ECB tool. Recruitment for the focus group participants began in late September in 2018 with focus groups scheduled through 
October and November of the same year. Each focus group was between 45-90 minutes.

Focus groups were held two weeks apart from one another to allow for time for transcription and analysis of data collected. Focus group data and results from the administered self-assessment were analyzed between October, 2018 and January, 2019.

Focus group topics are presented in Table 1. Focus group scripts are available in

\section{APPENDIX H.}

\section{Table 1. Focus Group Topics}

\begin{tabular}{|l|l|l|}
\hline \multicolumn{1}{|c|}{ Focus Group 1 } & \multicolumn{1}{|c|}{ Focus Group 2 } & \multicolumn{1}{c|}{ Focus Group 3 } \\
\hline $\begin{array}{l}\text { 1. Introduce participants } \\
\text { to research purpose and } \\
\text { organizational } \\
\text { evaluation capacity } \\
\text { self-assessment. }\end{array}$ & $\begin{array}{l}\text { 1. Review group results of } \\
\text { the assessment, } \\
\text { including the overall } \\
\text { score, dimensional } \\
\text { scores, and sub } \\
\text { dimensional scores. }\end{array}$ & $\begin{array}{l}\text { 1. Review overall ECB } \\
\text { process and experience. }\end{array}$ \\
$\begin{array}{l}\text { 2. Identify facilitators, } \\
\text { barriers, and } \\
\text { assessment } \\
\text { individually. }\end{array}$ & $\begin{array}{l}\text { ECommendations for } \\
\text { ECB process. }\end{array}$ \\
$\begin{array}{l}\text { 3iscuss their } \\
\text { experience with the } \\
\text { self-assessment. }\end{array}$ & $\begin{array}{l}\text { interpretation. } \\
\text { 3elect and prioritize } \\
\text { ECB strategies. }\end{array}$ & \\
\hline
\end{tabular}

First Focus Group with Organizational Evaluation Capacity Self-Assessment

The researcher's familiarity with Foothills prior to this research enabled her to recognize a lack of evaluation-related knowledge in that organization. Considering Foothills' current level of evaluation capacity and lack of resources, and the researcher's lack of in-depth and applied ECB experience, the researcher determined that the organizational evaluation capacity framework (Bourgeois \& Cousins, 2008) and associated self-assessment tool developed by Bourgeois and Cousins (2013) best fit the needs of this organization and research. The researcher assessed that this comprehensive tool would allow the participating NPO to gain a clearer understanding of the ECB process, diagnose areas of evaluation weaknesses, and select appropriate strategies from 
the experience without the guided use of a skilled evaluator, while the shorter ECAI did not offer the same in-depth ECB guidance. Thus, the researcher chose Bourgeois and Cousins' tool (2013) over others such as the ECAI. In accordance with Bourgeois and Cousins' (2008) framework, the researcher acted as both an observer of the ECB process within the organization and facilitator of the organizational evaluation capacity selfassessment (Bourgeois \& Cousins, 2013).

The organizational evaluation capacity self-assessment includes a total of 62 questions across six dimensions: human resources, organizational resources, planning and conducting evaluations, evaluation literacy, organizational decision-making, and learning benefits. A four-point Likert scale (Strongly disagree, Somewhat disagree, Somewhat agree, and Strongly agree) is used to rate the extent to which the participant agreed with each statement. For this research, the researcher added other response options, Not applicable and Don't know. The Not applicable option allowed participants and the researcher to rule out questions that truly did not pertain to the scope or context of the organization, while the Don't know option allowed the participants and researcher to understand where evaluation knowledge was entirely missing. During the focus group, the participants completed each section, separated by dimension, of the assessment (see APPENDIX C) individually first in relation to their department. And then, they engaged in group discussions to elaborate on their understanding on individual items and identify a selection that represented the whole of the department. The participants' names or any identifiable information were not collected on the individual responses to keep the anonymity of individual respondents. 
To score the data, Strongly disagree, Somewhat disagree, Somewhat agree, and Strongly agree selections were coded with 1,2,3, and 4, respectively to calculate average scores. Don't know and Not applicable selections were excluded when calculating the average scores. While these options were excluded from the scoring, the responses were still reviewed in the second focus group to better understand areas that were confusing or where the participants lacked foundational evaluation knowledge. Then, average scores on individual dimensions and subdimensions as well as the total average score were calculated, from the five individual participants' assessments and the group facilitated assessment. The total score, dimension scores, and subdimension scores were then compared to an established metric to determine their ranking. Available rankings included low capacity with an average score between 0.00 and 1.75 , developing capacity with an average score between 1.76 and 2.50, intermediate capacity with an average score between 2.51 and 3.25, and established capacity with an average score between 3.26 and 4.00 .

\section{$\underline{\text { Second Focus Group to Discuss Assessment Results and Plan Strategies }}$}

During the second focus group, the participants reviewed the results from the organizational capacity self-assessment. The participants reviewed their overall score, and individual dimensions and subdimensions that were lower than their average score. Through each score, the participants as a group discussed their perception of the score, the organizational context leading to that score, and their perceived accuracy of the score. For the lower scoring subdimensions, the group also reviewed the organizational assumptions provided by the assessment results and discussed the perceived accuracy of the assumptions provided. Specifically, participants were asked questions such as: 
- "Do you agree with the assumptions the assessment determined about the evaluation capacity within the organization?"

- "What differences or similarities do you see within the organization and the assumptions listed?"

The participants then reviewed strategies recommended by the assessment results and discussed which strategies would be feasible within the organization. Specific questions included:

- "Is this strategy something that you feel would be within the organization's resources to execute?"

- "Do you think this strategy would be effective within the organization? Why or why not?"

After all dimensions and subdimensions were reviewed, the participants looked at the list of strategies and prioritized which areas and strategies would be most important for them to implement to gain evaluation capacity.

\section{Third Focus Group to Discuss an ECB Plan}

The last focus group was designed for the participants to debrief the process of completing the assessment and associated decisions that resulted from the results. Specific questions asked were:

- "Was the instrument easy to interpret what was being requested and the terminology used was understandable?"

- "What areas in either completing the instrument or interpreting the results were barriers? What areas were positive?" 
- "Did completing the tool and reviewing the results provide information that could be readily used to establish a plan to build evaluation capacity?"

The participants reviewed areas of concern when taking the assessment as well as components that were not clear in the assessment and results. The participants also discussed areas where they felt the process was helpful towards them understanding their evaluation capacity and how to build it.

Focus group data were analyzed based on the procedure recommended by LeCompte and Schensul (1999) including item level, pattern level, and structure level analysis, as shown in Figure 8.

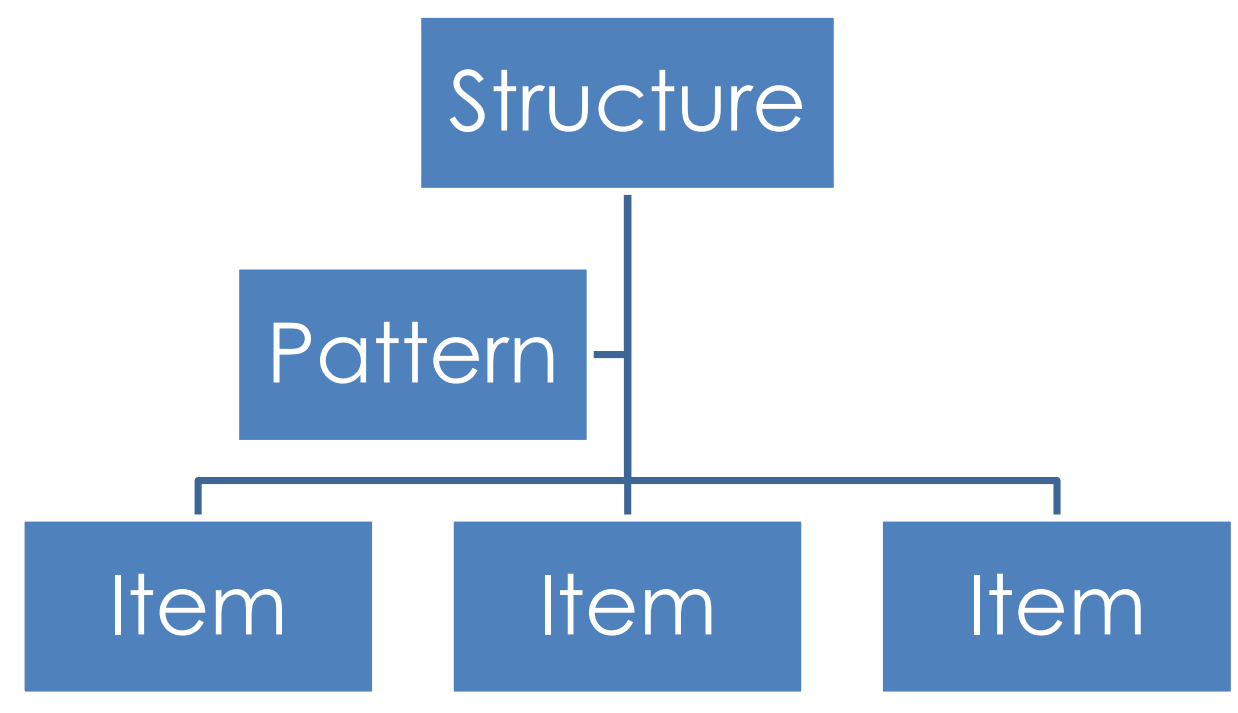

\section{Figure 8. Item level, pattern level, and structure level analysis.}

Discussions in the focus groups were recorded and transcribed. Transcriptions were then reviewed several times for item-level analysis. This included assigning codes to phrases within the data. Codes were then analyzed to identify similarities in pattern level analysis. Identified patterns, or domains, were then followed by structure level analysis of systematically analyzing similarities and differences between the transcript 
data and sorted into the following structures or themes: 'barriers to process,' 'barriers in tool,' 'facilitators to process,' and 'facilitators to tool.' Pattern and structure levels of analysis were completed by copying item-level data from the transcripts and entering them into a Microsoft Excel workbook with individual tabs associated with domains. Data was then organized within each spreadsheet to determine potential relationships between them.

All data was saved in the researcher's Google Drive folder provided by BSU with no external access to other parties. Any paper copies including identifiable information from the research were properly destroyed, after being scanned securely and uploaded to the Google Drive folder. 


\section{CHAPTER FOUR: DATA ANALYSIS AND FINDINGS}

To understand the process of how an NPO utilizes available tools to build their evaluation capacity, the data analysis was two-fold including the analysis of the assessment results and the analysis of the focus group discussion. As such, this chapter has two parts; Part 1: Assessment Results and Discussion, and Part 2: Review of ECB Process within the NPO.

\section{Part 1: Assessment Results and Discussion}

Assessment results were entered into the organizational evaluation capacity selfassessment instrument provided by Bourgeois (Bourgeois, personal communication, September 11,2018). A link to the online survey form and a detailed report available in APPENDIX I. The average results of the organizational evaluation capacity selfassessment for Foothills was 2.73, identifying the organization as intermediate capacity (see Table 2). The group of participants initially felt this was accurate as they were newer in developing their evaluation capacity but had made significant improvements in data reporting and were beginning to engage in performance improvement over the past six months.

Their rankings for each of the six dimensions were close to their average score as well, except for dimension four, evaluation literacy, which scored as developing capacity as seen in Figure 9. The total 62 questions separated into dimensions and subdimensions and their average scores are summarized in APPENDIX J. 
Table 2. Overall Evaluation Capacity Results

\begin{tabular}{|c|c|c|c|c|c|}
\hline \multicolumn{2}{|c|}{$\begin{array}{c}\text { Capacity Level } \\
\text { (Average Score Range) }\end{array}$} & $\begin{array}{c}\text { Low } \\
(1.00-1.75)\end{array}$ & $\begin{array}{l}\text { Developing } \\
(1.76-2.50)\end{array}$ & $\begin{array}{c}\text { Intermediate } \\
(2.51-3.25)\end{array}$ & $\begin{array}{c}\text { Established } \\
(3.26-4.00)\end{array}$ \\
\hline \multicolumn{2}{|c|}{$\begin{array}{l}\text { Foothill's Overall } \\
\text { Evaluation Capacity Level }\end{array}$} & - & - & 2.73 & - \\
\hline \multirow{6}{*}{ 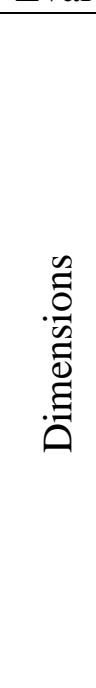 } & $\begin{array}{l}\text { 1. Human } \\
\text { Resources }\end{array}$ & - & - & 2.80 & - \\
\hline & $\begin{array}{l}\text { 2. Organizational } \\
\text { Resources }\end{array}$ & - & - & 2.67 & - \\
\hline & $\begin{array}{l}\text { 3. Planning and } \\
\text { Conducting } \\
\text { Evaluations }\end{array}$ & - & - & 2.75 & - \\
\hline & $\begin{array}{l}\text { 4. Evaluation } \\
\text { Literacy }\end{array}$ & - & 2.46 & - & - \\
\hline & $\begin{array}{l}\text { 5. Organizational } \\
\text { Decision- } \\
\text { Making }\end{array}$ & - & - & 2.87 & - \\
\hline & $\begin{array}{l}\text { 6. Learning } \\
\text { Benefits }\end{array}$ & - & - & 2.83 & - \\
\hline
\end{tabular}

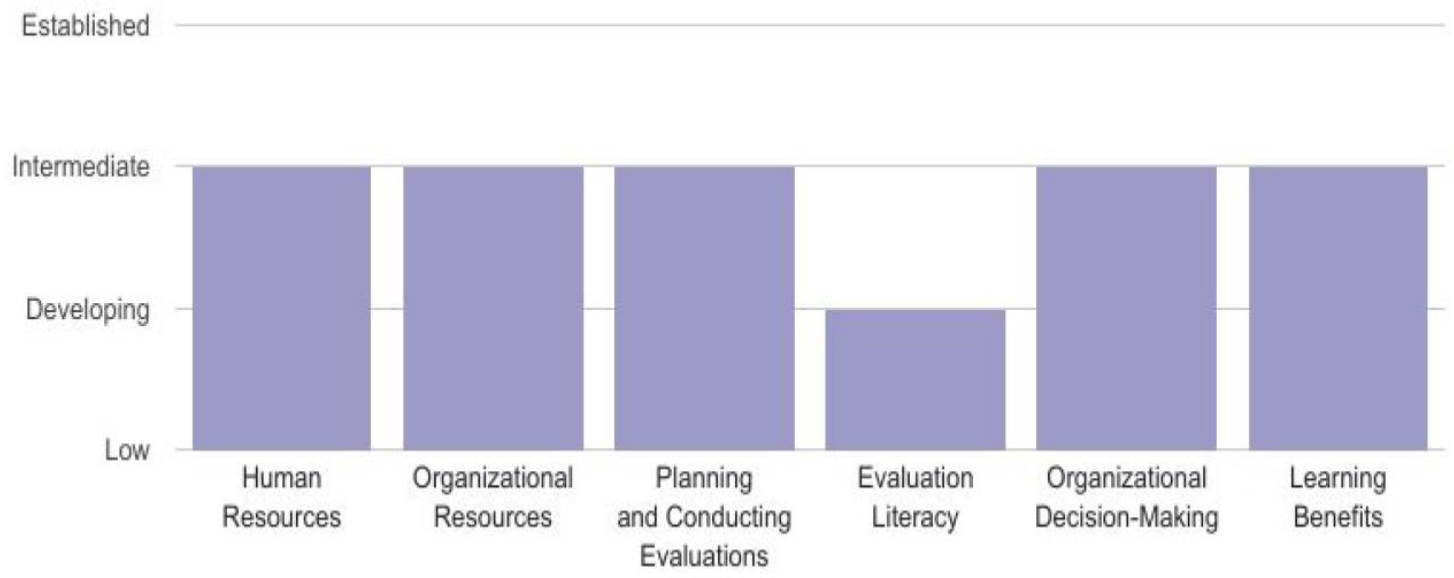

Figure 9. Most dimensions being 'intermediate' with one 'developing' capacity.

Dimension 1: Human Resources

For the human resources dimension, the organization scored intermediate capacity with each of the subdimensions scoring within that range except for leadership being 
developing capacity, as seen in Table 3. According to the assessment results (APPENDIX $\mathrm{J})$, the assumptions behind this score were:

- Unit headed by individual who is new to the area of evaluation and/or has limited evaluation experience.

- Leader is not generally involved in senior management discussions and therefore assigns work based only on operational requirements.

- Leader coordinates team activities but is not involved in guiding team members in their work.

Table 3. Human Resources Dimension Results

\begin{tabular}{|l|l|l|l|l|l|}
\hline & $\begin{array}{l}1.1 \\
\text { Staffing }\end{array}$ & $\begin{array}{l}1.2 \\
\text { Technical } \\
\text { Skills }\end{array}$ & $\begin{array}{l}1.3 \\
\text { Communication } \\
\text { Skills }\end{array}$ & $\begin{array}{l}1.4 \\
\text { Professional } \\
\text { Development }\end{array}$ & $\begin{array}{l}1.5 \\
\text { Leadership }\end{array}$ \\
\hline $\begin{array}{l}\text { Average } \\
\text { score for } \\
\text { each } \\
\text { subdimension }\end{array}$ & 2.83 & 3.06 & 3.06 & 2.63 & $\mathbf{2 . 4 2}$ \\
\hline $\begin{array}{l}\text { Average } \\
\text { score for } \\
\text { dimension }\end{array}$ & \multicolumn{3}{|c|}{2.80 (Intermediate capacity: 2.51-3.25) } \\
\hline
\end{tabular}

During the second focus group discussion, the participants determined that while these assumptions were mostly accurate, they expressed difficulty in answering the questions for this dimension. The group did not feel that the organization had a designated evaluation unit and thus answered the questions from the scope of each of them leading their management teams. One program director stated, "I'm still fuzzy on a lot of the questions like, who is the evaluator, what are the programs we are talking about. Is that organizationally, is that our definition of programs, is that me thinking just about [my program]?" Even with this confusion on definitions, the group did agree with the assumptions listed above due to the fact that several of the managers are new to 
management positions, know little about evaluation, and are separated from senior management. One program director commented, "I think if you are in developing, if you have new managers that would make sense." Based on the accuracy of the assumptions, the group accepted these results in spite of their confusion when answering the questions.

From these assumptions, the group reviewed the list of recommended strategies from the assessment results which included:

- Assess the evaluation team leaders' comfort level and knowledge of evaluation and management practices and offer professional development opportunities as needed.

- Support the development of formal ties between the evaluation team leader and senior managers.

While the group agreed that these strategies both fit their deficiencies, the group believed that the more pressing issue was the lack of an identified evaluation unit and lead. The group determined that the initial strategy for this dimension should be to formally define this unit and the evaluation lead in order to assess competency.

\section{Dimension 2: Organizational Resources}

The organizational resources dimension received a score of intermediate capacity with the lowest subdimension being performance measurement data, as seen in Table 4 . Assumptions for this score included:

- Performance measurement is done on a program-by-program basis.

- Ad hoc implementation of performance measures with uneven quality.

- Performance data is difficult to integrate into results-based management (including evaluation studies). 
Table 4. Organizational Resources Dimension Results

\begin{tabular}{|l|c|c|c|}
\hline & 2.1 Budget & $\begin{array}{l}2.2 \text { Performance } \\
\text { measurement data }\end{array}$ & $\begin{array}{l}2.3 \text { Infrastructure and } \\
\text { tools }\end{array}$ \\
\hline $\begin{array}{l}\text { Average } \\
\text { score for } \\
\text { each } \\
\text { subdimension }\end{array}$ & 2.79 & $\mathbf{2 . 5 0}$ & 2.72 \\
\hline $\begin{array}{l}\text { Average } \\
\text { score for } \\
\text { dimension }\end{array}$ & \multicolumn{3}{|c|}{2.67 (Intermediate capacity: 2.51-3.25) } \\
\hline
\end{tabular}

The group largely agreed with these assumptions, stating that they had just begun to use any sort of organized data within the past six months. The program's director stated, "It's just not been a real strength of the company in performance management so it's developing." Another program manager agreed stating, "I think we are definitely in the process of recognizing that this is something important and doing it." The group discussed, however, that over the past six months of having access to data, their performance measurement categories were altered each month and did not always include a consistent understanding of the interpretation behind the metrics. At the point of the second focus group, the group did not feel that their performance measurement data was fully reliable, and while improving, the group still voiced a need for more understanding of the data and its relationship to results-based management.

The strategies recommended for this dimension included:

- Work with program managers on results chains and ongoing performance data collection, to ensure the availability and quality of data to be included in future evaluations.

- Invest in an organization-wide performance data collection system. 
- Conduct evaluability assessments to confirm the availability and quality of administrative and performance data before planning an evaluation and identify any gaps/issues to be resolved before the evaluation starts.

As the group reviewed the strategies, they did not express confidence in any of the strategies, stating that they were not at a point that they could implement these strategies without laying more foundation first. The group remarked that they had just launched their program-wide client database just a few months ago which allowed them to have more transparent access to data and evaluate their programs, but managers were not familiar with results chains or what data to measure in their programs that would better inform their strategic decisions. From their current practice, the individual managers did not review much of their own performance measurement data but rather were supplied areas of opportunities by the quality assurance (QA) department. One program director stated:

Some of us have really struggled with [performance measurement], not really having a strong linkage to the team and the day to day. And looking to really measuring and developing and all of that. I feel like that's an area that all of us feel really strongly that we want to focus but we just need the resource of time to be able to do that.

This leaves a gap between program managers and their programs in understanding and developing the performance expectations for their teams and measuring performance against it. To address this, the group determined that in order to effectively execute performance management in their programs, they needed more time to tune into the programs and individual employees and easier access to data and evaluation results. 


\section{Dimension 3: Planning and Conducting Evaluations}

The third dimension received a score of intermediate capacity with the lowest subdimensions being organizational linkages and external support, as seen in Table 5 . Assumptions for organizational linkages include:

- Evaluation steering or advisory committees are sometimes used to guide projects.

- Senior managers are made aware of evaluation findings only through formal requirements.

- Evaluation is removed from key organizational areas such as policy development, strategic planning, and performance measurement.

Assumptions for external support include:

- Evaluators have access to basic external supports, such as a professional association or published quality standards but do not often make use of them.

- Evaluators do not generally liaise with external organizations or experts.

Table 5. Planning and Conducting Evaluations Dimension Results

\begin{tabular}{|l|l|l|l|l|l|}
\hline & $\begin{array}{l}3.1 \\
\text { Planning }\end{array}$ & $\begin{array}{l}3.2 \\
\text { Internal } \\
\text { and } \\
\text { external } \\
\text { evaluators }\end{array}$ & $\begin{array}{l}3.3 \\
\text { Information } \\
\text { and support }\end{array}$ & $\begin{array}{l}\text { l.4 } \\
\text { Organizational } \\
\text { linkages }\end{array}$ & $\begin{array}{l}3.5 \\
\text { External } \\
\text { support }\end{array}$ \\
\hline $\begin{array}{l}\text { Average } \\
\text { score for } \\
\text { each } \\
\text { subdimension }\end{array}$ & 3.00 & 3.00 & 2.81 & $\mathbf{2 . 4 6}$ & $\mathbf{2 . 4 6}$ \\
\hline $\begin{array}{l}\text { Average } \\
\text { score for } \\
\text { dimension }\end{array}$ & \multicolumn{4}{|c|}{ 2.75 (Intermediate capacity: 2.51-3.25) } \\
\hline
\end{tabular}

The group strongly agreed with the assumptions provided for organizational linkages, as the team felt that they were not only physically removed from the 
organizations headquarters, but also not often involved in the components mentioned. One program manager stated,

There is a big disconnect from people like the executive leadership team and... staff. There is just kind of this disconnect, but I think from an organization we are much more aware than we were 6 months ago when I first started working here.

Group members reported feeling a disconnect between the choices being made by organizational leaders in regards to policies and planning, and sometimes even reporting requirements that made it difficult for them to keep up with funder requirements, let alone performance improvement measures. In addition to feeling siloed within their organization, members of the focus group also reported low use of external supports for their evaluation efforts. One program director mentioned that the only external support that was known to the group was the overall program outcomes that were analyzed by a local university. Other program managers mentioned more efforts in the past few months to establish new partnerships within the community, but these partnerships did not often include any assistance or collaboration in relation to their evaluation efforts.

The strategies recommended for organizational linkages include:

- Set up steering or advisory committees made up of program representatives, external evaluators and other experts at the outset of each evaluation.

- Establish a formal path for evaluation to reach senior management.

- Coordinate efforts with other organizational groups to avoid duplication. Strategies for external support include: 
- Develop a network of external support in academia and other similar organizations that can be drawn upon to resolve evaluation problems or to access information about evaluation.

After reviewing the strategies provided, the group again struggled to feel ready to implement any of the recommendations. Given that the organization had limited partnerships externally and no formalized evaluation unit, the idea of a steering committee seemed too distant. The group did, however, agree that a formal path for evaluation results to be dispersed in a timely manner was crucial in increasing the use of evaluation within the organization. One program manager commented:

It seems like we've got a lot of layers for information to be transferred between, so it starts here, then [the programs director] takes it to the executive leadership team, then it goes to the directors meeting, then it goes to the board, so it seems like there's a process for our evaluation findings to be shared out more often than that, and not just through formal processes, but I am sure that we could get better.

Additionally, the group noted the need to decrease duplication of efforts as these often undermined the value of the evaluation results as there were often discrepancies between the different groups results. One program director mentioned:

I think that the problem is that there is kind of a lack of centralized data. So, people pull data from different sources all of the time, externally, and so some of that is conflicting [and] there is no centralized way like 'this is where we get this data from and that data from'. 
The group also prioritized the need to increase their evaluation-based partnerships with academia, funders, and other organizations to increase their knowledge and resolve evaluation problems.

Dimension 4: Evaluation Literacy

The fourth dimension, evaluation literacy was the lowest scoring dimension, scoring as developing capacity, as seen in Table 6. While one subdimension, stakeholder involvement, scored at intermediate capacity, the second subdimension, resultsmanagement orientation, was the lowest scoring subdimension at 2.24.

Assumptions for this subdimension include:

- Organizational outcomes and expected results are not articulated clearly for all organizational members; most are not aware of results-based management principles and practices.

- Some programs are engaged in developing results chains such as logic models or theories of change.

Table 6. Evaluation Literacy Dimension Results

\begin{tabular}{|l|c|c|}
\hline & 4.1 Stakeholder involvement & $\begin{array}{l}\text { 4.2 Results-management } \\
\text { orientation }\end{array}$ \\
\hline $\begin{array}{l}\text { Average } \\
\text { score for } \\
\text { each } \\
\text { subdimension }\end{array}$ & 2.68 & $\mathbf{2 . 2 4}$ \\
\hline $\begin{array}{l}\text { Average } \\
\text { score for } \\
\text { dimension }\end{array}$ & 2.46 (Developing capacity: 1.76-2.50) \\
\hline
\end{tabular}

Throughout the discussion in the second focus group, the group mentioned their unfamiliarity with results-based management, including logic models, theories of change and results chains. It was not a surprise to them that this dimension scored the lowest. 
The program's director mentioned in the focus group that with such fresh managers, it made sense that they were so unfamiliar with these components. The organization had initiated some results-based management activities for program managers to complete just weeks prior to the focus group, which program managers mentioned their struggles, and frustrations, with completing. One program director mentioned his experience with the shift in the past few months "I think in the growing phase that we are on, I think that we are all focusing on results-based management."

Strategies for this dimension include:

- Develop logic models or results chains for programs or groups of programs in conjunctions with key stakeholders.

- Ask senior management to provide time and resources to program managers for results-based management presentations and discussions.

Out of these strategies, the group agreed that results-based presentations and discussions were likely to be the most impactful, given the group's limited knowledge of logic models and results chains. Having group presentations would allow the group to both research and learn components of results-based management and share them between each other. However, the concerns with this strategy were the time commitment and that the group was not confident that senior management would be able to facilitate time for these learning experiences. One program director stated, “it's always good to do that stuff, but how do you carve out the time. It's a vicious circle. How do you carve the time because if you can do that well then obviously everything else is better." 
Dimension 5: Organizational Decision Making

The fifth dimension scored intermediate capacity with each subdimension also falling in that range, as seen in Table 7 . The group agreed with these results and decided not to discuss potential strategies for these areas.

Table 7. Organizational Decision-Making Dimension Results

\begin{tabular}{|l|c|c|}
\hline & 5.1 Management processes & 5.2 Decision support \\
\hline $\begin{array}{l}\text { Average } \\
\text { score for } \\
\text { each } \\
\text { component }\end{array}$ & 3.00 & 2.74 \\
\hline $\begin{array}{l}\text { Average } \\
\text { score for } \\
\text { dimension }\end{array}$ & 2.87 (Intermediate capacity: 2.51-3.25) \\
\hline
\end{tabular}

Dimension 6: Learning Benefits

The sixth dimension also scored intermediate capacity with each subdimension within that range, as seen in Table 8 . The group agreed with these results and decided not to discuss potential strategies for these areas.

Table 8. Learning Benefits Dimension Results

\begin{tabular}{|l|c|c|}
\hline & $\begin{array}{l}\text { 6.1 Instrumental and conceptual } \\
\text { use }\end{array}$ & 6.2 Process use \\
\hline $\begin{array}{l}\text { Average } \\
\text { score for } \\
\text { each } \\
\text { component }\end{array}$ & 2.86 & 2.79 \\
\hline $\begin{array}{l}\text { Average } \\
\text { score for } \\
\text { dimension }\end{array}$ & 2.83 (Intermediate capacity: 2.51-3.25) \\
\hline
\end{tabular}




\section{Prioritizing Strategies}

Out of the five subdimensions that scored below the intermediate capacity

threshold, the group then assessed priorities of potential strategies as seen in Table 9, with 1 being the highest priority and 5 being the lowest priority.

Table 9. Prioritized Strategies

\begin{tabular}{|l|l|l|}
\hline Priority & Subdimension (Score) & Strategies \\
\hline 1 & $\begin{array}{l}\text { 2.2 Performance } \\
\text { measurement data (2.50) }\end{array}$ & $\begin{array}{l}\text { Establish a foundational understanding of } \\
\text { evaluation practices and performance } \\
\text { measurement }\end{array}$ \\
\hline 2 & $\begin{array}{l}\text { 4.2 Results-management } \\
\text { orientation (2.24) }\end{array}$ & $\begin{array}{l}\text { Establish an understanding of foundational } \\
\text { results-management principals }\end{array}$ \\
\hline 3 & 1.5 Leadership (2.42) & $\begin{array}{l}\text { Identify formal evaluation unit and evaluation } \\
\text { lead }\end{array}$ \\
\hline 4 & $\begin{array}{l}3.4 \text { Organizational } \\
\text { linkages (2.46) }\end{array}$ & $\begin{array}{l}\text { Establish formal path for evaluation results to } \\
\text { reach all levels of managers/ directors }\end{array}$ \\
\hline 5 & $\begin{array}{l}3.5 \text { External support } \\
(2.46)\end{array}$ & $\begin{array}{l}\text { Establish evaluation-based partnerships with } \\
\text { universities and similar NPOs }\end{array}$ \\
\hline
\end{tabular}

Based on the group's lack of foundational evaluation and performance improvement knowledge, the group determined that the top two priorities for their ECB initiative needed to be building their competencies in these areas. They found that these skills were foundational to their understanding of the other components mentioned in the assessment results and critical to ensuring that evaluation results were utilized and valued within the organization. One group member noted that without these foundational elements, any sort of evaluation efforts were likely to fail if the team could not understand its purpose and how to use the results. At the conclusion of the second focus group, the group felt that their acceptance of their score of 'intermediate capacity' may have been premature and as the discussions around the various questions were facilitated, the group agreed that they were more likely under 'developing capacity' as they lacked foundational evaluation knowledge and skills. The group agreed that priorities 1-3 each 
were foundational knowledge that the organization would need to engage in evaluation practices at all, and priorities 4-5 were strategies that would assist the organization in building their capacity but could not be engaged in until foundational knowledge was present.

However, when asked about the feasibility of applying these strategies, the group had concerns about the time they could allocate towards ECB efforts. One program manager mentioned,

Part of being able to evaluate that effectively, whenever it was me or whoever it is, we don't have time... At least me personally I don't have a lot of time to feel super confident, like $100 \%$ confident that I have a good hold on a lot of things.

\section{Part 2: Review of ECB Process Within the NPO}

During the three focus groups, group members highlighted several facilitators and barriers they were experiencing in relation to the ECB process.

\section{Facilitators of the ECB Process}

Group members unanimously agreed that the organization had several key areas to strengthen in order to build their evaluation capacity and would not have had an idea of where to start before completing this assessment. The largest facilitator the group identified was that the process was guided, initiated discussion on crucial topics, and provided them with in-depth results that could be immediately applied. Additionally, the group agreed that the process of using the assessment guided and supported their goal of determining ways to increase their evaluation capacity. Given their lack of confidence in their overall understanding of evaluation knowledge, the group did feel that undergoing 
an assessment to 'diagnose' their evaluation concerns and highlight areas of opportunities was helpful. The overall design of the results document included both assumptions behind the organization's score for each dimension and subdimension and strategies that could be used to increase the organizations capacity in that area. The assumptions specifically assisted the group in discussing and validating their assessment response, especially given the group's initial lack of understanding of assessment questions. The group also appreciated the recommended strategies acting as a clear guide towards their efforts to increase their evaluation capacity. Having both the assessment and the results available as they were was helpful to the researcher as well to facilitate the process, discussion, and results with the group in a systematic process.

As the group reviewed the results, they noted that while they were leery of the instrument, they supported the findings overall. One program director stated, "I think there were a few things on there that were interesting to look at and say huh, we should do something with that." Several components that the organization scored low on were components that members of the group agreed they were not aware of or were not strong in but would directly benefit their programs. This opened the door to several capacity building conversations that highlighted the need to grow capacities in these areas, and their foundation of evaluation understanding. Additionally, the strategies listed support the components the group felt they needed to improve upon, to which the group agreed that successfully executing these strategies would be directly beneficial to their roles and program. While the group appreciated the systematic nature of the tool and the associated process, the team still felt many challenges existed in both understanding and applying ECB principles. 


\section{Barriers in the ECB Process}

Overall, while the group felt the process was well-guided, each member expressed concern for the definitions and lack of understanding within the group of the content of the assessment questions and results. Key barriers the group mentioned were feeling the assessment was too technical, was unclear in its definitions and scope, and was overly complicated in relation to the groups understanding of evaluation. The group thought the assessment itself was "too academic" for their level of evaluation knowledge. One program director stated he felt the assessment was "too focused in a world of analytical folks" and that with their evaluation expertise being lower, the assessment would need to be adjusted to those "who aren't in that world all the time." Another program director attributed understanding the assessment in their context as "trying to decipher it like a scrabble game."

Through all three focus groups, participants expressed concern about not understanding questions and definitions mentioned. One program director stated, "the way things were worded, it kind of felt like reading a thesaurus," while the operations lead stated her confusion with the scope of the questions as her role encompasses several programs, "My biggest challenge was who I was supposed to be referring to." Even with the researcher as a facilitator to assist the group members in defining the terminology and scope of the questions, the group members still struggled with understanding the basis of several of the questions and how to determine an appropriate response. Key areas that group members struggled with were defining the evaluation unit, evaluation lead, and the various evaluation projects and processes that the organization had participated in, as indicated by an increase of Don't Know responses on the assessment and discussion 
within the focus groups. Other questions with higher numbers of Don't know responses included questions regarding specific evaluation terminology such as 'results chains' 'logic model' and 'cross-cutting/ supporting information.' This supported the group's determination that foundational knowledge in evaluation was limited. This lack of knowledge of these terms and functions hindered the group's ability to both answer the question and fully understand the role of evaluation within the organization.

One group member mentioned that they didn't feel that their organization fit into the structure that the assessment was assuming would exist in an organization, suggesting that the tool was not customized for smaller or under-resourced organizations to use. Key components included 'evaluation lead' and 'evaluation unit' which were not present in Foothills and caused confusion amongst group members during the assessment. Members mentioned concerns about the assessment specifically in regards to the definitions for organizational evaluation units and leads, understanding that many NPOs also did not have these formally defined roles. Additionally one program manager mentioned concerns with the scope of the questions being too general:

I think it's especially difficult too where it's like throwing in evaluation of everything all at once because I think that's really hard to generalize. I think we have strengths and in one area and weaknesses in another or strengths in one program where it's a weakness in another one and vice versa. And that's really hard to give a score to.

This led the group to be concerned about the validity of the assessment to measure low or developing capacity for organizations when organizations that truly fall in those 
areas would likely not understand or be able to complete the assessment accurately due to a lack of fundamental knowledge of the questions. As one program director stated:

I think it could be really helpful if we had a better understanding of evaluation and evaluation practices... and all those things because it's still a foggy concept to be able to draw conclusions about when you don't understand the fundamentals.

At the conclusion of the final focus group, the group determined that the assessment was able to highlight key areas of concern within the organization and effective ways for the group to mediate these areas; however, given the wording and erudite nature of the assessment, the group struggled to value its accuracy in successfully gauging their level of evaluation understanding. 


\section{CHAPTER FIVE: CONCLUSION}

The purpose of this research was to answer the question, how does an NPO use an ECB framework and its tool as a guide while building evaluation capacity? In order to gauge a deep level of understanding of an organization's experience with the process, the researcher reviewed available literature on ECB frameworks and tools and facilitated a case study within an NPO as its key stakeholders used a selected tool towards engaging in ECB. Initially in the research, it appeared that the field and practice of ECB was still developing. The results of this case study indicate the importance of having evaluationspecific knowledge to initiate the evaluation capacity building process and support the need for additional ECB tools and resources to better support NPOs looking to engage in ECB and performance improvement practices.

\section{$\underline{\text { Overview of ECB Process }}$}

Through researching various frameworks and tools, it appears that the literature offers good education on the concept of ECB but is less detailed in the steps for executing ECB tools and strategies. In researching the different tools for ECB in NPOs, the researcher selected the organizational evaluation capacity self-assessment developed by Bourgeois and Cousins (2008) to use in the case study, as it was the most in depth, detailed, and guided approach. Given the case study organization's low evaluation knowledge, having a more systematic approach seemed to be the best option to guide their ECB process. While the framework and tool presented by Bourgeois and Cousins $(2008,2013)$ was the most robust in the literature to date, there is still a concern that this 
tool is too difficult to use with under-resourced NPOs without a skilled evaluator to guide them through the process and 'decode' some of the terminologies they may be unfamiliar with. This presents a problem as one of the main concerns for NPOs because of their limited resources and availability to skilled evaluators while engaging in ECB. Additionally, during the case study, it became obvious that the facilitator of the assessment and ECB process would need to be familiar with the instrument, its intent, ECB strategies, and the organization's current evaluation practices and structures. This finding furthers the concern that ECB can often be a lengthy and expensive process and remains limited in its success for under-resourced NPOs.

In addition, it seems that the foundational knowledge of evaluation may be a prerequisite for organizations to completing ECB assessments. This leaves organizations that have low levels of evaluation capacity with fewer resources and options to build their evaluation capacity. To better fit the lack of resources and knowledge for NPOs with low and developing evaluation capacities, it may be worth providing them with ECB resources to help grow their foundational knowledge, prior to engaging in the more advanced ECB work with the help of a skilled evaluator. This could eventually save the overall cost for NPOs with low and developing evaluation capacities as they use available tools to build foundational knowledge before hiring a potentially expensive evaluation expert for the rest of the ECB process.

\section{Recommendations for the Use of the ECB Tool}

While the systematic nature made facilitating the process of ECB within an organization easier, problems arose when the organization had limited foundational knowledge of ECB to begin with. Since the tool is based strongly off evaluation 
terminology and systems within an organization, it can be difficult for organizations with low or developing capacity to successfully complete the assessment and apply the strategies. While Bourgeois and Cousins (2008) recommend having a knowledgeable evaluator guiding the process, it still made it difficult for the participating stakeholders to engage fully when they did not understand the components. Another option for organizations may be to have a trained evaluator who understands the assessment components use the assessment as an interview tool (rather than having stakeholders use it as a self-assessment tool) and gather the information directly from organizational members when needed. This may help alleviate the confusion between assessment terminology and allow the evaluator to provide the strategies and priorities to the organization. The concern with this route, however, is that without participating fully in the process, organization leaders may have less buy-in to the results or importance of the strategies in building their evaluation capacity. Additionally, several defined roles stated in the instrument (evaluation lead, evaluation unit, etc.) may not be fully defined within an NPO, which would cause even a knowledgeable evaluator to struggle to successfully complete the associated questions. These definitions also apply the assumption that a successful organization must have these defined roles, which can put pressure on underresourced NPOs to establish new job positions that may be otherwise facilitated through delegation of tasks to capable employees.

If an organization engages in an ECB assessment and has some of the same struggles that Foothills had, it could result in the stakeholders feeling discouraged and slowing or potentially derailing the their motivation to engage in ECB altogether. Thus, it is important for the tool to be relevant and applicable to the organization's needs. In order 
to make the tool more generalizable to different organizations and support organizations with low and developing capacities, it is recommended that the organization, with the help of a knowledgeable evaluator, assign clear definitions to the roles and definitions within the assessment before beginning. This should allow the organizational stakeholders to ensure that they answer within the same scope for the questions, alleviate confusion, and reach relevant results. Additionally, it may be beneficial to host evaluation information sessions on foundational evaluation knowledge prior to an organization taking the assessment to ensure the organizational stakeholders understand the content and can answer accurately.

From the perspective of the tool, for future researchers, it may be worth looking into adding definitions to the various evaluation elements to ensure organizations are answering the questions consistently. Organizations and practitioners who use the tool may benefit from having the language adjusted to be less academic and including more commonly understood language. This would both help the tool be more practitioner oriented and increase the utility of this resource for the desired population of organizations with limited evaluation capacity and knowledge. Another option for this problem could also be to establish a manual or detailed guide that interprets definitions and enhances the organization's understanding of the questions presented. Additionally, in some cases, organizations may benefit from using a customized version of the tools that contain guidelines tailored to their organizational understanding and context. This could allow NPOs to be more guided and have a clearer understanding of the instrument and give a centralized resource for facilitators to use when guiding the ECB process using this tool. 
In reviewing Foothills' experience in completing the organizational evaluation capacity self-assessment, the researcher determined that while the stakeholders struggled with the definitions of the assessment, this assessment still offered more directional guidance than the ECAI assessment that was also considered. While the ECAI had more easily understood language and seemed to be more generalizable to different organizations, it was still missing the guidance of assisting under-resourced organizations in selecting appropriate ECB strategies. Without this component, it would be difficult for NPOs to build their capacity having only a list of their deficiencies and no potential solutions. However, given that the practice of completing the organizational evaluation capacity self-assessment established by Bourgeois and Cousins (2013) resulted in the need for a trained evaluator to interpret the assessment for the organization, it is possible that an organization could complete the ECAI and use a trained evaluator to review their results and suggest potential strategies to build. This could also be a less involved and require less resources than the level of depth needed for the facilitating evaluator of the organizational evaluation capacity self-assessment. This could be a potential solution for low and developing evaluation capacity organizations to identify their foundational evaluation deficiencies, work to improve them, and then engage in the organizational evaluation capacity self-assessment when their capacity was higher.

\section{$\underline{\text { Recommendations for the ECB Process }}$}

From the current literature, it appears that much of the framework and discussion in regards to ECB is still largely conceptual and being applied primarily by skilled evaluators and researchers. This still leaves an area for concern for NPOs who have both the need and desire to increase their evaluation capacity. As shown in this case study, 
foundational evaluation knowledge may be a requirement to engage in some of the existing ECB frameworks, so in order to establish a starting place for low or developing evaluation capacity, more work needs to be built into these models to facilitate building foundational knowledge and skills. In Preskill and Boyle's (2008b) model, they mention several different strategies that can be used to facilitate ECB within an organization, which may also be helpful to establish foundational knowledge. Some examples of these strategies include formal evaluation training, engaging in evaluation-centered communities of practice, and applying appreciative inquiry within the organization to reinforce the value of evaluation practices. Existing ECB models may also benefit from establishing a set standard of foundational elements or strategies that will be most useful for organizations who wish to engage in ECB but are seemingly "too far behind" to do so. Additionally, under-resourced NPOs may benefit from establishing partnerships with universities or other organizations with higher evaluation capacity to share experiences and grow.

\section{Application to Human Performance Technology}

Human performance technology (HPT), also known as human performance improvement (HPI), is focused on establishing a systematic and systemic approach to identifying performance issues, vetting feasible and productive solutions, implementing identified solutions, and evaluating the process and outcomes, while managing constant changes (International Society for Performance Improvement, 2018). In communities, NPOs exist to help provide a solution to identified societal problems, but without having essential evaluation skills, these NPOs are unable to accurately report their effectiveness towards resolving the societal problems. In order to support NPOs practice HPT 
principles and measure their progress in closing society problems, their ability to engage in evaluation practices is crucial. In doing so, these organizations can also apply these skills internally to identify performance issues that detract from their purpose and select effective solutions to resolve them in a manner that is aligned with their purpose and feasible within their limited resources. By growing evaluation capacity of nonprofits, the field will create organizations that are more effective, more efficient, and practice better use of supplied funds towards meeting their organization goals. To do so, more resources and tools need to be established within the field to give these organizations easy access to build their evaluation capacity and increase their ability to also engage in HPT practices.

\section{Conclusion}

Through the experience of this case study, it appears that the literature and supporting tools for ECB lack generalizability and utility for under-resourced NPOs looking to engage in ECB without the assistance of a skilled evaluator. The experience of The Foothills leads the researcher to believe that more direction, foundational evaluation knowledge support, and personalized tools may be required before NPOs with low or developing evaluation capacities can meaningfully engage in ECB to meet the growing demands of funders and apply performance improvement practices within their organization. Without these supports, NPOs will likely need to hire a trained evaluator to guide their ECB process or risk falling behind in a competitively funded market and high evaluation expectations. To assist these organizations, practitioners can look to adjust these tools to better fit the knowledge level and contexts of these organizations and develop additional ECB resources for NPOs to use to build their foundational evaluation knowledge. 


\section{$\underline{\text { Limitations }}$}

Given that this research was based on a single case study, the study results are not to be generalized. However, the application of this ECB process in even just one setting still leads to some insights that would be interesting to explore in other organizations with different capacity levels. Additionally, there was the limitation of having a low level of evaluation knowledge within the case study organization that inhibited the participating stakeholders from fully understanding the ECB process and application. While this was a meaningful conclusion, it does blur the lines of what was ineffective- the tool or the process.

Another limitation was the lack of interpersonal anonymity for the respondents during the study. All participants were in a room together discussing topics that were largely their areas of influence and could have potentially be biased by their peer interactions and desire to appear successful in their roles. In future research, it is recommended that focus groups and interviews are used to triangulate both individual and group knowledge.

\section{$\underline{\text { Recommendations for Future Research }}$}

Given the small case study type of research used in this thesis, it would be beneficial for the field to have more experiences of organizations of varying types and to use different tools for researchers to reference. Additionally, the organizational evaluation capacity self-assessment instrument appears to have only been researched by the tool developers and this researcher, which limits the understanding of the specific tool in various contexts and with different organizations and facilitators. Having more information about the impact of the organizations' and facilitators' capacities in relation 
to completing this tool during the ECB process would be beneficial in understanding the full utility of the tool.

Much of the current research with ECB processes and tools have been completed by ECB experts or researchers and not by individual organizations. It could be valuable to explore the ECB process in a more organic state with organizations who are exploring ECB on their own. This could also give more insight into the true needs of these organizations and how models, frameworks, and tools can be better developed to support the needs of these organizations without having to acquire the use of a trained evaluator for the whole ECB process.

As this is still largely a budding field, there are several avenues of research to explore in understanding the levels of evaluation capacity for various organizations, successes of different strategies, and stories of success and non-success cases. 


\section{REFERENCES}

American Evaluation Association. (n.d.). Annual conference history. Retrieved from American Evaluation Association: https://www.eval.org/p/cm/ld/fid=106

Bourgeois, I. (2008). Understanding the dimensions of organizational evaluation capacity. Dissertation Abstracts International Section A: Humanities and Social Sciences. Retrieved from ProQuest Information \& Learning. Retrieved from http://libproxy.boisestate.edu/login?url=http://search.ebscohost.com/login.aspx?di rect=true \&db=psyh\&AN=2009-99191-274\&site=ehost-live

Bourgeois, I., \& Cousins, J. B. (2008). Informing evaluation capacity building through profiling organizational capacity for evaluation: An empirical examination of four canadian federal government organizations. Canadian Journal of Program Evaluation, 23(3), 127-146.

Bourgeois, I., \& Cousins, J. B. (2013). Understanding dimensions of organizational evaluation capacity. American Journal of Evaluation, 34(3), 299-319. doi:10.1177/1098214013477235

Bourgeois, I., Chouinard, J. A., \& Cousins, J. B. (2008). Understanding organization capacity for evaluation: Synthesis and integration. Canadian Journal of Program Evaluation, 23(3), 225-237.

Bourgeois, I., Simmons, L., \& Buetti, D. (2018). Building evaluation capacity in Ontario's public health units: Promising practices and strategies. Public Health, 15989-15994. doi:10.1016/j.puhe.2018.01.031

Bourgeois, I., Whynot, J., \& Theriault, E. (2015). Application of an organizational capacity self-assessment instrument to different organizations: Similarities and lessons learned. Evaluation Program Planning, 50, 47-55. doi:10.1016/j.evalprogplan.2015.01.004 
Brown, M. (2012). Enhancing and measuring organizational capacity: Assessing the results of the U.S. department of justice rural pilot program evaluation. Public Administration Review, 72(4), 506-514. doi:10.111/j.1540-6210.2012.0

Carman, J. G. (2007). Evaluation practice among community-based organizations. American Journal of Evaluation, 28(1), 60-75. doi:10.1177/1098214006296245

Carman, J. G., \& Fredericks, K. A. (2009). Evaluation capacity and nonprofit organizations. American Journal of Evaluation, 31(1), 84-104. doi:10.1177/1098214009352361

Chyung, S. Y. (2019). Ten-step evaluation for training and performance improvement. Thousand Oaks, CA: Sage.

Cooper, K. R., \& Shumate, M. (2016). Policy brief: The case for using robust measures to evaluate nonprofit organizations. Nonprofit Policy Forum, 7(1), 39-47. doi:10.1515/npf-2015-0029

Cousins, J. B., Goh, S. C., \& Clark, S. (2005). Data use leads to data valuing: Evaluative inquiry for school decision making. Leadership and Policy in Schools, 4, 155176.

Cousins, J. B., Goh, S. C., Elliot, C., Aubry, T., \& Gilbert, N. (2013). Government and voluntary sector differences in organizational capacity to do and use evaluation. Evaluation and program planning, 1-13. doi:10.1016/j.evalprogplan.2013.12.001

Cousins, J. B., Goh, S. C., Elliott, C. J., \& Bourgeois, I. (2014). Framing the capacity to do and use evaluation. New Directions for Evaluation, 141, 7-23. doi:10.1002/ev.20076

Despard, M. R. (2017). Can nonprofit capacity be measured? Nonprofit \& Voluntary Sector Quarterly, 46(3), 607-626. doi:doi:10.1177/0899764016661425

Eckerd, A., \& Moulton, S. (2011). Heterogeneous roles and heterogeneous practices: Understanding the adopting and uses of nonprofit performance evaluations. American Journal of Evaluation, 32(1), 98-117. doi:10.1177/109821410381780 
Garcia-Iriarte, E., Suarez-Balcazar, Y., Taylor-Ritzler, T., \& Luna, M. (2011). A catalyst for change approach to evaluation capacity building. American Journal of Evaluation, 32(2), 168-182. doi:10.1177/1098214010387114

Goh, S. C., \& Richards, G. (1997). Benchmarking the learning capability of organizations. European Management Journal, 15(5), 575-583.

Herman, R. D., \& Renz, D. O. (2008). Advancing nonprofit organizational effectiveness research and theory: Nine theses. Nonprofit Management \& Leadership, 18(4), 399-415. doi:10.1002/nm

Hilton, L., \& Libretto, S. (2017). Evaluation capacity building in the context of military psychological health: Utilizing Preskill and Boyle's multidisciplinary model. American Journal of Evaluation, 38, 393-404.

Hoefer, R. (2000). Accountability in action? Nonprofit Management \& Leadership, 11(2), 167.

Huffman, D., Lawrenz, F., Thomas, K., \& Clarkson, L. (2006). Collaborative evaluation communities in urban schools: A model for evaluation capacity building for STEM education. New Directions for Evaluation, 109, 73-85. doi:10.1002/ev.179

International Society for Performance Improvement. (2018). Performance improvement/ HPT model. Retrieved from ISPI: https://www.ispi.org/ISPI/ISPI/About_ISPI/PI__HPT__Model.aspx

King, J. A. (2007). Developing evaluation capacity through process use. New Directions for Evaluation, 116, 45-59. doi:10.1002/ev.4242

King, J. A., \& Volkov, B. (2005). A framework for building evaluation capacity based on the experiences of three organizations. CURA Reporter, 35(3), 10-16.

Labin, S., Duffy, J., Meyers, D., Wandersman, A., \& Lesesne, C. (2012). A research sythesis of the evaluation capacity building liturature. American Journal of Evaluation, 33(3), 307-338. doi:10.1177/1098214011434608

LeCompte, M. D., \& Schensul, J. J. (1999). Analyzing \& interpreting ethnographic data. Walnut Creek, CA: AltaMira Press. 
McKeever, B. S. (2015). The nonprofit sector in brief 2015: Public charities, giving, and volunteering. Retrieved from Urban Institute: https://www.urban.org/sites/default/files/publication/72536/2000497-TheNonprofit-Sector-in-Brief-2015-Public-Charities-Giving-and-Volunteering.pdf

Milstein, B., Chapel, T. J., Wetterhall, S. F., \& Cotton, D. A. (2002). Building capacity for program evaluation at the centers for disease control and prevention. New Directions for Evaluation, 93(Spring), 27-46.

Minzner, A., Klerman, J. A., Markovitz, C. E., \& Fink, B. (2014). The impact of capacity-building programs on nonprofits: A random assignment evaluation. Nonprofit and Voluntary Sector Quarterly, 43(3), 547-569. doi:10.1177/0899764013491013

Mitchell, G. E., \& Berlan, D. (2016). Evaluation and evaluative rigor in the nonprofit sector. Nonprofit Management \& Leadership, 27(2), 237-250. doi:10.1002/nml.21236

National Council of Nonprofits. (n.d.). What is a "nonprofit"? Retrieved from National Council of Nonprofits: https://www.councilofnonprofits.org/what-is-a-nonprofit

Newcomer, K. E., Hatry, H. H., \& Wholey, J. S. (2004). Meeting the need for practical evaluation approaches: An introduction. In J. S. Wholey, H. P. Hatry, \& K. E. Newcomer, Handbook of practical program evaluation (p. xxxiv). San Francisco: Jossey-Bass.

Patton, M. Q. (1997). Utilization-focused evaluation (3rd ed.). Thousand Oaks, CA: Sage.

Patton, M. Q. (2008). Utilization-focused evaluation (4th ed.). Thousand Oaks, CA: Sage.

Preskill, H., \& Boyle, S. (2008a). A multidisciplinary model of evaluation capacity building. American Journal of Evaluation, 29, 443-459.

Preskill, H., \& Boyle, S. (2008b). Insights into evaluation capacity building; Motivations, strategies, outcomes, and lessons learned. Canadian Journal of Program Evaluation, 23(3), 147-174. 
Preskill, H., \& Torres, R. T. (2000). Readiness for organization learning and evaluation instrument. Retrieved June 6, 2018, from FSG: http://www.fsg.org/rools-andresources/readiness-organizational-learning-and-evaluation-instrument-role

Stockdill, S. H., Baizerman, M., \& Compton, D. W. (2002). Toward a definition of the ECB process: A conversation with ECB literature. New Directions for Evaluation, 93, 7-25.

Taylor-Ritzler, T., Suarez-Balcazar, Y., Garcia-Iriarte, E., Henry, D. B., \& Balcazar, F. E. (2013). Understanding and measuring evaluation capacity: A model and instrument validation study. American Journal of Evaluation, 34(2), 190-206. doi:10.1177/1098214012471421

Volkov, B. (2008). A bumpy journey to evaluation capacity: A case study of evaluation capacity building in a private foundation. Canadian Journal of Program Evaluation, 23(3), 175-197.

Volkov, B., \& King, J. (2007). A checklist for building organizational evaluation capacity. Retrieved June 6, 2018, from DME for Peace: http://dmeforpeace.org/sites/default/files/Volkov\%20and\%20King_Checklist\%20 for\%20Building\%20Organizational\%20Evaluation\%20Capacity.pdf

Wandersman, A. (2014). Moving forward with the science and practice evaluation capacity building (ECB): The why, how, what, and outcomes of ECB. American Journal of Evaluation, 35(1), 87-89. doi:10.1177/1098214013503895 
APPENDIX A 


\section{Volkov and Kings (2007) Checklist for Building Organizational Evaluation Capacity}

The purpose of this checklist is to provide a set of guidelines for organizational evaluation capacity building (ECB), i.e., for incorporating evaluation routinely into the life of an organization. The checklist, which was developed from case study data and an extensive literature review, can be a resource for a wide range of stakeholders in organizations seeking to increase their long-term capacity to conduct and use program evaluations in everyday activities.

Organizational Context: Be aware of the internal and external organizational context, power hierarchies, administrative culture, and decision-making processes.

\section{Cultivate a positive, ECB-friendly internal organizational context.}

$\square$ Make sure that key leaders of the organization support and share responsibility for ECB.

Locate existing and enlist new evaluation champion(s) in the organization.

$\square$ Determine and work to increase the organization's interest in and demand for evaluation information.

Determine if and to what extent the internal environment is supportive of change.

$\square$ Provide opportunities for sufficient input in decision making, ensuring that people in the organization are able to use data to make decisions.

$\square$ Organize opportunities for socializing around evaluation activities during the workday (for example, working on a survey collaboratively or discussing evaluation findings at brown bag lunches).

\section{Understand and take advantage of the external environment and its influence on} the organization.

$\square$ Identify external mandates/accountability requirements and expectations, and integrate them into the ECB efforts.

$\square$ Determine if and to what extent the external environment is supportive of change (for example, accreditation agencies encourage innovation, professional communities promote evaluation activities, external stakeholders provide support for evaluation).

ECB Structures: Purposefully create structures - mechanisms within the organizationthat enable the development of evaluation capacity.

\section{Develop and implement a purposeful long-term ECB plan for the organization.}

$\square$ Establish a capable ECB oversight group (composed of members of the staff, board of directors, and community) to initiate, evaluate, and advance evaluation processes continually in the organization.

$\checkmark$ Generate an appropriate conception of evaluation for organizational policies and procedures.

$\square$ Create a strategy for conducting and using evaluations in the organization that applies existing evaluation frameworks, guidelines, and professional standards.

$\square$ Integrate evaluation processes purposefully into organizational policies and procedures. 
Make sure that a detailed written ECB plan exists, is distributed throughout the organization, and is used to assess progress.

$\square$ Evaluate the capacity building activities routinely to insure that capacity is increasing and the evaluation function is growing.

\section{Build and reinforce infrastructure to support specific components of the evaluation process and communication systems.}

$\square$ Create organizational structures that will facilitate evaluation activities (for example, framing evaluation questions; generating needed studies; conducting needs assessments; designing evaluations; and collecting, analyzing, and interpreting data).

$\square$ Assign responsibility for facilitating the ongoing development and evaluation of evaluation processes.

$\square$ Build individuals' readiness and skills to implement evaluation activities.

$\square$ Develop and use an internal reporting/monitoring/tracking system.

$\square$ Develop an effective communication and reporting capability to explain evaluation processes and disseminate findings, both positive and negative, to stakeholder groups.

\section{Introduce and maintain purposeful socialization into the organization's evaluation} process.

$\square$ Establish clear expectations for people's evaluation roles and provide sufficient time during the work day for evaluation activities.

Offer tangible incentives for participation in the evaluation process.

Provide or make available formal training, professional development, and coaching in evaluation.

$\square$ Promote and facilitate people's learning evaluation by involving them in meaningful ways in evaluation planning and implementation ("learning by doing").

$\square$ Model a willingness to be evaluated by insuring that evaluations and the ECB process itself are routinely and visibly evaluated.

\section{Build and expand peer learning structures.}

$\square$ Emphasize and implement purposeful trust building (both interpersonal and organizational) and interdependent roles in the evaluation process.

$\square$ Incorporate a feedback mechanism in the decision-making process and an effective communication system so that people will learn from evaluation activities.

$\square$ Create ongoing learning activities through which people interact around evaluation processes and results.

$\square$ Provide ample opportunities for both individual and group reflection (for example, databased discussions of successes, challenges, and failures in the organization).

Resources: Make evaluation resources available and use them.

\section{Provide and continuously expand access to evaluation resources.}

$\square$ Use evaluation personnel effectively (for example, have internal professionals model high quality practice, teach evaluation processes by engaging staff in evaluation activities, have external consultants present findings to staff). 
Provide easy access to relevant research bases that contain "best practice" content for evaluation in general and for evaluation in specific program content and to examples of high quality evaluation descriptions and reports.

$\square$ Ensure the availability of sufficient information on how to access existing evaluation resources (for example, websites, professional organizations, evaluation consultants).

\section{Secure sources of support for program evaluation in the organization.}

Assure long-term fiscal support from the board or administration-explicit, dedicated funding for program evaluation activities.

$\square$ Provide basic resources (copying, equipment for data collection and analysis, computers and software, etc.).

Allow adequate time and opportunities to collaborate on evaluation activities, including, when possible, being physically together in an environment free from interruptions.

$\square$ If needed, develop revenue-generating strategies to support program evaluation (for example, selling copies of data collection instruments or serving as evaluation consultants to other organizations for pay). 
APPENDIX B 


\title{
Evaluation Capacity Assessment Instrument (ECAI)
}

\author{
Reprinted with permission Copyright (C) 2013, (C SAGE Publications
}

Section I: About You (Individual Factors) Awareness: Thoughts About Evaluation (1-4 scale, where 1 = strongly disagree, 2 = somewhat disagree, $3=$ somewhat agree, and $4=$ strongly agree)

I think that an evaluation ...

1. Will help me understand my program.

2. Will inform the decisions I make about my program.

3. Will justify funding for my program.

4. Will help to convince managers that changes are needed in my program.

5. Will inform changes in our documentation systems.

6. Is absolutely necessary to improve my program.

7. Should involve program participants in the evaluation process.

8. Will influence policy relevant to my program.

9. Will help improve services to people from diverse ethnic backgrounds who also have disabilities

10. Is unnecessary because we already know what is best for our participants.

11. Is too complex for staff to do.

Motivation: Motivation to Engage in Evaluation

I am motivated to ...

1. Learn about evaluation.

2. Start evaluating my program.

3. Support other staff to evaluate their program.

4. Encourage others to buy into evaluating our program.

Competence: Evaluation Knowledge and Skills

I know how to ...

1. Develop an evaluation plan.

2. Clearly state measurable goals and objectives for my program.

3. Identify strategies to collect information from participants.

4. Define outcome indicators of my program.

5. Decide what questions to answer in an evaluation.

6. Decide from whom to collect the information.

7. Collect evaluation information.

8. Analyze evaluation information.

9. Develop recommendations based on evaluation results.

10. Examine the impact of my program on people from diverse ethnic/racial backgrounds and/or people with disabilities.

11. Write an evaluation report.

12. Conduct an evaluation of my program on my own.

13. Conduct an evaluation of my program with support from others.

14. Present evaluation findings orally. 
Section II: About your Organization (Organizational Factors)

( $1-4$ scale, where $1=$ strongly disagree, $2=$ somewhat disagree, $3=$ somewhat agree, and $4=$ strongly agree)

Leadership

1. Program managers provide effective leadership.

2. Staff understands how everyone's duties fit together as part of the overall mission of the program.

3. Program managers communicate program goals and objectives clearly.

4. Program managers have a clear plan for accomplishing program goals.

5. Program managers have realistic expectations of what staff can accomplish given the resources they have available.

Learning Climate

The program where I work fosters an environment in which ...

1. Evaluation information is shared in open forums.

2. Staff is supported to introduce new approaches in the course of their work.

3. It is easy for staff to meet regularly to discuss issues.

4. Staff is provided opportunities to assess how well they are doing, what they can do better, and what is working.

5. Staff can encourage managers and peers to make use of evaluation findings.

6. Staff respects each other's perspectives and opinions.

7. Staff errors lead to teachable moments rather than criticisms.

8. Staff participates in making long-term plans for their program.

9. Staff concerns are ignored in most decisions regarding strategic planning and evaluation.

Resources for Evaluation

In my program ...

1. Resources are allocated to provide accommodations for people from diverse ethnic backgrounds

and for people with disabilities to collect evaluation information (e.g., interpreters,

translated documents).

2. Staff has time to conduct evaluation activities (e.g., identifying or developing a survey, collecting

information from participants).

3. Staff has access to technology to compile information into computerized records.

4. Staff has access to adequate technology to produce summary reports of information collected

from participants (e.g., computerized database).

5. Resources are allocated for staff training (e.g., money, time, bringing in consultants).

6. Technical assistance is available to staff to address questions related to evaluation. 
7. Funders provide resources (e.g., training, money, etc.) to conduct evaluation.

8. Funders provide leadership for conducting evaluation.

9. Agency leadership engages in ongoing dialogue with funders regarding evaluation.

Section III: About your Work (Evaluation Capacity Outcomes)

(1-4 scale, where $1=$ strongly disagree, $2=$ somewhat disagree, $3=$ somewhat agree, and $4=$ strongly agree)

Mainstreaming: Evaluation as part of your Job

1. My program gathers information from diverse stakeholders to gauge how well the program is doing.

2. My program has adequate records of past evaluation efforts and what happened as a result.

3. I have access to the information I need to make decisions regarding my work.

4. I am able to integrate evaluation activities into my daily work practices.

5. The evaluation activities I engage in are consistent with funders' expectations.

Use of Evaluation Findings

Please indicate the extent to which your program currently uses evaluation results for the following purposes ( $1 \frac{1 / 4}{4}$ not at all, $2 \frac{1}{4}$ to some extent, $3 \frac{1 / 4}{4}$ to a considerable extent, and $4 \frac{1 / 4}{4}$ to a very great extent)

1. To report to a funder.

2. To improve services or programs.

3 . To get additional funding.

4. To design ongoing monitoring processes.

5. To assess implementation of a program.

6. To assess quality of a program.

7. To improve outreach.

8. To make informed decisions.

9. To train staff.

10. To develop best practices.

11. To eliminate unneeded services or programs. 
APPENDIX C 


\section{Bourgeois and Cousins' (2008) Organizational Evaluation Capacity Self-Assessment}

Table 10. Organizational Evaluation Capacity Self-Assessment

\begin{tabular}{|c|c|}
\hline Item & Response scale \\
\hline \multicolumn{2}{|l|}{ Dimension 1. Human Resources } \\
\hline \multicolumn{2}{|l|}{ 1.1 Human Resources - Staffing } \\
\hline $\begin{array}{l}\text { 1. Employee retention initiatives and/or policies (e.g. clear career path, internal recognition) have been } \\
\text { implemented to facilitate promotion and employee retention }\end{array}$ & $\begin{array}{l}\text { SD D A SA N/A Don't } \\
\text { Know }\end{array}$ \\
\hline $\begin{array}{l}\text { 2. The evaluation unit or function has an appropriate balance of junior, senior, and support positions to } \\
\text { complete evaluation projects efficiently }\end{array}$ & $\begin{array}{l}\text { SD D A SA N/A Don't } \\
\text { Know }\end{array}$ \\
\hline \multicolumn{2}{|l|}{ 1.2 Human Resources - Technical Skills } \\
\hline 3. Senior management and program managers recognize evaluation reports as rigorous and well researched & $\begin{array}{l}\text { SD D A SA N/A Don't } \\
\text { Know }\end{array}$ \\
\hline 4. Sound data collection and analysis methods are used to produce evaluation findings & $\begin{array}{l}\text { SD D A SA N/A Don't } \\
\text { Know }\end{array}$ \\
\hline 5. Evaluators follow sound project management practices to keep evaluations on schedule & $\begin{array}{l}\text { SD D A SA N/A Don't } \\
\text { Know }\end{array}$ \\
\hline \multicolumn{2}{|l|}{ 1.3 Human Resources - Communication Skills } \\
\hline 6. Evaluation staff maintain good working relationships with program managers for ongoing trust & $\begin{array}{l}\text { SD D A SA N/A Don't } \\
\text { Know }\end{array}$ \\
\hline 7. Processes exist to ensure that evaluation staff are impartial, unbiased and avoid any conflicts of interest & $\begin{array}{l}\text { SD D A SA N/A Don't } \\
\text { Know }\end{array}$ \\
\hline 8. Evaluation reports are clear and precise (e.g., jargon-free and accessible) & $\begin{array}{l}\text { SD D A SA N/A Don't } \\
\text { Know }\end{array}$ \\
\hline \multicolumn{2}{|l|}{ 1.4 Human Resources - Professional Development } \\
\hline $\begin{array}{l}\text { 9. Evaluation skill sets are assessed regularly to identify gaps and corresponding training (e.g. individual } \\
\text { learning plans) }\end{array}$ & $\begin{array}{l}\text { SD D A SA N/A Don't } \\
\text { Know }\end{array}$ \\
\hline 10. Training budget and allocated training time is adequate to meet the needs identified by staff members & $\begin{array}{c}\text { SD D A SA N/A Don't } \\
\text { Know }\end{array}$ \\
\hline $\begin{array}{l}\text { 11. New evaluators (staff members who are new to evaluation) are encouraged to develop their evaluation } \\
\text { skills through formal or informal apprentice/mentor arrangement }\end{array}$ & $\begin{array}{l}\text { SD D A SA N/A Don't } \\
\text { Know }\end{array}$ \\
\hline 1.5 Human Resources - Leadership & \\
\hline
\end{tabular}




\begin{tabular}{|l|c|}
\hline 12. Evaluation unit lead/manager has a strong background in evaluation and management & $\begin{array}{c}\text { SD D A SA N/A Don't } \\
\text { Know }\end{array}$ \\
\hline 13. Evaluation unit lead/manager reconciles senior management expectations with evaluation capacity & $\begin{array}{c}\text { SD D A SA N/A Don't } \\
\text { Know }\end{array}$ \\
\hline $\begin{array}{l}\text { 14. Evaluation champion(s) are clearly identified throughout the organization (e.g. in evaluation and } \\
\text { program areas) }\end{array}$ & SD D A SA N/A Don't \\
Know \\
$\begin{array}{l}\text { 15. Evaluation unit lead/manager provides support to evaluators faced with political/organizational } \\
\text { interference during an evaluation }\end{array}$ & SD D A SA N/A Don't \\
\end{tabular}




\begin{tabular}{|l|c|}
\hline \multicolumn{1}{|c|}{ Item } & Response scale \\
\hline Dimension 2. Organizational Resources & \\
\hline 2.1 Organizational Resources - Budget & $\begin{array}{c}\text { SD D A SA N/A Don't } \\
\text { Know }\end{array}$ \\
\hline 16. Allocation of evaluation unit budget is transparent and reflects organizational concerns and priorities & $\begin{array}{c}\text { SD D A SA N/A Don't } \\
\text { Know }\end{array}$ \\
\hline 17. New program financing includes the cost of the corresponding evaluation & SD D A SA N/A Don't \\
\hline 18. The evaluation budget is controlled and managed by the evaluation unit & Kn D A SA N/A Don't \\
\hline 19. Adequate, stable resources are available to complete evaluation projects & \\
\hline 2.2 Organizational Resources - Performance Measurement Data & SD D A SA N/A Don't \\
\hline 20. Performance measurement data reflect program outcomes and results-oriented management & Know \\
\hline 21. Ongoing performance measurement data are available, accessible and complete at the corporate and & SD D A SA N/A Don't \\
program levels & Know \\
\hline 2.3 Organizational Resources - Infrastructure and Tools & SD D A SA N/A Don't \\
\hline 22. Policies and procedures have been established to guide evaluation activities & Know \\
\hline 23. Evaluators have the necessary tools to complete their work (e.g. software, hardware) & Know \\
\hline 24. A quality assurance and improvement program is in place and covers all aspects of the evaluation & SD D A SA N/A Don't \\
activity within the organization & Know \\
\hline
\end{tabular}




\begin{tabular}{|c|c|}
\hline Item & Response scale \\
\hline \multicolumn{2}{|l|}{ Dimension 3. Planning and Conducing Evaluations } \\
\hline \multicolumn{2}{|l|}{ 3.1 Conducting Evaluations - Planning } \\
\hline $\begin{array}{l}\text { 25. Organization develops and implements a planning process to identify evaluation priorities for upcoming } \\
\text { years }\end{array}$ & $\begin{array}{l}\text { SD D A SA N/A Don't } \\
\text { Know }\end{array}$ \\
\hline $\begin{array}{l}\text { 26. Organizational evaluation plan sets out clear, reasonable project completion targets and timelines in } \\
\text { relation to resources and organizational priorities }\end{array}$ & $\begin{array}{l}\text { SD D A SA N/A Don't } \\
\text { Know }\end{array}$ \\
\hline \multicolumn{2}{|l|}{ 3.2 Conducting Evaluation - Internal and External Evaluators } \\
\hline 27. Evaluation unit has the capacity to conduct evaluations in-house & $\begin{array}{l}\text { SD D A SA N/A Don't } \\
\text { Know }\end{array}$ \\
\hline $\begin{array}{l}\text { 28. Use of consultants complements organization's evaluation capacity (e.g. specific skills, expert } \\
\text { knowledge) }\end{array}$ & $\begin{array}{l}\text { SD D A SA N/A Don't } \\
\text { Know }\end{array}$ \\
\hline \multicolumn{2}{|l|}{ 3.3 Conducting Evaluations - Information and Support } \\
\hline 29. Evaluators actively gather information on new policy and strategic development trends & $\begin{array}{l}\text { SD D A SA N/A Don't } \\
\text { Know }\end{array}$ \\
\hline $\begin{array}{l}\text { 30. Evaluation resources are used towards the development of cross-cutting/supporting information (e.g., } \\
\text { evaluability assessment, feasibility studies, special studies, program theory development, etc.) }\end{array}$ & $\begin{array}{l}\text { SD D A SA N/A Don't } \\
\text { Know }\end{array}$ \\
\hline 31. Evaluators maintain regular formal/informal contact with program managers & $\begin{array}{l}\text { SD D A SA N/A Don't } \\
\text { Know }\end{array}$ \\
\hline \multicolumn{2}{|l|}{ 3.4 Conducting Evaluations - Organizational Linkages } \\
\hline $\begin{array}{l}\text { 32. Evaluation unit lead/manager communicates directly with senior managers on issues related to } \\
\text { evaluation }\end{array}$ & $\begin{array}{l}\text { SD D A SA N/A Don't } \\
\text { Know }\end{array}$ \\
\hline 33. Evaluation steering or advisory committees are regularly used to guide evaluations & $\begin{array}{l}\text { SD D A SA N/A Don't } \\
\text { Know }\end{array}$ \\
\hline 34. Evaluation, research and policy units coordinate efforts to minimize duplication and leverage research & $\begin{array}{l}\text { SD D A SA N/A Don't } \\
\text { Know }\end{array}$ \\
\hline \multicolumn{2}{|l|}{ 3.5 Conducting Evaluations - External Support } \\
\hline 35. Evaluators actively network to expand their contacts with other evaluators and academia & $\begin{array}{l}\text { SD D A SA N/A Don't } \\
\text { Know }\end{array}$ \\
\hline $\begin{array}{l}\text { 36. Evaluators actively use external supports (e.g. professional associations, published quality standards, } \\
\text { etc.) to remain current on developments in the field }\end{array}$ & $\begin{array}{l}\text { SD D A SA N/A Don't } \\
\text { Know }\end{array}$ \\
\hline
\end{tabular}




\begin{tabular}{|l|c|}
\hline \multicolumn{1}{|c|}{ Item } & Response scale \\
\hline Dimension 4. Evaluation Literacy & \\
\hline 4.1 Evaluation Literacy - Stakeholder Involvement & SD D A SA N/A Don't \\
\hline 37. Program managers and/or staff understand the purposes of evaluation and how it is used & Know \\
\hline 38. Program managers and/or staff understand and apply the principles of results-based management & SD D A SA N/A Don't \\
Know
\end{tabular}




\begin{tabular}{|l|c|}
\hline \multicolumn{1}{|c|}{ Item } & Response scale \\
\hline Dimension 5. Organizational Decision Making & \\
\hline 5.1 Organizational Decision-Making - Management Processes & \\
\hline $\begin{array}{l}\text { 48. Program managers and/or staff routinely consult evaluators on matters related to evaluation and } \\
\text { performance measurement }\end{array}$ & $\begin{array}{c}\text { SD D A SA N/A Don't } \\
\text { Know }\end{array}$ \\
\hline $\begin{array}{l}\text { 49. Evaluators are involved in broader management processes within the organization (e.g., budgetary } \\
\text { reallocations, funding applications, program development) }\end{array}$ & SD D A SA N/A Don't \\
Know \\
\hline $\begin{array}{l}\text { 5.2 Organizational Decision-Making - Decision Support } \\
\text { staff up to senior executives) }\end{array}$ \\
\hline $\begin{array}{c}\text { 51. Evaluation findings and recommendations are routinely sought out and considered in budget allocation } \\
\text { exercises and other organizational decisions }\end{array}$ & $\begin{array}{c}\text { SD D A SA N/A Don't } \\
\text { Know }\end{array}$ \\
\hline $\begin{array}{l}\text { 52. Demand for evaluation services extends beyond mandatory requirements (e.g., funding requirements) } \\
\text { SD D A SA N/A Don't } \\
\text { Know }\end{array}$ \\
\hline
\end{tabular}




\begin{tabular}{|c|c|}
\hline Item & Response scale \\
\hline \multicolumn{2}{|l|}{ Dimension 6. Learning Benefits } \\
\hline \multicolumn{2}{|l|}{ 6.1 Learning Benefits - Instrumental and Conceptual Use } \\
\hline 53. Managers generally agree with evaluation recommendations & $\begin{array}{l}\text { SD D A SA N/A Don't } \\
\text { Know }\end{array}$ \\
\hline 54. Evaluation recommendations are implemented in a timely manner & $\begin{array}{l}\text { SD D A SA N/A Don't } \\
\text { Know }\end{array}$ \\
\hline 55. Evaluation is used to meet external accountability requirements & $\begin{array}{l}\text { SD D A SA N/A Don't } \\
\text { Know }\end{array}$ \\
\hline 56. Evaluation is used to learn about program functioning & $\begin{array}{l}\text { SD D A SA N/A Don't } \\
\text { Know }\end{array}$ \\
\hline 57. Evaluation is used to make decisions about budgetary allocations & $\begin{array}{l}\text { SD D A SA N/A Don't } \\
\text { Know }\end{array}$ \\
\hline 58. Evaluation reports are disseminated outside of the organization & $\begin{array}{l}\text { SD D A SA N/A Don't } \\
\text { Know }\end{array}$ \\
\hline \multicolumn{2}{|l|}{ 6.2 Learning Benefits - Process Use } \\
\hline 59. Program managers and/or staff report an increased understanding of a program following an evaluation & $\begin{array}{l}\text { SD D A SA N/A Don't } \\
\text { Know }\end{array}$ \\
\hline $\begin{array}{l}\text { 60. Program managers and/or staff recognize the value of systematic inquiry to identify solutions to } \\
\text { organizational problems }\end{array}$ & $\begin{array}{l}\text { SD D A SA N/A Don't } \\
\text { Know }\end{array}$ \\
\hline $\begin{array}{l}\text { 61. Program management and/or staff report expanded and/or expedited use of evaluation findings due to } \\
\text { their involvement in the evaluation process }\end{array}$ & $\begin{array}{l}\text { SD D A SA N/A Don't } \\
\text { Know }\end{array}$ \\
\hline $\begin{array}{l}\text { 62. Formal or informal processes to share lessons learned during evaluations are in place and involve the } \\
\text { entire organization (e.g., seminars, brown-bag lunch sessions, brochures, etc.) }\end{array}$ & $\begin{array}{l}\text { SD D A SA N/A Don't } \\
\text { Know }\end{array}$ \\
\hline
\end{tabular}


APPENDIX D 


\section{Summary of ECB Frameworks and Tools}

Table 11. Summary of ECB Frameworks and Tools

\begin{tabular}{|c|c|c|c|c|c|c|}
\hline $\begin{array}{l}\text { ECB } \\
\text { Component/ } \\
\text { Framework } \\
\text { and/or tool }\end{array}$ & $\begin{array}{l}\text { Before engaging } \\
\text { in ECB }\end{array}$ & $\begin{array}{l}\text { Establishing } \\
\text { ECB Objectives } \\
\text { and Plan }\end{array}$ & $\begin{array}{l}\text { Selecting ECB } \\
\text { Strategies }\end{array}$ & $\begin{array}{l}\text { Evaluator } \\
\text { Approach and } \\
\text { Use of } \\
\text { Evaluation } \\
\text { Champions }\end{array}$ & $\begin{array}{l}\text { Measure } \\
\text { Progress/ } \\
\text { Sustainability } \\
\text { and any } \\
\text { Associated Tools }\end{array}$ & $\begin{array}{l}\text { Strengths and } \\
\text { Weaknesses }\end{array}$ \\
\hline $\begin{array}{l}\text { King and Volkov's } \\
\text { (2005) } \\
\text { Framework }\end{array}$ & $\begin{array}{l}\text { Include assessing } \\
\text { a mix of internal } \\
\text { and external } \\
\text { factors of } \\
\text { organizational } \\
\text { context. } \\
\text { Recommends } \\
\text { using a } \\
\text { preliminary } \\
\text { assessment, } \\
\text { formal or } \\
\text { informal, on the } \\
\text { viability of ECB } \\
\text { in the } \\
\text { organization. } \\
\text { King (2005) } \\
\text { considers this step } \\
\text { to be important as } \\
\text { ECB is highly } \\
\text { context sensitive } \\
\text { and the } \\
\text { organizational } \\
\text { context must be a } \\
\text { fertile ground for }\end{array}$ & $\begin{array}{l}\text { Has set of } 4 \text { goals: } \\
1 \text { - increase } \\
\text { capacity to design, } \\
\text { implement, and } \\
\text { manage } \\
\text { evaluation } \\
2 \text { - use evaluation } \\
\text { knowledge and } \\
\text { skills } \\
3 \text { - cultivate } \\
\text { organizational } \\
\text { learning } \\
4-\text { establish } \\
\text { support for } \\
\text { evaluation and PI } \\
\text { Organizational } \\
\text { ECB plan is } \\
\text { established by an } \\
\text { internally } \\
\text { established ECB } \\
\text { advisory group } \\
\text { based on their } \\
\text { assessment of }\end{array}$ & $\begin{array}{l}\text { Recommends } \\
\text { process use of } \\
\text { evaluation. Any } \\
\text { specific strategies } \\
\text { are a result of the } \\
\text { ECB advisory } \\
\text { group of } \\
\text { evaluation } \\
\text { champions }\end{array}$ & $\begin{array}{l}\text { Evaluator } \\
\text { Approach: } \\
\text { Facilitate ECB } \\
\text { process and guide } \\
\text { activities, but only } \\
\text { to establish } \\
\text { evaluative inquiry } \\
\text { within the } \\
\text { organization. } \\
\text { Evaluator does } \\
\text { not act as a } \\
\text { teacher. } \\
\text { Require use of } \\
\text { evaluation } \\
\text { champions to } \\
\text { form as ECB } \\
\text { advisory group to } \\
\text { guide ECB } \\
\text { process. } \\
\text { Champions lead } \\
\text { evaluative inquiry } \\
\text { and identify ECB }\end{array}$ & $\begin{array}{l}\text { King and } \\
\text { Volkov's (2006) } \\
\text { ECB Checklist } \\
\text { established to } \\
\text { assist ECB } \\
\text { advisory groups to } \\
\text { identify needed } \\
\text { resources, } \\
\text { processes, and } \\
\text { planning to create } \\
\text { a tailored strategy } \\
\text { for evaluation in } \\
\text { the organization. } \\
\text { Also established } \\
\text { the ECB wheel } \\
\text { and driving forces } \\
\text { that influence } \\
\text { both the adoption } \\
\text { and sustainability } \\
\text { of ECB within an } \\
\text { organization. }\end{array}$ & $\begin{array}{l}\text { Strengths: } \\
\text { Checklist } \\
\text { establishes a } \\
\text { starting point for } \\
\text { ECB advisory } \\
\text { groups to work } \\
\text { from to } \\
\text { understand what } \\
\text { components they } \\
\text { may need to build } \\
\text { their evaluation } \\
\text { capacity. } \\
\text { Weaknesses: } \\
\text { Does not include } \\
\text { enough guidance } \\
\text { on identifying } \\
\text { appropriate ECB } \\
\text { strategies for the } \\
\text { organization or } \\
\text { measuring ECB } \\
\text { progress. }\end{array}$ \\
\hline
\end{tabular}




\begin{tabular}{|c|c|c|c|c|c|c|}
\hline & $\begin{array}{l}\text { learning for ECB } \\
\text { to be successful. } \\
\text { Recommends } \\
\text { measuring } \\
\text { organizational } \\
\text { readiness for } \\
\text { learning but does } \\
\text { not recommend } \\
\text { any specific tools. }\end{array}$ & $\begin{array}{l}\text { organizational } \\
\text { need. }\end{array}$ & & $\begin{array}{l}\text { steps and } \\
\text { progress. }\end{array}$ & & \\
\hline $\begin{array}{l}\text { Preskill and } \\
\text { Boyle's }(2008 a) \\
\text { Framework }\end{array}$ & $\begin{array}{l}\text { Include assessing } \\
\text { a mix of internal } \\
\text { and external } \\
\text { factors } \\
\text { High priority on } \\
\text { assessing } \\
\text { readiness. } \\
\text { Recommends } \\
\text { ROLE, or similar } \\
\text { measure of } \\
\text { organizational } \\
\text { learning capacity. }\end{array}$ & $\begin{array}{l}\text { Established a } \\
\text { comprehensive } \\
\text { list of ECB } \\
\text { outcomes in areas } \\
\text { of knowledge, } \\
\text { skill, and affect. } \\
\text { Also established } \\
\text { multidisciplinary } \\
\text { model that } \\
\text { included several } \\
\text { components to } \\
\text { assess when } \\
\text { establishing an } \\
\text { ECB plan that tie } \\
\text { in organizational } \\
\text { readiness, } \\
\text { motivations, } \\
\text { assumptions, and } \\
\text { resources into } \\
\text { selecting } \\
\text { appropriate ECB } \\
\text { strategies. }\end{array}$ & $\begin{array}{l}\text { Established a } \\
\text { standardized list } \\
\text { of ten ECB } \\
\text { strategies } \\
\text { organizations may } \\
\text { engage in during } \\
\text { the ECB process. }\end{array}$ & $\begin{array}{l}\text { Includes use of an } \\
\text { ECB facilitator, } \\
\text { who has sufficient } \\
\text { evaluation } \\
\text { knowledge and } \\
\text { knowledge of the } \\
\text { organization to } \\
\text { influence how } \\
\text { participants may } \\
\text { learn. }\end{array}$ & $\begin{array}{l}\text { States importance } \\
\text { of evaluating ECB } \\
\text { initiative, but does } \\
\text { not give a } \\
\text { measure or tool } \\
\text { specifically to do } \\
\text { so. }\end{array}$ & $\begin{array}{l}\text { Strengths: This } \\
\text { model is more } \\
\text { robust than prior } \\
\text { models and } \\
\text { includes a } \\
\text { systemic and } \\
\text { systematic view } \\
\text { of the ECB } \\
\text { process within an } \\
\text { organization. The } \\
\text { model } \\
\text { incorporates } \\
\text { components } \\
\text { established } \\
\text { throughout } \\
\text { research in a } \\
\text { comprehensive } \\
\text { resource that } \\
\text { allowed case } \\
\text { study participants } \\
\text { to establish ECB } \\
\text { successfully. } \\
\text { Weakness: The } \\
\text { model is more }\end{array}$ \\
\hline
\end{tabular}




\begin{tabular}{|c|c|c|c|c|c|c|}
\hline & & & & & & $\begin{array}{l}\text { conceptual as it } \\
\text { does not offer any } \\
\text { sort of } \\
\text { measurement to } \\
\text { assess the } \\
\text { progress of an } \\
\text { ECB initiative } \\
\text { within an } \\
\text { organization. }\end{array}$ \\
\hline $\begin{array}{l}\text { Labin et al.'s } \\
\text { (2012) Integrative } \\
\text { ECB Model }\end{array}$ & $\begin{array}{l}\text { Include } \\
\text { assessment of } \\
\text { motivational } \\
\text { factors, both } \\
\text { internal and } \\
\text { external, that are } \\
\text { driving the } \\
\text { organization to } \\
\text { participate in } \\
\text { ECB. Mirrors } \\
\text { Preskill and } \\
\text { Boyle's need for } \\
\text { readiness } \\
\text { assessment but } \\
\text { recommend using } \\
\text { a needs } \\
\text { assessment } \\
\text { approach. }\end{array}$ & $\begin{array}{l}\text { Emphasizes } \\
\text { establishing a plan } \\
\text { to guide ECB and } \\
\text { to use for meta- } \\
\text { evaluation during } \\
\text { the ECB process. } \\
\text { Does not include } \\
\text { an established list } \\
\text { of objectives but } \\
\text { includes the need } \\
\text { to understand } \\
\text { individual and } \\
\text { organizational } \\
\text { level desired } \\
\text { outcomes. } \\
\text { Recommend } \\
\text { building outcomes } \\
\text { that support } \\
\text { research on } \\
\text { components that } \\
\text { increase sustained } \\
\text { ECB efforts. }\end{array}$ & $\begin{array}{l}\text { Recommends } \\
\text { using needs } \\
\text { assessment to } \\
\text { tailor selected } \\
\text { strategies to the } \\
\text { organization's } \\
\text { resources, } \\
\text { interests, and } \\
\text { availability. }\end{array}$ & $\begin{array}{l}\text { Does not include a } \\
\text { determination on } \\
\text { the role of } \\
\text { evaluator or } \\
\text { champions. }\end{array}$ & $\begin{array}{l}\text { No established } \\
\text { measurements. } \\
\text { Recommends } \\
\text { establishing ECB } \\
\text { objectives based } \\
\text { on sustainability } \\
\text { of ECB research. }\end{array}$ & $\begin{array}{l}\text { Strengths: While } \\
\text { simplified, this } \\
\text { model establishes } \\
\text { an easy to } \\
\text { understand } \\
\text { synthesis of ECB } \\
\text { research that can } \\
\text { be applied by } \\
\text { knowledge } \\
\text { evaluators. } \\
\text { Weaknesses: The } \\
\text { simplified nature } \\
\text { of this model is } \\
\text { not conducive as a } \\
\text { guide to unskilled } \\
\text { evaluators or } \\
\text { organizations with } \\
\text { low evaluation } \\
\text { knowledge. It also } \\
\text { does not include a } \\
\text { measurement for } \\
\text { ECB progress. }\end{array}$ \\
\hline
\end{tabular}




\begin{tabular}{|c|c|c|c|c|c|c|}
\hline $\begin{array}{l}\text { Taylor-Ritzler et } \\
\text { al.'s (2013) } \\
\text { Evaluation } \\
\text { Capacity } \\
\text { Assessment } \\
\text { Instrument }\end{array}$ & $\begin{array}{l}\text { Developed as an } \\
\text { enhanced version } \\
\text { of the ROLE } \\
\text { instrument to } \\
\text { measure } \\
\text { evaluation } \\
\text { capacity building } \\
\text { in NPOs }\end{array}$ & $\begin{array}{l}\text { Does not include } \\
\text { direction on } \\
\text { establishing an } \\
\text { ECB plan, but } \\
\text { does incorporate } \\
\text { objectives as } \\
\text { established by } \\
\text { Preskill and Boyle } \\
\text { (2008b) to be } \\
\text { measured. }\end{array}$ & $\begin{array}{l}\text { Does not include } \\
\text { direction on } \\
\text { selecting ECB } \\
\text { strategies. }\end{array}$ & $\begin{array}{l}\text { Does not include } \\
\text { direction on the } \\
\text { role of the } \\
\text { evaluator or } \\
\text { champions. }\end{array}$ & $\begin{array}{l}\text { Established the } \\
\text { ECAI to measure } \\
\text { progress of ECB } \\
\text { initiatives in } \\
\text { NPOs and } \\
\text { establish } \\
\text { organizational } \\
\text { outcomes related } \\
\text { to ECB. }\end{array}$ & $\begin{array}{l}\text { Strengths: } \\
\text { Includes } \\
\text { components of } \\
\text { other frameworks } \\
\text { that establish a } \\
\text { robust tool to } \\
\text { measure ECB } \\
\text { progress and } \\
\text { sustainability over } \\
\text { time. } \\
\text { Weaknesses: The } \\
\text { tool does not } \\
\text { include any } \\
\text { metrics to base a } \\
\text { judgment off of } \\
\text { for the } \\
\text { dimensions. It can } \\
\text { still be used to } \\
\text { establish progress } \\
\text { of ECB initiatives } \\
\text { but not } \\
\text { necessarily to } \\
\text { diagnosis areas to } \\
\text { focus on in ECB. }\end{array}$ \\
\hline $\begin{array}{l}\text { Cousins et al.'s } \\
\text { (2014) } \\
\text { Framework }\end{array}$ & $\begin{array}{l}\text { Includes less } \\
\text { emphasis on } \\
\text { establishing } \\
\text { readiness for } \\
\text { ECB, and more on } \\
\text { understanding } \\
\text { organization } \\
\text { context, and } \\
\text { sources of }\end{array}$ & $\begin{array}{l}\text { Includes } \\
\text { increasing both } \\
\text { the capacity to do } \\
\text { and use evaluation } \\
\text { within the } \\
\text { organization. } \\
\text { Does not specify } \\
\text { on establishing a } \\
\text { plan or outcomes }\end{array}$ & $\begin{array}{l}\text { Priority on } \\
\text { establishing } \\
\text { evaluative inquiry } \\
\text { and less on } \\
\text { individual } \\
\text { strategies. }\end{array}$ & $\begin{array}{l}\text { Does not include a } \\
\text { determination on } \\
\text { the role of } \\
\text { evaluator or } \\
\text { champions. }\end{array}$ & $\begin{array}{l}\text { Consider } \\
\text { organizational } \\
\text { learning capacity } \\
\text { to be an outcome } \\
\text { of ECB and } \\
\text { recommend using } \\
\text { the Organizational } \\
\text { Learning Survey. }\end{array}$ & $\begin{array}{l}\text { Strengths: } \\
\text { Emphasizes } \\
\text { establishing a root } \\
\text { of evaluative } \\
\text { inquiry within an } \\
\text { organization, } \\
\text { rather than a full- } \\
\text { fledged ECB plan } \\
\text { which could be }\end{array}$ \\
\hline
\end{tabular}




\begin{tabular}{|c|c|c|c|c|c|c|}
\hline & $\begin{array}{l}\text { evaluation } \\
\text { knowledge within } \\
\text { the organization. }\end{array}$ & $\begin{array}{l}\text { within the } \\
\text { organization. }\end{array}$ & & & $\begin{array}{l}\text { (Goh \& Richards, } \\
\text { 1997) }\end{array}$ & $\begin{array}{l}\text { more realistic for } \\
\text { under-resourced } \\
\text { organizations. } \\
\text { Weaknesses: The } \\
\text { framework is } \\
\text { more of a general } \\
\text { understanding of } \\
\text { components of } \\
\text { ECB but does not } \\
\text { give any } \\
\text { actionable } \\
\text { components for } \\
\text { organizations to } \\
\text { apply. }\end{array}$ \\
\hline $\begin{array}{l}\text { Bourgeois and } \\
\text { Cousins' (2008) } \\
\text { Framework }\end{array}$ & $\begin{array}{l}\text { Promote } \\
\text { understanding } \\
\text { organizational } \\
\text { factors leading to } \\
\text { desire to build } \\
\text { capacity. }\end{array}$ & $\begin{array}{l}\text { Discussed } \\
\text { different types of } \\
\text { ECB: Direct ECB } \\
\text { implies an } \\
\text { intentional effort } \\
\text { to build } \\
\text { evaluation } \\
\text { capacity. While } \\
\text { Indirect ECB, } \\
\text { happens more } \\
\text { organically and } \\
\text { can be a result of } \\
\text { organizations with } \\
\text { a strong learning } \\
\text { culture and } \\
\text { general proximity } \\
\text { to evaluation use. } \\
\text { Establish an } \\
\text { understanding of }\end{array}$ & $\begin{array}{l}\text { Splits evaluation } \\
\text { capacity into } \\
\text { individual } \\
\text { components } \\
\text { within the } \\
\text { organization } \\
\text { based on their } \\
\text { effect to either do } \\
\text { evaluation or use } \\
\text { evaluation. } \\
\text { Gives specific } \\
\text { guidance based on } \\
\text { the area that the } \\
\text { ECB is needed to } \\
\text { support NPOs to } \\
\text { choose a strategy } \\
\text { to apply. }\end{array}$ & $\begin{array}{l}\text { Designed to be } \\
\text { used by either an } \\
\text { external or } \\
\text { internal evaluator. } \\
\text { ECB process can } \\
\text { be participatory - } \\
\text { collaborative } \\
\text { actions of trained } \\
\text { evaluators } \\
\text { working with } \\
\text { program, as this } \\
\text { has been shown to } \\
\text { increase capacity. } \\
\text { Evaluator can also } \\
\text { act as a facilitator } \\
\text { by fostering } \\
\text { organizational } \\
\text { learning and }\end{array}$ & $\begin{array}{l}\text { Established the } \\
\text { organizational } \\
\text { evaluation } \\
\text { capacity self- } \\
\text { assessment, } \\
\text { designed } \\
\text { specifically for } \\
\text { use with under- } \\
\text { resourced NPOs } \\
\text { to guide them } \\
\text { through ECB } \\
\text { initiatives. } \\
\text { Purpose of tool is } \\
\text { to establish the } \\
\text { baseline } \\
\text { diagnostic of } \\
\text { evaluation } \\
\text { capacity within }\end{array}$ & $\begin{array}{l}\text { Strengths: This } \\
\text { framework and } \\
\text { associated tool are } \\
\text { designed to be a } \\
\text { robust tool that } \\
\text { can be used } \\
\text { without the need } \\
\text { for a skilled } \\
\text { evaluator and in } \\
\text { community } \\
\text { organizations. The } \\
\text { tool itself acts as } \\
\text { both a diagnostic } \\
\text { tool and } \\
\text { measurement tool } \\
\text { to guide } \\
\text { establishing an } \\
\text { ECB process and }\end{array}$ \\
\hline
\end{tabular}




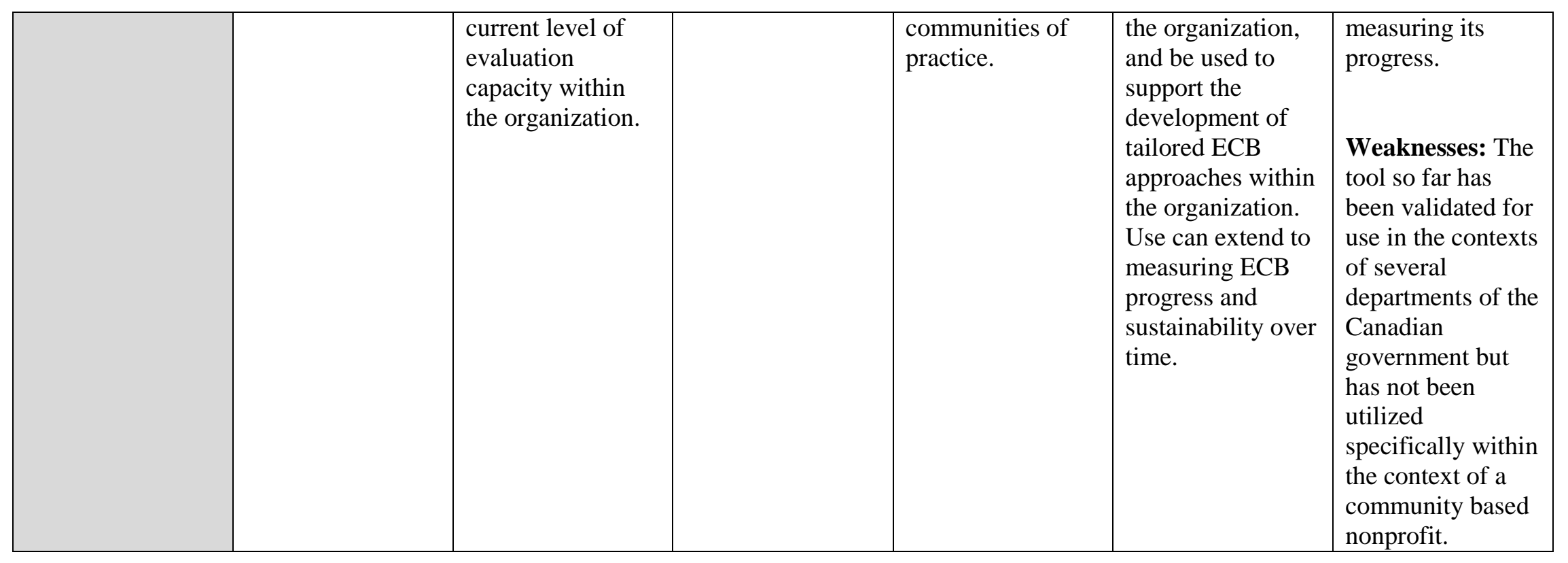


APPENDIX E 
Site Authorization Letter
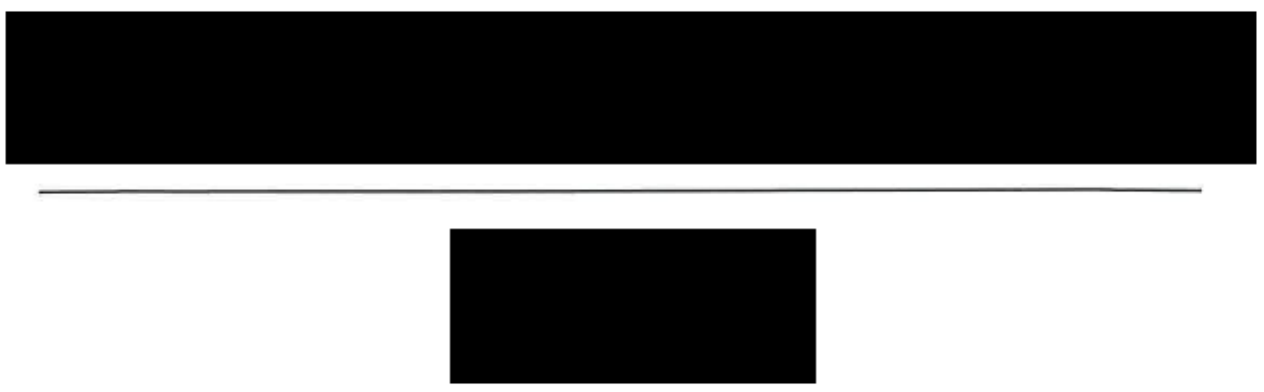

September $15^{\text {th }}, 2018$

Please note that Megan Kennedy, an University, has the permission

graduate student at Boise State

Department for her study, "Using Evaluation Capacity Tools to Build Evaluation Capacity in Nonprofit Organizations."

Ms. Kennedy will contact employees via email invitation to participate in three focus groups. Her plan is to facilitate these focus groups within the months of October and November during normal working hours. Participating in these focus groups can be included into employees normal working routine and eligible under employees existing compensation.

Ms. Kennedy has agreed keep any identifiable information gathered from this research confidential.

If there are any questions, please contact my office.

Signed,

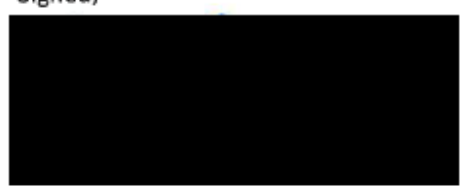


APPENDIX F 


\section{Recruitment Email}

\section{RECRUITMENT EMAIL}

Greetings.

My name is Megan Kennedy

and a student at Boise State University in the Organizational Performance and Workplace Learning program. I am conducting a research study about the ability for nonprofits to effectively evaluate their programs and apply evaluation practices towards performance improvement in their organization. I am emailing to ask before your participation in this study.

Participation will include three focus groups during October and November of this year. Each focus group will last 60-90 minutes. Your involvement in this process is completely voluntary and has been approved by the Senior Programs Director_to take place during normal working hours and

as part of your established compensation. The information shared within the focus groups will be kept confidential. For more information about the study, please see the attached informed consent form.

If you are willing to participate in the study and/or have any questions, please reply to mkennedy@

Thank you for your time.

Megan Kennedy

Graduate student, Boise State University 
APPENDIX G 


\section{Informed Consent}

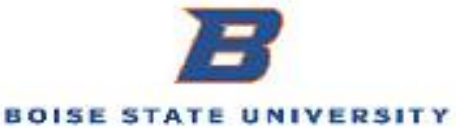

INFORMED CONSENT

Study Title: Using Evaluation Capacity Tools to Build Evaluation Capacity in Nonprofit Organizations Sponsor: Boise State University

Principal Investigator: Megan Kennedy,

Boise State University

Co-principal Investigator: Dr. Yonnie Chyung, Thesis Advisor, Boise State University

This consent form will give you the information you will need to understand why this research study is being done and why you are being invited to participate. It will also describe what you will need to do to participate as well as any known risks, inconveniences or discomforts that you may have while participating. I encourage you to ask questions at any time. If you decide to participate, you will be asked to sign this form and it will be a record of your agreement to participate. You will be given a copy of this form to keep.

\section{PURPOSE AND BACKGROUND}

The goal of this research is to understand the experience building evaluation capacity within a nonprofit organization. You are invited to participate in a research study to provide feedback on experience with building their evaluation capacity. Additionally, this research is being used as my master's thesis to be completed at Boise State University.

\section{PROCEDURES}

I will invite a total of six key stakeholders, including you, to participate in focus groups, which will be facilitated by me. This research has been granted approval by the Senior Programs Director to take place as part of your normal working hours and routine.

If you agree to be in the study, you will be asked to participate in three focus groups in October and November of 2018. Each focus group will last between $60-90$ minutes. All three focus groups will take place in the conference room at

- The first focus group will include using the Organization Capacity Self-Assessment developed by Bourgeois and Cousins (2008) to identify areas of evaluation capacity that may be weaker in.

- The second focus group will be used to interpret the results of the assessment and plan strategies to increase the evaluation capacity within the organization.

- The third focus group will be used to debrief the process of assessing evaluation capacity within the organization and developing an evaluation capacity building plan.

\section{RISKS}

Some of the questions asked during the focus groups may make you uncomfortable or upset. You are always free to decline to answer any question or to stop your participation at any time. 
Should you feel discomfort after participating you are welcome to withdraw from the research at any time with no repercussions.

\section{$>$ BENEFITS}

There will be no direct benefit to you from participating in this study. However, the information that you provide may help increase the ability for you to engage in performance improvement practices and better understand the programs you manage.

\section{$>$ EXTENT OF CONFIDENTIALITY}

Reasonable efforts will be made to keep the personal information in your research record private and confidential. Any identifiable information obtained in connection with this study will remain confidential and will be disclosed only with your permission or as required by law. Only the investigators, participants in the study, and the Boise State University Office of Research Compliance $(\mathrm{ORC})$ may access the data. The $\mathrm{ORC}$ monitors research studies to protect the rights and welfare of research participants.

The organization name reports or publications which result from this research. Data will be kept for three years (per federal regulations) after the study is complete and then destroyed.

\section{PAYMENT/COMPENSATION}

There is no payment or compensation provided exclusively for participating in this study. However, if you choose to participate you will be compensated by $\quad$ as part of your typical job duties.

\section{PARTICIPATION IS VOLUNTARY}

You do not have to be in this study if you do not want to. If you volunteer to be in this study, you may withdraw from it at any time without consequences of any kind or loss of benefits to which you are otherwise entitled.

\section{$>$ QUESTIONS}

If you have any questions or concerns about your participation in this study, you should first contact the principal investigator at mkennedy@ or (208) 891

If you have questions about your rights as a research participant, you may contact the Boise State University Institutional Review Board (IRB), which is concerned with the protection of volunteers in research projects. You may reach the board office between 8:00 AM and 5:00 PM, Monday through Friday, by calling (208) 426-5401 or by writing: Institutional Review Board, Office of Research Compliance, Boise State University, 1910 University Dr., Boise, ID 83725-1138.

If you have any questions or concerns about your participation in this study, you should first contact the principal investigator at mkennedy@ _ or (208) 891- You may also contact the co-principal investigator at ychyung@boisestate.edu or (208) 426-3091. 


\section{DOCUMENTATION OF CONSENT}

I have read this form and decided that I will participate in the project described above. Its general purposes, the particulars of involvement and possible risks have been explained to my satisfaction. I understand I can withdraw at any time. I have received a copy of this form.

Printed Name of Study Participant

Signature of Study Participant

Date

Signature of Person Obtaining Consent

Date

Approved IRB Protocol Number: $\quad$ 126-SB18-203

Page 3 of 3 
APPENDIX H 


\section{Focus Group Script}

\section{First Focus Group Script}

Investigator will collect consent forms.

Welcome and thank you for participating in this focus group. The goal of this research is to understand the experience of using this assessment as a tool to establish an ECB plan within an organization. This research could inform other similar organizations on how this tool can be used within their contexts to build their internal evaluation capacity as well.

The purpose of this focus group is to get your feedback on the organization's current ability to evaluate our programs. To do this, we will work together to complete the Organizational Capacity Self-Assessment tool developed by Bourgeois and Cousins (2008).

From the results of this assessment, we will identify areas of evaluation within the organization that could use improvement. A subsequent focus group will be facilitated to review the results of the assessment and establish strategies to build the organization's evaluation capacity.

A concluding focus group will take place to debrief to process and discuss barriers and facilitators to establishing an evaluation capacity building plan.

Each focus groups will last between sixty and ninety minutes each and will be recorded to make sure that it is reflected accurately.

We'd like to remind you that to protect the privacy of focus group members, all transcripts will be coded with pseudonyms and we ask that you not discuss what is 
discussed in the focus group with anyone else. Do you have any questions for us before we begin?

*As a group, complete the organizational capacity self-assessment tool.

Investigator will facilitate discussion on the questions presented in the assessment to reach consensus prior to recording a response in the tool.* 


\section{$\underline{\text { Second Focus Group Script }}$}

As a reminder, the goal of this research is to understand the experience of using this assessment as a tool to establish an ECB plan within an organization.

We would like to remind you that to protect the privacy of focus group members, all transcripts will be coded with pseudonyms and we ask that you not discuss what is discussed in the focus group with anyone else.

Today's focus groups will last between sixty and ninety minutes each and will be recorded to make sure that it is reflected accurately.

We would like to remind you that to protect the privacy of focus group members, all transcripts will be coded with pseudonyms and we ask that you not discuss what is discussed in the focus group with anyone else.

Do you have any questions for us before we begin?

Today we will review the results of the organizational capacity self-assessment that we completed during the last focus group. As we review this assessment, we will identify the areas of strengths and weaknesses within the organization in relation to evaluation capacity.

Some examples of questions asked are:

- Do you agree with the score assigned based on your assessment responses?

- Do you agree with the assumptions the assessment determined about the evaluation capacity within the organization?

- What differences or similarities do you see within the organization and the assumptions listed? 
- Is this strategy something that you feel would be within the organizations resources to execute?

- Do you think this strategy would be effective within the organization? Why or why not?

- Do you think this strategy would be effective in increasing the organizations evaluation capacity? 


\section{Third Focus Group Script}

As a reminder, the goal of this research is to understand the experience of using this assessment as a tool to establish an ECB plan within an organization.

Today's focus groups will last between sixty and ninety minutes each and will be recorded to make sure that it is reflected accurately.

We would like to remind you that to protect the privacy of focus group members, all transcripts will be coded with pseudonyms and we ask that you not discuss what is discussed in the focus group with anyone else.

Do you have any questions for us before we begin?

During this focus group we will debrief the experience of completing the Organizational Capacity Self-Assessment and using it to guide an ECB plan.

Some examples of questions asked:

- Was the instrument easy to interpret what was being requested and the terminology used was understandable?

- Were the results provided by the instrument easy to interpret with terminology that was understandable?

- What areas in either completing the instrument or interpreting the results were barriers?

- What areas were positive?

- Did completing the tool and reviewing the results provide information that could be readily used to establish a plan to build evaluation capacity?

- Was the process of identifying strategies easy to complete?

- Did the whole process seem to provide useful results to the organization? 
- Does the organization intend to follow through on the strategies and plan identified to build their evaluation capacity?

- What about the experience might the organization have changed? 
APPENDIX I 


\section{Organizational Evaluation Capacity Self-Assessment Results}

Provided from Bourgeois, I. Organizational Evaluation Capacity Self-Assessment found at:

https://docs.google.com/forms/d/e/1FAIpQLScCfLhEBBC_jtoSUmVV_31zslU8Y5rByx U1nmtcEJvYv0BzUA/viewform 


\section{Organizational Evaluation Capacity Self-Assessment}

\section{Results Report}

This report outlines the average scores obtained for the various components of evaluation capacity assessed and provides basic interpretation data based on previous empirical research. Each description may not completely represent your organization; the descriptions are meant to highlight typical organizations at each capacity level.

The scale below was used to identify your organization's capacity level for each sub-dimension:

\begin{tabular}{|c|c|}
\hline Capacity Level & Average Score Ranges \\
\hline Low Capacity & 1.00 to 1.75 \\
\hline Developing Capacity & 1.76 to 2.50 \\
\hline Intermediate Capacity & 2.51 to 3.25 \\
\hline Established Capacity & 3.26 to 4.00 \\
\hline
\end{tabular}

\section{Overview of Results}

The chart below identifies the capacity levels achieved for each for the main sections of the self-assessment instrument.

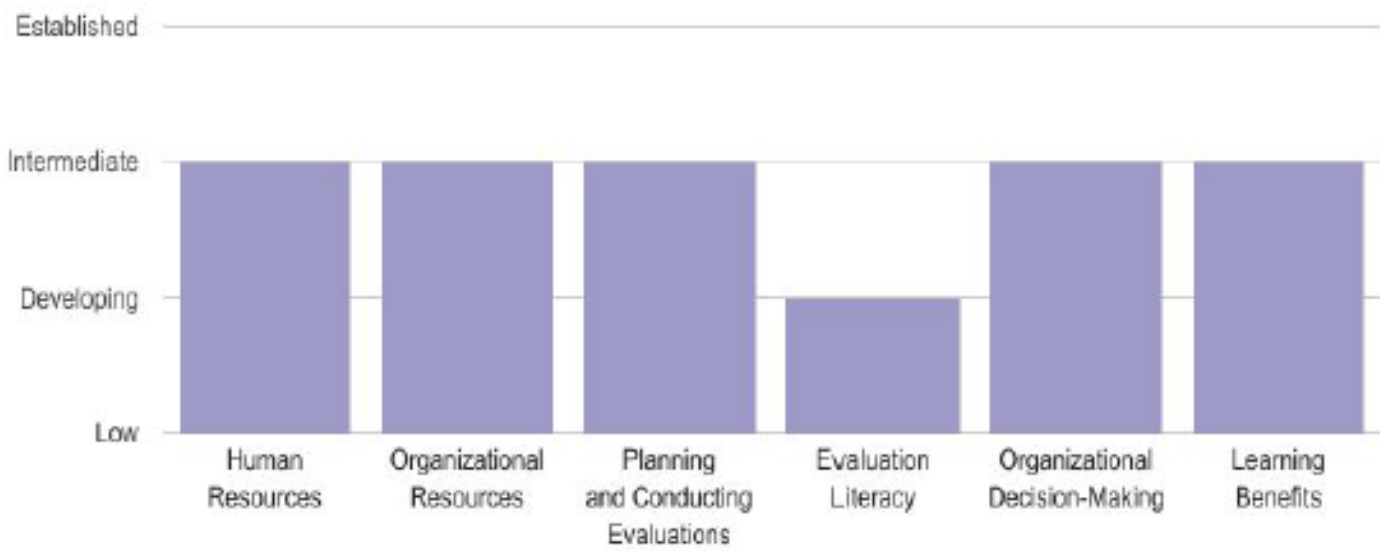




\section{Detailed Findings}

The following sections identify the average scores for each section of the self-assessment instrument ${ }^{1}$. These scores are then linked to capacity levels and interpreted in generic terms.

\section{Organizational Capacity to Do Evaluation}

The following components refer to an organization's capacity to conduct quality evaluations. They focus on the availability of qualified personnel, their technical and interpersonal skills, as well as the professional development available to continue to develop those skills. They also focus on how the evaluation unit or function is managed, since this also has a significant impact on an organization's capacity to do evaluation.

\section{Human Resources}

\begin{tabular}{|l|l|l|l|l|l|}
\hline & $\begin{array}{l}1.1 \\
\text { Staffing }\end{array}$ & $\begin{array}{l}1.2 \\
\text { Technical } \\
\text { Skills }\end{array}$ & $\begin{array}{l}1.3 \\
\text { Communicat } \\
\text { ion Skills }\end{array}$ & $\begin{array}{l}1.4 \\
\text { Professional } \\
\text { Development }\end{array}$ & $\begin{array}{l}1.5 \\
\text { Leadership }\end{array}$ \\
\hline $\begin{array}{l}\text { Average score } \\
\text { for each } \\
\text { subdimension }\end{array}$ & 2.83 & 3.06 & 3.06 & 2.63 & 2.42 \\
\hline $\begin{array}{l}\text { Average score } \\
\text { for dimension }\end{array}$ & \multicolumn{5}{|c|}{2.80 (Intermediate capacity: 2.51-3.25) } \\
\hline
\end{tabular}

Interpretation Information for Human Resources

\begin{tabular}{|l|l|l|}
\multicolumn{1}{|c|}{ Component } & \multicolumn{2}{c|}{ Capacity Level } \\
\hline 1.1 Staffing & $\begin{array}{l}\text { Intermediate } \\
\text { Capacity }\end{array}$ & $\begin{array}{l}\text { The evaluation unit or function is generally able to meet } \\
\text { its project requirements through its existing staffing } \\
\text { structure } \\
\text { i A career progression process is available for some } \\
\text { levels of evaluation professionals wishing to gain } \\
\text { experience and is part of the unit's succession planning }\end{array}$ \\
\hline 1.2 Technical Skills & $\begin{array}{c}\text { Intermediate } \\
\text { Capacity }\end{array}$ & $\begin{array}{l}\text { Evaluation methods and approaches respect accepted } \\
\text { standards and yield defensible findings } \\
\text { Evaluation reports are generally sound } \\
\text { Evaluation projects are fairly well-managed and } \\
\text { problems are usually identified and resolved }\end{array}$ \\
\hline
\end{tabular}

${ }^{1}$ An "N/A" rating for an item excludes it from the calculation of the average for that section of the instrument. An "N/A" rating for ALL of the items found within a section of the instrument excludes that section completely. Therefore, any "N/A" selections will not influence the capacity level calculation shown in this report. 


\begin{tabular}{|c|c|c|}
\hline $\begin{array}{l}\text { 1.3 Communication } \\
\text { Skills }\end{array}$ & $\begin{array}{l}\text { Intermediate } \\
\text { Capacity }\end{array}$ & $\begin{array}{l}\text { Evaluation unit is committed to building and maintaining } \\
\text { client trust } \\
\text { messages } \\
\text { Evaluation reports and other products deliver clear } \\
\text { to any conflicts of interest are identified at the outset of } \\
\text { each project }\end{array}$ \\
\hline $\begin{array}{l}\text { 1.4 Professional } \\
\text { Development }\end{array}$ & $\begin{array}{l}\text { Intermediate } \\
\text { Capacity }\end{array}$ & $\begin{array}{l}\text { - Most team members have personalized learning plans } \\
\text { professional development activities directly related to their } \\
\text { work (i.e., conferences, mentoring) } \\
\text { + Skill sets among staff are assessed fairly regularly and } \\
\text { various options concerning learning activities are discussed }\end{array}$ \\
\hline 1.5 Leadership & $\begin{array}{l}\text { Developing } \\
\text { Capacity }\end{array}$ & $\begin{array}{l}\text { - Unit headed by individual who is new to the area of } \\
\text { evaluation and/or has limited management experience } \\
\text { - Leader is not generally involved in senior management } \\
\text { discussions and therefore assigns work based only on } \\
\text { operational requirements } \\
\text { guiding team members in their work }\end{array}$ \\
\hline
\end{tabular}

\section{Organizational Resources}

\begin{tabular}{|l|c|c|c|}
\hline & 2.1 Budget & $\begin{array}{l}\text { 2.2 Performance } \\
\text { measurement data }\end{array}$ & $\begin{array}{l}\text { 2.3 Infrastructure } \\
\text { and tools }\end{array}$ \\
\hline $\begin{array}{l}\text { Average } \\
\text { score for } \\
\text { each } \\
\text { subdimension }\end{array}$ & 2.79 & 2.50 & 2.72 \\
\hline $\begin{array}{l}\text { Average } \\
\text { score for } \\
\text { dimension }\end{array}$ & \multicolumn{2}{|c|}{2.67 (Intermediate capacity: 2.51-3.25) } \\
\hline
\end{tabular}

Interpretation Information for Organizational Resources

\begin{tabular}{|l|l|l|}
\hline \multicolumn{1}{|c|}{ Component } & Capacity Level & \multicolumn{1}{c|}{ Interpretation } \\
\hline 2.1 Budget & $\begin{array}{c}\text { Intermediate } \\
\text { Capacity }\end{array}$ & $\begin{array}{l}\text { Evaluation budget is stable but shared with some other } \\
\text { corporate groups (i.e., policy or audit) } \\
\text { New program/initiative financing sometimes includes } \\
\text { cost of evaluation }\end{array}$ \\
\hline $\begin{array}{l}\text { 2.2 Performance } \\
\text { Measurement Data }\end{array}$ & $\begin{array}{l}\text { Developing } \\
\text { Capacity }\end{array}$ & $\begin{array}{l}\text { Performance measurement is done on a } \\
\text { program-by-program basis } \\
\text { udd hoc implementation of performance measures, with } \\
\text { inerformance data is difficult to integrate into }\end{array}$ \\
\hline
\end{tabular}




\begin{tabular}{|l|l|l|}
\hline & & results-based management (including evaluation studies) \\
\hline 2.3 Infrastructure and & $\begin{array}{l}\text { Intermediate } \\
\text { Capacity } \\
\text { Tools }\end{array}$ & $\begin{array}{l}\text { Organizational infrastructure showing some maturity } \\
\text { of evaluation) } \\
\text { Evaluators have most of the tools and services needed } \\
\text { to produce timely and useful evaluations } \\
\text { A quality assurance process is in place and covers } \\
\text { most of the evaluation activities within the organization }\end{array}$ \\
\hline
\end{tabular}

\section{Planning and Conducting Evaluations}

\begin{tabular}{|l|l|l|l|l|l|}
\hline & $\begin{array}{l}3.1 \\
\text { Planning }\end{array}$ & $\begin{array}{l}3.2 \text { Internal } \\
\text { and } \\
\text { external } \\
\text { evaluators }\end{array}$ & $\begin{array}{l}3.3 \\
\text { Information } \\
\text { and support }\end{array}$ & $\begin{array}{l}3.4 \\
\text { Organization } \\
\text { al linkages }\end{array}$ & $\begin{array}{l}3.5 \\
\text { External } \\
\text { support }\end{array}$ \\
\hline $\begin{array}{l}\text { Average score } \\
\text { for each } \\
\text { subdimension }\end{array}$ & 3.00 & 3.00 & 2.81 & 2.46 & 2.46 \\
\hline $\begin{array}{l}\text { Average score } \\
\text { for dimension }\end{array}$ & \multicolumn{5}{|c|}{2.75 (Intermediate capacity: 2.51-3.25) } \\
\hline
\end{tabular}

Interpretation Information for Planning and Conducting Evaluations

\begin{tabular}{|c|c|c|}
\hline Component & Capacity Level & Interpretation \\
\hline 3.1 Planning & $\begin{array}{l}\text { Intermediate } \\
\text { Capacity }\end{array}$ & $\begin{array}{l}\text { Evaluation plan follows a five-year cycle and is updated } \\
\text { annually } \\
\text { Evaluation plan developed in consultation with most } \\
\text { senior managers } \\
\text { project completion } \\
\text { provisions made for reviewing the plan on an ongoing } \\
\text { basis }\end{array}$ \\
\hline $\begin{array}{l}3.2 \text { Internal and } \\
\text { External Evaluators }\end{array}$ & $\begin{array}{l}\text { Intermediate } \\
\text { Capacity }\end{array}$ & $\begin{array}{l}\text { Evaluation staff involved in conducting the evaluation } \\
\text { (i.e., contribute to some of the field work done by } \\
\text { consultants) } \\
\text { evaluation staff }\end{array}$ \\
\hline $\begin{array}{l}3.3 \text { Information and } \\
\text { Support }\end{array}$ & $\begin{array}{l}\text { Intermediate } \\
\text { Capacity }\end{array}$ & $\begin{array}{l}\text { Evaluation resources sometimes contribute to other } \\
\text { knowledge generation activities in the organization } \\
\text { Evaluators are generally aware of new developments in } \\
\text { policy and strategic planning } \\
\text { Evaluators try to maintain contact with program } \\
\text { managers to stay aware of any new developments }\end{array}$ \\
\hline $\begin{array}{l}3.4 \text { Organizational } \\
\text { Linkages }\end{array}$ & $\begin{array}{l}\text { Developing } \\
\text { Capacity }\end{array}$ & $\begin{array}{l}\text { Evaluation steering or advisory committees are } \\
\text { sometimes used to guide projects }\end{array}$ \\
\hline
\end{tabular}




\begin{tabular}{|l|l|l|}
\hline & & $\begin{array}{l}\text { Senior managers are made aware of evaluation } \\
\text { findings only through formal requirements (e.g., internal } \\
\text { evaluation committee) } \\
\text { Evaluation unit is removed (either physically or } \\
\text { structurally) from key organizational areas such as policy } \\
\text { development, strategic planning and performance } \\
\text { measurement }\end{array}$ \\
\hline 3.5 External Support & $\begin{array}{c}\text { Developing } \\
\text { Capacity }\end{array}$ & $\begin{array}{l}\text { Evaluators have access to basic external supports, } \\
\text { such as a professional association or published quality } \\
\text { standards but do not often make use of them } \\
\text { Evaluators do not generally liaise with external } \\
\text { organizations or experts }\end{array}$ \\
\hline
\end{tabular}

\section{Organizational Capacity to Use Evaluation}

These components refer to an organization's broader capacity to access and use evaluation findings and reports in order to inform strategic decisions pertaining to resource allocation and program improvements. Evaluation literacy refers to the general level of knowledge in the organization regarding evaluation and results-based management; organizational decision-making looks at the extent to which evaluations are used by senior managers; and finally, learning benefits consider some of the most common uses of the evaluation, including process use which extends to the entire organization.

\section{Evaluation Literacy}

\begin{tabular}{|l|c|c|}
\hline & 4.1 Stakeholder involvement & $\begin{array}{l}\text { 4.2 Results-management } \\
\text { orientation }\end{array}$ \\
\hline $\begin{array}{l}\text { Average } \\
\text { score for } \\
\text { each } \\
\text { subdimension }\end{array}$ & 2.68 & 2.24 \\
\hline $\begin{array}{l}\text { Average } \\
\text { score for } \\
\text { dimension }\end{array}$ & \multicolumn{2}{|c|}{2.46 (Developing capacity: 1.76-2.50) } \\
\hline
\end{tabular}

Interpretation Information for Evaluation Literacy

\begin{tabular}{|c|c|c|}
\hline Component & Capacity Level & Interpretation \\
\hline $\begin{array}{l}4.1 \text { Stakeholder } \\
\text { Involvement }\end{array}$ & $\begin{array}{l}\text { Intermediate } \\
\text { Capacity }\end{array}$ & $\begin{array}{l}\text { Organizational staff members are familiar with the } \\
\text { general principles of evaluation and how it can help them in } \\
\text { their work (e.g., they understand the difference between } \\
\text { evaluation and audit) } \\
\text { (e.g., sit on Evaluation Steering or Advisory Committees) } \\
\text { and provide program-related feedback on report drafts }\end{array}$ \\
\hline $\begin{array}{l}4.2 \\
\text { Results-Management }\end{array}$ & $\begin{array}{l}\text { Developing } \\
\text { Capacity }\end{array}$ & $\begin{array}{l}\text { - Organizational outcomes or expected results are not } \\
\text { articulated clearly for all organizational members; most are }\end{array}$ \\
\hline
\end{tabular}




\begin{tabular}{|l|l|l|}
\hline Orientation & $\begin{array}{l}\text { not aware of results-based management principles and } \\
\text { practices } \\
\text { Some programs are engaged in developing results } \\
\text { chains such as logic models or theories of change }\end{array}$ \\
\hline
\end{tabular}

\section{Organizational Decision-Making}

\begin{tabular}{|l|c|c|}
\hline & 5.1 Management processes & 5.2 Decision support \\
\hline $\begin{array}{l}\text { Average } \\
\text { score for } \\
\text { each } \\
\text { component }\end{array}$ & 3.00 & 2.74 \\
\hline $\begin{array}{l}\text { Average } \\
\text { score for } \\
\text { dimension }\end{array}$ & 2.87 (Intermediate capacity: 2.51-3.25) \\
\hline
\end{tabular}

Interpretation Information for Organizational Decision-Making

\begin{tabular}{|c|c|c|}
\hline Component & Capacity Level & Interpretation \\
\hline $\begin{array}{l}5.1 \text { Management } \\
\text { Processes }\end{array}$ & $\begin{array}{l}\text { Intermediate } \\
\text { Capacity }\end{array}$ & $\begin{array}{l}\text { Program and policy staff are aware of the evaluation } \\
\text { services that can be provided and sometimes contact } \\
\text { evaluation staff for advice }\end{array}$ \\
\hline 5.2 Decision Support & $\begin{array}{l}\text { Intermediate } \\
\text { Capacity }\end{array}$ & $\begin{array}{l}\text { Evaluation findings and recommendations usually } \\
\text { considered in program management decisions and some } \\
\text { policy decisions } \\
\text { as a management support tool (i.e., evaluation as provider } \\
\text { of ongoing management information) }\end{array}$ \\
\hline
\end{tabular}

\section{Learning Benefits}

\begin{tabular}{|l|c|c|}
\hline & $\begin{array}{l}6.1 \text { Instrumental and conceptual } \\
\text { use }\end{array}$ & 6.2 Process use \\
\hline $\begin{array}{l}\text { Average } \\
\text { score for } \\
\text { each } \\
\text { component }\end{array}$ & 2.86 & 2.79 \\
\hline $\begin{array}{l}\text { Average } \\
\text { score for } \\
\text { dimension }\end{array}$ & 2.83 (Intermediate capacity: 2.51-3.25) \\
\hline
\end{tabular}

Interpretation Information for Learning Benefits

\begin{tabular}{|l|c|l|}
\hline \multicolumn{1}{|c|}{ Component } & \multicolumn{1}{c|}{ Interpretation } \\
\hline $\begin{array}{l}\text { 6.1 Instrumental and } \\
\text { Conceptual Use }\end{array}$ & $\begin{array}{c}\text { Intermediate } \\
\text { Capacity }\end{array}$ & $\begin{array}{l}\text { Evaluation findings are sometimes used as a basis for } \\
\text { action and change (i.e., evaluation recommendations are } \\
\text { sometimes implemented) }\end{array}$ \\
\hline
\end{tabular}




\begin{tabular}{|l|l|l|}
\hline & & $\begin{array}{l}\text { + Evaluation findings and reports can have an impact on } \\
\text { stakeholders' understanding and attitudes about programs }\end{array}$ \\
\hline 6.2 Process Use & $\begin{array}{l}\text { - Some evidence of behavioural or cognitive changes } \\
\text { occurring in stakeholders by virtue of their proximity to } \\
\text { evaluation } \\
\text { Evidence that organizational members sometimes } \\
\text { apply evaluation logic to other organizational issues (e.g., } \\
\text { by using an inquiry-based process to identify organizational } \\
\text { issues and their solutions) } \\
\text { Capsons learned through evaluations are shared with } \\
\text { organizational members directly involved with the program } \\
\text { (e.g., memos, formal presentation of report) }\end{array}$ \\
\hline
\end{tabular}

\section{What's Next? Developing your organization's ECB strategy}

Now that you have a better sense of where your organization needs to focus to continue to build its evaluation capacity, an intentional, detailed strategy is in order. The potential strategies below were identified in literature reviews and empirical studies of ECB and provide some ideas of what to do next. These are suggestions and should be selected and adapted based on organizational context and need.

\begin{tabular}{|c|c|}
\hline Component & Potential Strategies \\
\hline \multicolumn{2}{|l|}{ Human Resources } \\
\hline 1.1 Staffing & $\begin{array}{l}\text { - Identify any missing or unstaffed positions in the evaluation unit; seek } \\
\text { budgetary and organizational resources to fill them } \\
\text { - Identify any clear inefficiencies in how evaluation work is distributed } \\
\text { within the evaluation team and try to resolve them } \\
\text { - Develop a succession plan to ensure that any potential turnover does } \\
\text { not hinder the progress of planned and ongoing evaluation work; this } \\
\text { plan should also leverage organizational resources to promote } \\
\text { evaluation staff along a predetermined career path }\end{array}$ \\
\hline 1.2 Technical Skills & $\begin{array}{l}\text { - Assess current technical skills of existing staff; consider qualitative and } \\
\text { quantitative data collection and analysis competencies and identify } \\
\text { potential gaps at team level } \\
\text { - Identify opportunities for training or recruitment of individuals who have } \\
\text { the missing competencies to complete the skill set of the team } \\
\text { - Develop a "community of practice" made up of evaluators and analysts } \\
\text { in order to foster shared leaming of technical aspects of evaluation }\end{array}$ \\
\hline $\begin{array}{l}1.3 \text { Communications } \\
\text { Skills }\end{array}$ & $\begin{array}{l}\text { - Assess current communications and interpersonal skills; consider } \\
\text { various ways to help staff acquire the desired competencies, such as } \\
\text { mentoring or experience-based learning } \\
\text { - Identify opportunities for more formal training or recruitment of } \\
\text { individuals who have the missing competencies to complete the skill set } \\
\text { of the team } \\
\text { - Arrange meetings with program managers to describe and explain the } \\
\text { evaluation process prior to starting any evaluation work with them }\end{array}$ \\
\hline
\end{tabular}




\begin{tabular}{|c|c|}
\hline & $\begin{array}{l}\text { - Encourage systematic reviews of draft evaluation reports to ensure } \\
\text { clarity and to improve individual writing skills }\end{array}$ \\
\hline $\begin{array}{l}\text { 1.4 Professional } \\
\text { Development }\end{array}$ & $\begin{array}{l}\text { - Develop individual learning plans for team members that support their } \\
\text { professional development related to evaluation } \\
\text { - Assess skill development and staff performance on an annual basis to } \\
\text { help them identify learning objectives and strategies } \\
\text { - Offer a variety of in-house professional development opportunities (e.g., } \\
\text { assignments in program units, brown bag lunch sessions, research } \\
\text { projects) }\end{array}$ \\
\hline 1.5 Leadership & $\begin{array}{l}\text { - Assess the evaluation team leader's comfort level and knowledge of } \\
\text { evaluation and management practices and offer professional } \\
\text { development opportunities if needed } \\
\text { - Support the development of formal ties between the evaluation team } \\
\text { leader and senior managers }\end{array}$ \\
\hline \multicolumn{2}{|l|}{ Organizational Resources } \\
\hline 2.1 Budget & $\begin{array}{l}\text { - Develop a budget for the evaluation unit that includes resources for } \\
\text { professional development, tools and infrastructure, as well as for the } \\
\text { implementation of evaluation projects } \\
\text { - Seek any additional resources from senior managers on an annual basis } \\
\text { in order to ensure the stability of the evaluation function }\end{array}$ \\
\hline $\begin{array}{l}\text { 2.2 Performance } \\
\text { Measurement Data }\end{array}$ & $\begin{array}{l}\text { - Work with program managers on results chains and ongoing } \\
\text { performance data collection, to ensure the availability and quality of data } \\
\text { to be included in future evaluations } \\
\text { - Invest in an organization-wide performance data collection system } \\
\text { - Conduct evaluability assessments to confirm the availability and quality } \\
\text { of administrative and performance data before planning an evaluation } \\
\text { and identify any gaps/issues to be resolved before the evaluation starts }\end{array}$ \\
\hline $\begin{array}{l}2.3 \text { Infrastructure and } \\
\text { Tools }\end{array}$ & $\begin{array}{l}\text { - Develop an organization-wide evaluation policy that outlines clear roles, } \\
\text { responsibilities, and procedures for evaluators, program managers and } \\
\text { senior management } \\
\text { - Invest in any required software or other tools for data collection and } \\
\text { analysis } \\
\text { - Implement a quality-assurance process within the evaluation team to } \\
\text { ensure that data collection, analysis and reporting meets organizational } \\
\text { and professional standards }\end{array}$ \\
\hline \multicolumn{2}{|c|}{ Evaluation Planning and Conducting } \\
\hline 3.1 Planning & $\begin{array}{l}\text { - Develop a multi-year, organizational evaluation plan through } \\
\text { consultations with managers and senior executives to ensure that the } \\
\text { evaluations to be conducted will meet their needs and be conducted at } \\
\text { the right time }\end{array}$ \\
\hline $\begin{array}{l}3.2 \text { Internal and External } \\
\text { Evaluators }\end{array}$ & $\begin{array}{l}\text { - Ensure that internal evaluators are able to develop their skills and gain } \\
\text { experience in conducting evaluations; this can be done through in-house } \\
\text { evaluation projects or by collaborating with external evaluators on } \\
\text { specific components of an evaluation }\end{array}$ \\
\hline $\begin{array}{l}3.3 \text { Information and } \\
\text { Support }\end{array}$ & $\begin{array}{l}\text { - Task evaluation team members with continuous intelligence-gathering } \\
\text { activities in specific organizational sectors, to ensure that evaluation }\end{array}$ \\
\hline
\end{tabular}




\begin{tabular}{|c|c|}
\hline & $\begin{array}{l}\text { plans can be adapted to emerging needs if needed } \\
\text { Identify ways in which evaluation resources can support other functions } \\
\text { within the organization (e.g., policy, planning) and establish linkages with } \\
\text { these groups }\end{array}$ \\
\hline $\begin{array}{l}3.4 \text { Organizational } \\
\text { Linkages }\end{array}$ & $\begin{array}{l}\text { - Set up steering or advisory committees made up of program } \\
\text { representatives, external evaluators and other experts at the outset of } \\
\text { each evaluation } \\
\text { - Establish a formal path for evaluation to reach senior management } \\
\text { - Coordinate efforts with other organizational groups to avoid duplication }\end{array}$ \\
\hline 3.5 External Support & $\begin{array}{l}\text { - Develop a network of external support in academia and other similar } \\
\text { organizations that can be drawn upon to resolve evaluation problems or } \\
\text { to access information about evaluation }\end{array}$ \\
\hline \multicolumn{2}{|l|}{ Evaluation Literacy } \\
\hline $\begin{array}{l}\text { 4.1 Stakeholder } \\
\text { Involvement }\end{array}$ & $\begin{array}{l}\text { - Ask for a timeslot during program manager or program staff meetings to } \\
\text { provide general information about evaluation, even when an evaluation } \\
\text { is not currently ongoing } \\
\text { - Prepare "Evaluation } 101^{*} \text { documentation that can be accessed on the } \\
\text { organization's intranet site or distributed to staff members } \\
\text { - Encourage program managers and staff to join evaluation steering } \\
\text { committees to leam and provide input } \\
\text { - Engage program managers and staff in data collection and analysis } \\
\text { activities; consider holding analysis workshops that involve } \\
\text { organizational staff } \\
\text { - Invite feedback on evaluation report drafts; negotiate evaluation } \\
\text { recommendations with key stakeholders }\end{array}$ \\
\hline $\begin{array}{l}4.2 \\
\text { Results-Management } \\
\text { Orientation }\end{array}$ & $\begin{array}{l}\text { - Develop logic models or results chains for programs or groups of } \\
\text { programs in conjunction with key stakeholders } \\
\text { - Ask senior management to provide time and resources to program } \\
\text { managers for results-based management presentations and discussions }\end{array}$ \\
\hline \multicolumn{2}{|c|}{ Organizational Decision-Making } \\
\hline $\begin{array}{l}5.1 \text { Management } \\
\text { Processes }\end{array}$ & $\begin{array}{l}\text { - Integrate evaluation managers or staff into management processes such } \\
\text { as budget reallocation meetings, program development activities, } \\
\text { funding requests } \\
\text { - Provide ongoing evaluation and performance measurement advice to } \\
\text { programs through open consultations or individual meetings with } \\
\text { program managers } \\
\text { - Identify "evaluation champions" amongst senior executives who will } \\
\text { ensure the integration of evaluation data into organizational processes }\end{array}$ \\
\hline 5.2 Decision Support & $\begin{array}{l}\text { - Provide training to senior executives and program managers on } \\
\text { evaluation and how it can support decision-making within the } \\
\text { organization } \\
\text { - Provide evaluation data and findings in various formats to support } \\
\text { decision-making and create a future demand for evaluation }\end{array}$ \\
\hline \multicolumn{2}{|l|}{ Learning Benefits } \\
\hline $\begin{array}{l}6.1 \text { Instrumental and } \\
\text { Conceptual Use }\end{array}$ & $\begin{array}{l}\text { - Develop a recommendation action plan for managers and follow up } \\
\text { periodically to monitor recommendation implementation }\end{array}$ \\
\hline
\end{tabular}




\begin{tabular}{|l|l|}
\hline & $\begin{array}{l}\text { - Identify lessons learned in evaluation reports and present them to } \\
\text { program managers }\end{array}$ \\
& $\begin{array}{l}\text { - Provide training to program managers in evaluation so that they better } \\
\text { understand the findings, how they were derived and how to turn } \\
\text { recommendations into actions }\end{array}$ \\
\hline Develop a dissemination pathway for evaluation reports, both internally \\
and externally
\end{tabular}


APPENDIX J 


\section{Summary of Organizational Evaluation Capacity Self-Assessment Results}

Table 12. Summary of Organizational Evaluation Capacity Self-Assessment Results

\begin{tabular}{|c|c|c|c|c|c|c|}
\hline \multirow[b]{2}{*}{ Item } & \multirow[b]{2}{*}{$\begin{array}{l}\text { Average } \\
\text { Score }\end{array}$} & \multicolumn{5}{|c|}{ Percent } \\
\hline & & 1 & 2 & 3 & 4 & $\begin{array}{l}\text { NA or } \\
\text { Don't } \\
\text { Know }\end{array}$ \\
\hline Dimension 1. Human Resources & 2.8 & $7 \%$ & $11 \%$ & $76 \%$ & $5 \%$ & $1 \%$ \\
\hline 1.1 Human Resources - Staffing & 2.83 & $0 \%$ & $0 \%$ & $83 \%$ & $17 \%$ & $0 \%$ \\
\hline $\begin{array}{l}\text { 1. Employee retention initiatives and/or policies (e.g. clear career path, internal } \\
\text { recognition) have been implemented to facilitate promotion and employee retention }\end{array}$ & 2.83 & $0 \%$ & $0 \%$ & $83 \%$ & $17 \%$ & $0 \%$ \\
\hline $\begin{array}{l}\text { 2. The evaluation unit or function has an appropriate balance of junior, senior, and support } \\
\text { positions to complete evaluation projects efficiently }\end{array}$ & 2.83 & $0 \%$ & $0 \%$ & $83 \%$ & $17 \%$ & $0 \%$ \\
\hline 1.2 Human Resources - Technical Skills & 3.06 & $\mathbf{0 \%}$ & $6 \%$ & $83 \%$ & $11 \%$ & $\mathbf{0 \%}$ \\
\hline $\begin{array}{l}\text { 3. Senior management and program managers recognize evaluation reports as rigorous and } \\
\text { well researched }\end{array}$ & 3 & $0 \%$ & $0 \%$ & $100 \%$ & $0 \%$ & $0 \%$ \\
\hline 4. Sound data collection and analysis methods are used to produce evaluation findings & 3 & $0 \%$ & $17 \%$ & $67 \%$ & $17 \%$ & $0 \%$ \\
\hline 5. Evaluators follow sound project management practices to keep evaluations on schedule & 3.17 & $0 \%$ & $0 \%$ & $83 \%$ & $17 \%$ & $0 \%$ \\
\hline 1.3 Human Resources - Communication Skills & 3.06 & $\mathbf{0 \%}$ & $\mathbf{0 \%}$ & $94 \%$ & $6 \%$ & $\mathbf{0 \%}$ \\
\hline $\begin{array}{l}\text { 6. Evaluation staff maintain good working relationships with program managers for } \\
\text { ongoing trust }\end{array}$ & 3 & $0 \%$ & $0 \%$ & $100 \%$ & $0 \%$ & $0 \%$ \\
\hline $\begin{array}{l}\text { 7. Processes exist to ensure that evaluation staff are impartial, unbiased and avoid any } \\
\text { conflicts of interest }\end{array}$ & 3.17 & $0 \%$ & $0 \%$ & $83 \%$ & $17 \%$ & $0 \%$ \\
\hline 8. Evaluation reports are clear and precise (e.g., jargon-free and accessible) & 3 & $0 \%$ & $0 \%$ & $100 \%$ & $0 \%$ & $0 \%$ \\
\hline 1.4 Human Resources - Professional Development & 2.63 & $0 \%$ & $28 \%$ & $56 \%$ & $\mathbf{0 \%}$ & $17 \%$ \\
\hline
\end{tabular}




\begin{tabular}{|c|c|c|c|c|c|c|}
\hline $\begin{array}{l}\text { 9. Evaluation skill sets are assessed regularly to identify gaps and corresponding training } \\
\text { (e.g. individual learning plans) }\end{array}$ & 3 & $0 \%$ & $0 \%$ & $100 \%$ & $0 \%$ & $0 \%$ \\
\hline $\begin{array}{l}\text { 10. Training budget and allocated training time is adequate to meet the needs identified by } \\
\text { staff members }\end{array}$ & 2.9 & $0 \%$ & $17 \%$ & $80 \%$ & $0 \%$ & $17 \%$ \\
\hline $\begin{array}{l}\text { 11. New evaluators (staff members who are new to evaluation) are encouraged to develop } \\
\text { their evaluation skills through formal or informal apprentice/mentor arrangement }\end{array}$ & 2 & $0 \%$ & $67 \%$ & $0 \%$ & $0 \%$ & $33 \%$ \\
\hline 1.5 Human Resources - Leadership & 2.42 & $25 \%$ & $33 \%$ & $42 \%$ & $0 \%$ & $0 \%$ \\
\hline $\begin{array}{l}\text { 13. Evaluation unit lead/manager reconciles senior management expectations with } \\
\text { evaluation capacity }\end{array}$ & 2.83 & $0 \%$ & $17 \%$ & $83 \%$ & $0 \%$ & $0 \%$ \\
\hline $\begin{array}{l}\text { 14. Evaluation champion(s) are clearly identified throughout the organization (e.g. in } \\
\text { evaluation and program areas) }\end{array}$ & 1.5 & $67 \%$ & $17 \%$ & $17 \%$ & $0 \%$ & $0 \%$ \\
\hline $\begin{array}{l}\text { 15. Evaluation unit lead/manager provides support to evaluators faced with } \\
\text { political/organizational interference during an evaluation }\end{array}$ & 2.17 & $33 \%$ & $17 \%$ & $50 \%$ & $0 \%$ & $0 \%$ \\
\hline 17. New program financing includes the cost of the corresponding evaluation & 3 & $0 \%$ & $0 \%$ & $100 \%$ & $0 \%$ & $0 \%$ \\
\hline 18. The evaluation budget is controlled and managed by the evaluation unit & 3 & $0 \%$ & $0 \%$ & $83 \%$ & $0 \%$ & $17 \%$ \\
\hline 19. Adequate, stable resources are available to complete evaluation projects & 2 & $0 \%$ & $50 \%$ & $0 \%$ & $0 \%$ & $50 \%$ \\
\hline 2.2 Organizational Resources - Performance Measurement Data & 2.5 & $17 \%$ & $17 \%$ & $67 \%$ & $\mathbf{0 \%}$ & $\mathbf{0 \%}$ \\
\hline $\begin{array}{l}\text { 20. Performance measurement data reflect program outcomes and results-oriented } \\
\text { management }\end{array}$ & 2 & $33 \%$ & $33 \%$ & $33 \%$ & $0 \%$ & $0 \%$ \\
\hline $\begin{array}{l}\text { 21. Ongoing performance measurement data are available, accessible and complete at the } \\
\text { corporate and program levels }\end{array}$ & 3 & $0 \%$ & $0 \%$ & $100 \%$ & $0 \%$ & $0 \%$ \\
\hline
\end{tabular}




\begin{tabular}{|c|c|c|c|c|c|c|}
\hline 2.3 Organizational Resources - Infrastructure and Tools & 2.72 & $0 \%$ & $22 \%$ & $78 \%$ & $\mathbf{0 \%}$ & $0 \%$ \\
\hline 22. Policies and procedures have been established to guide evaluation activities & 3 & $0 \%$ & $0 \%$ & $100 \%$ & $0 \%$ & $0 \%$ \\
\hline 23. Evaluators have the necessary tools to complete their work (e.g. software, hardware) & 2.17 & $0 \%$ & $83 \%$ & $17 \%$ & $0 \%$ & $0 \%$ \\
\hline Dimension 3. Planning and Conducting Evaluations & 2.75 & $4 \%$ & $24 \%$ & $56 \%$ & $8 \%$ & $7 \%$ \\
\hline 3.1 Conducting Evaluations - Planning & 3 & $0 \%$ & $0 \%$ & $100 \%$ & $0 \%$ & $\mathbf{0 \%}$ \\
\hline $\begin{array}{l}\text { 26. Organizational evaluation plan sets out clear, reasonable project completion targets and } \\
\text { timelines in relation to resources and organizational priorities }\end{array}$ & 3 & $0 \%$ & $0 \%$ & $100 \%$ & $0 \%$ & $0 \%$ \\
\hline 3.2 Conducting Evaluation - Internal and External Evaluators & 3 & $0 \%$ & $0 \%$ & $100 \%$ & $0 \%$ & $0 \%$ \\
\hline 27. Evaluation unit has the capacity to conduct evaluations in-house & 3 & $0 \%$ & $0 \%$ & $100 \%$ & $0 \%$ & $0 \%$ \\
\hline 29. Evaluators actively gather information on new policy and strategic development trends & 3 & $0 \%$ & $0 \%$ & $50 \%$ & $0 \%$ & $50 \%$ \\
\hline $\begin{array}{l}\text { 30. Evaluation resources are used towards the development of cross-cutting/supporting } \\
\text { information (e.g., evaluability assessment, feasibility studies, special studies, program } \\
\text { theory development, etc.) }\end{array}$ & 1.6 & $33 \%$ & $50 \%$ & $0 \%$ & $0 \%$ & $33 \%$ \\
\hline 31. Evaluators maintain regular formal/informal contact with program managers & 3.83 & $0 \%$ & $0 \%$ & $17 \%$ & $83 \%$ & $0 \%$ \\
\hline 3.4 Conducting Evaluations - Organizational Linkages & 2.46 & $0 \%$ & $56 \%$ & $33 \%$ & $6 \%$ & $6 \%$ \\
\hline $\begin{array}{l}\text { 32. Evaluation unit lead/manager communicates directly with senior managers on issues } \\
\text { related to evaluation }\end{array}$ & 3.17 & $0 \%$ & $0 \%$ & $83 \%$ & $17 \%$ & $0 \%$ \\
\hline 33. Evaluation steering or advisory committees are regularly used to guide evaluations & 2 & $0 \%$ & $100 \%$ & $0 \%$ & $0 \%$ & $0 \%$ \\
\hline
\end{tabular}




\begin{tabular}{|c|c|c|c|c|c|c|}
\hline $\begin{array}{l}\text { 34. Evaluation, research and policy units coordinate efforts to minimize duplication and } \\
\text { leverage research }\end{array}$ & 2.2 & $0 \%$ & $67 \%$ & $17 \%$ & $0 \%$ & $17 \%$ \\
\hline 3.5 Conducting Evaluations - External Support & 2.46 & $8 \%$ & $42 \%$ & $50 \%$ & $0 \%$ & $0 \%$ \\
\hline $\begin{array}{l}\text { 35. Evaluators actively network to expand their contacts with other evaluators and } \\
\text { academia }\end{array}$ & 2.25 & $0 \%$ & $83 \%$ & $17 \%$ & $0 \%$ & $0 \%$ \\
\hline $\begin{array}{l}\text { 36. Evaluators actively use external supports (e.g. professional associations, published } \\
\text { quality standards, etc.) to remain current on developments in the field }\end{array}$ & 2.67 & $17 \%$ & $0 \%$ & $83 \%$ & $0 \%$ & $0 \%$ \\
\hline Dimension 4. Evaluation Literacy & 2.46 & $6 \%$ & $38 \%$ & $48 \%$ & $0 \%$ & $8 \%$ \\
\hline 4.1 Evaluation Literacy - Stakeholder Involvement & 2.68 & $0 \%$ & $33 \%$ & $67 \%$ & $0 \%$ & $0 \%$ \\
\hline $\begin{array}{l}\text { 37. Program managers and/or staff understand the purposes of evaluation and how it is } \\
\text { used }\end{array}$ & 2 & $0 \%$ & $100 \%$ & $0 \%$ & $0 \%$ & $0 \%$ \\
\hline $\begin{array}{l}\text { 38. Program managers and/or staff understand and apply the principles of results-based } \\
\text { management }\end{array}$ & 3 & $0 \%$ & $0 \%$ & $100 \%$ & $0 \%$ & $0 \%$ \\
\hline $\begin{array}{l}\text { 39. Program managers and/or staff have the opportunity to provide input into the } \\
\text { development of evaluation frameworks by identifying issues of concern or interest }\end{array}$ & 3 & $0 \%$ & $0 \%$ & $100 \%$ & $0 \%$ & $0 \%$ \\
\hline $\begin{array}{l}\text { 40. Program managers and/or staff members are involved in facilitating data collection } \\
\text { activities }\end{array}$ & 2.83 & $0 \%$ & $17 \%$ & $83 \%$ & $0 \%$ & $0 \%$ \\
\hline $\begin{array}{l}\text { 41. Program managers and/or staff have the opportunity to conduct a factual verification of } \\
\text { draft evaluation reports }\end{array}$ & 2.83 & $0 \%$ & $67 \%$ & $33 \%$ & $0 \%$ & $0 \%$ \\
\hline 42. Program managers accept and act on evaluation recommendations & 2.42 & $0 \%$ & $67 \%$ & $33 \%$ & $0 \%$ & $0 \%$ \\
\hline 4.2 Evaluation Literacy - Results-Management Orientation & 2.24 & $13 \%$ & $43 \%$ & $27 \%$ & $0 \%$ & $17 \%$ \\
\hline 43. All programs/organizational units have a logic model, program theory or results chain & 1.2 & $67 \%$ & $17 \%$ & $0 \%$ & $0 \%$ & $17 \%$ \\
\hline $\begin{array}{l}\text { 44. Staff and managers have opportunities to discuss and share ideas related to } \\
\text { organizational goals and how best to attain them }\end{array}$ & 3 & $0 \%$ & $0 \%$ & $100 \%$ & $0 \%$ & $0 \%$ \\
\hline 45. Senior managers provide time and resources for results-based management & 2 & $0 \%$ & $100 \%$ & $0 \%$ & $0 \%$ & $0 \%$ \\
\hline
\end{tabular}


46. Senior executives provide time and resources for performance measurement and evaluation activities

47. Evaluators are consulted on/involved in the development of performance measurement frameworks and systems

\section{Dimension 5. Organizational Decision Making}

5.1 Organizational Decision-Making - Management Processes

48. Program managers and/or staff routinely consult evaluators on matters related to evaluation and performance measurement

49. Evaluators are involved in broader management processes within the organization (e.g., budgetary reallocations, funding applications, program development)

\subsection{Organizational Decision-Making - Decision Support}

50. Demand for evaluation services originates from all levels of the organization (i.e., from program-level staff up to senior executives)

51. Evaluation findings and recommendations are routinely sought out and considered in budget allocation exercises and other organizational decisions

52. Demand for evaluation services extends beyond mandatory requirements (e.g., funding requirements)

\begin{tabular}{|c|c|c|c|c|c|c|}
\hline Dimension 6. Learning Benefits & 2.83 & $\mathbf{0 \%}$ & $18 \%$ & $80 \%$ & $2 \%$ & $0 \%$ \\
\hline 6.1 Learning Benefits - Instrumental and Conceptual Use & 2.86 & $\mathbf{0 \%}$ & $17 \%$ & $81 \%$ & $3 \%$ & $\mathbf{0 \%}$ \\
\hline 53. Managers generally agree with evaluation recommendations & 3 & $0 \%$ & $0 \%$ & $100 \%$ & $0 \%$ & $0 \%$ \\
\hline 54. Evaluation recommendations are implemented in a timely manner & 2 & $0 \%$ & $100 \%$ & $0 \%$ & $0 \%$ & $0 \%$ \\
\hline 55. Evaluation is used to meet external accountability requirements & 3 & $0 \%$ & $0 \%$ & $100 \%$ & $0 \%$ & $0 \%$ \\
\hline 56. Evaluation is used to learn about program functioning & 3.17 & $0 \%$ & $0 \%$ & $83 \%$ & $17 \%$ & $0 \%$ \\
\hline 57. Evaluation is used to make decisions about budgetary allocations & 3 & $0 \%$ & $0 \%$ & $100 \%$ & $0 \%$ & $0 \%$ \\
\hline 58. Evaluation reports are disseminated outside of the organization & 3 & $0 \%$ & $0 \%$ & $100 \%$ & $0 \%$ & $0 \%$ \\
\hline 6.2 Learning Benefits - Process Use & 2.79 & $0 \%$ & $19 \%$ & $81 \%$ & $0 \%$ & $\mathbf{0 \%}$ \\
\hline
\end{tabular}




\begin{tabular}{|c|c|c|c|c|c|c|}
\hline $\begin{array}{l}\text { 59. Program managers and/or staff report an increased understanding of a program } \\
\text { following an evaluation }\end{array}$ & 3 & $0 \%$ & $0 \%$ & $100 \%$ & $0 \%$ & $0 \%$ \\
\hline $\begin{array}{l}\text { 60. Program managers and/or staff recognize the value of systematic inquiry to identify } \\
\text { solutions to organizational problems }\end{array}$ & 3 & $0 \%$ & $0 \%$ & $100 \%$ & $0 \%$ & $0 \%$ \\
\hline $\begin{array}{l}\text { 61. Program management and/or staff report expanded and/or expedited use of evaluation } \\
\text { findings due to their involvement in the evaluation process }\end{array}$ & 3 & $0 \%$ & $0 \%$ & $100 \%$ & $0 \%$ & $0 \%$ \\
\hline $\begin{array}{l}\text { 62. Formal or informal processes to share lessons learned during evaluations are in place } \\
\text { and involve the entire organization (e.g., seminars, brown-bag lunch sessions, brochures, } \\
\text { etc.) }\end{array}$ & 2.17 & $0 \%$ & $83 \%$ & $17 \%$ & $0 \%$ & $0 \%$ \\
\hline
\end{tabular}

